RAFAEL RIBEIRO RODRIGUES

\title{
INTERPRETAÇÃO DO PEDIDO
}

Dissertação de Mestrado

Orientador: Professor Associado Paulo Henrique dos Santos Lucon

UNIVERSIDADE DE SÃO PAULO

FACULDADE DE DIREITO

São Paulo-SP 

RAFAEL RIBEIRO RODRIGUES

INTERPRETAÇÃO DO PEDIDO

Dissertação de Mestrado, apresentada à Banca Examinadora do Programa de Pós-Graduação em Direito, da Faculdade de Direito da Universidade de São Paulo, como exigência parcial para obtenção do título de Mestre em Direito, na área de concentração Direito Processual Civil, sob a orientação do Professor Associado Paulo Henrique dos Santos Lucon.

\section{UNIVERSIDADE DE SÃO PAULO}

FACULDADE DE DIREITO

São Paulo-SP 
Serviço de Processos Técnicos da Biblioteca da

Faculdade de Direito da Universidade de São Paulo

\section{Rodrigues, Rafael Ribeiro \\ Interpretação do pedido / Rafael Ribeiro Rodrigues.}

São Paulo: R. R. Rodrigues, 2019.

$367 \mathrm{f} . ; 30 \mathrm{~cm}$.

Dissertação (Mestrado em Processo Civil) - Faculdade de Direito, Universidade de São Paulo, São Paulo, 2019.

Orientador: Prof. Paulo Henrique dos Santos Lucon.

Notas de rodapé.

Inclui bibliografia

Interpretação. Pedido. Princípio da congruência. Conjunto da postulação. Vontade do demandante. Contraditório do demandado. 
Nome: RODRIGUES, Rafael Ribeiro

Título: Interpretação do pedido

Dissertação de Mestrado, apresentada à Banca Examinadora do Programa de Pós-Graduação em Direito, da Faculdade de Direito da Universidade de São Paulo, como exigência parcial para obtenção do título de Mestre em Direito, na área de concentração Direito Processual Civil, sob a orientação do Professor Associado Paulo Henrique dos Santos Lucon.

Aprovado em:

Banca Examinadora:

Prof.(a) $\operatorname{Dr}(a)$ :

Instituição:

Julgamento:

Prof.(a) $\operatorname{Dr}(a)$.:

Instituição:

Julgamento:

Prof.(a) $\operatorname{Dr}(a)$. :

Instituição:

Julgamento: 
Dedico este trabalho à minha amada esposa, à minha dedicada mãe, à memória do meu querido pai e, por certo, aos meus estimados irmãos. 
“O juiz não pode fazer um processo se não é provocado para isso."

(Francesco Carnelutti. Como se faz um processo) 


\section{RESUMO}

RODRIGUES, Rafael Ribeiro. Interpretação do pedido. 2019. 367 p. Dissertação (Mestrado em Processo Civil) - Faculdade de Direito, Universidade de São Paulo, São Paulo, 2019.

O pedido formulado pelo demandante no processo civil possui direta influência na delimitação do objeto litigioso do processo, reverberando na atuação do magistrado e na decisão a ser proferida. Não por outro motivo a lei determina que o demandante exponha e delimite adequadamente o seu pedido logo no início do processo. Entretanto, na prática nem sempre é esta a postura adotada pelo demandante e a ausência desta diligência ocasionou a eclosão da interpretação do pedido como meio de superar a ausência de clareza do pedido, visando a obtenção da integral resolução do mérito no processo civil. Como reflexo desta solução pretoriana encontrada para delimitar o pedido, outros problemas acabaram por surgir. Em um primeiro momento este trabalho enfrentará toda esta problemática para, em um segundo momento, apresentar soluções práticas, tendo por base o estudo conjunto da lei, da doutrina e da jurisprudência.

Palavras-chave: Interpretação. Pedido. Princípio da congruência. Conjunto da postulação. Vontade do demandante. Contraditório do demandado. 


\begin{abstract}
RODRIGUES, Rafael Ribeiro. Interpretation of the claim. 2019. 367 p. Dissertation (Master's degree in Civil Procedure) - Faculdade de Direito, Universidade de São Paulo, São Paulo, 2019.

The claim formulated by the plaintiff in the civil proceeding has a direct influence on the delimitation of the litigious object of the proceedings, reverberating in the magistrate's action and in the decision to be rendered. For this reason the law requires the plaintiff to set out and properly delimit his claim at the outset of the proceedings. However, in practice this is not always the position adopted by the plaintiff and the absence of this diligence has led to the outbreak of the request interpretation as a manner to overcome the lack of clarity on the request and obtaining a full resolution of the merits of the case. As a reflection of this praetorian solution found to delimit the request, other problems eventually emerged. In a first moment this work will face this problematic for, in a second moment, present practical solutions, based on the joint study of the law, the doctrine and the jurisprudence.
\end{abstract}

Palavras-chave: Interpretation. Claim. Principle of congruence. Set of the postulation. Claimant's volition. Adversarial system by defendant. 


\section{AGRADECIMENTOS}

Para a elaboração deste trabalho contei com o apoio de três grupos: família, Arcadas e profissional.

Da família, agradeço à minha esposa Vivian Westphalen e à minha mãe Rita Aparecida. Agradeço ao meu pai, Jose Rodrigues, que mesmo não estando mais do meu lado, ainda guia meus paços. Como não poderia deixar de ser, agradeço aos meus irmãos Marcela, Anselmo e Wagner. Deixo também um especial agradecimento aos meus pequenos sobrinhos Philipe e Sophia, novos na família, mas já essenciais, como se sempre tivessem pertencido a ela. Agradeço por compreenderem minha ausência.

Das Arcadas, primeiramente agradeço ao meu Professor e Orientador, Paulo Henrique dos Santos Lucon, o qual gentilmente me acolheu como seu orientando e sempre demonstrou respeito e hombridade. Espero, sinceramente, ter correspondido às suas expectativas. Muito obrigado!

Agradeço aos Professores José Rogério Cruz e Tucci e Antonio Carlos Marcato, pelas aulas ministradas no decorrer do curso e pelas relevantes considerações feitas na banca de qualificação. Agradeço ao João Paulo Hecker da Silva que, em razão de seus apontamentos feitos durante a assistência nas aulas do Pós-Graduação, acabou por me municiar de conteúdo para a elaboração deste trabalho. Agradeço ao time de monitores das aulas da Graduação: Rodolfo da Costa Manso Real Amadeo, João Pereira Monteiro Neto, Felipe Bragantini de Lima, Pedro Jesus, Marco Aurélio Rangel, Raul Longo Zocal, Luccas Lima, Mateus Bessa e Giovani Ravagnani. Agradeço aos alunos da Graduação, com os quais tive a oportunidade de aprender durante as aulas em que fui monitor. Por fim, agradeço aos amigos que fiz durante o curso de Mestrado.

E em âmbito profissional, inicialmente agradeço aos sócios Gianfrancesco Genoso e à Prof. Thereza Arruda Alvim, na pessoa dos quais agradeço aos demais sócios do escritório. O primeiro, agradeço pela confiança em mim depositada, por me convidar para ingressar no time de advogados do qual faço parte, e a segunda agradeço pelo carinho, respeito, incentivo e exemplo a ser seguido.

Como não poderia deixar de ser, destino um especial agradecimento àqueles que sempre apoiaram e incentivaram meus estudos e estiveram presente neste momento: Rosane Pereira dos Santos, Wadson Veloso Silva, Rennan Thamay, Daniel Granado, Milena Gomes Teixeira, Eduardo Aranha, Igor Martins da Cunha e Vinícius Bellato. 


\section{SUMÁRIO}

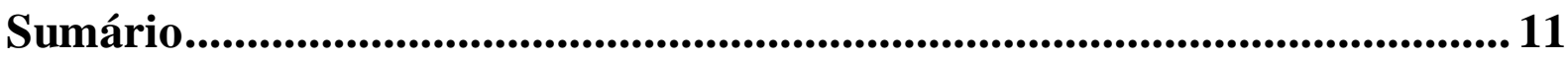

$\S 1^{0}$ Introdução .................................................................................................... 13

§ $2^{\mathrm{o}}$ Teoria geral da interpretação .......................................................................... 16

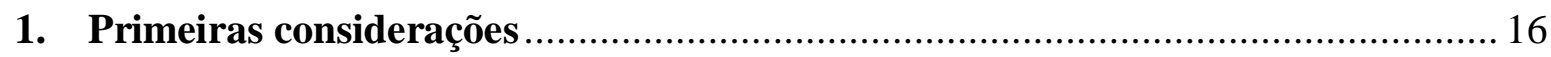

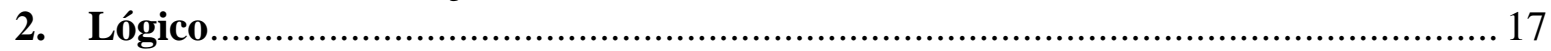

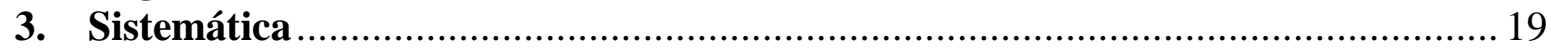

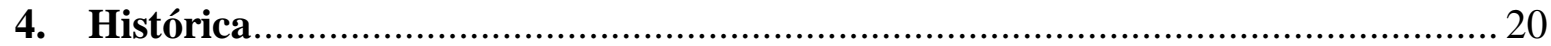

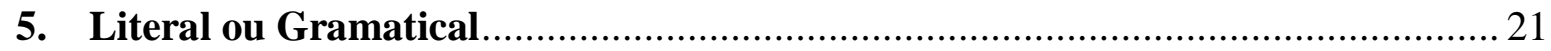

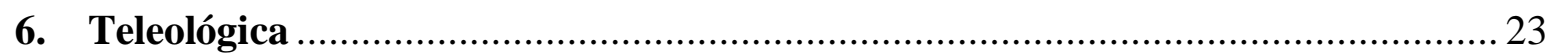

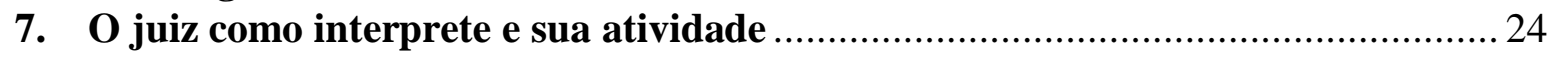

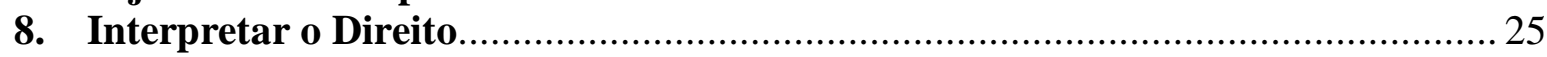

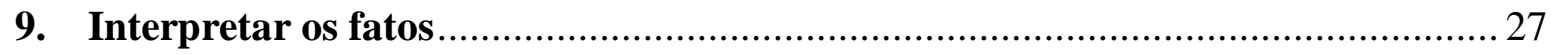

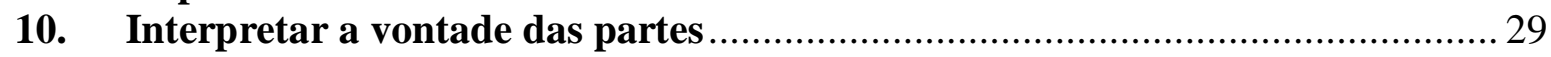

11. A escola do realismo jurídico norte-americano .............................................. 31

$\S 3^{\circ} \mathbf{O}$ pedido e sua relação com as partes no processo civil .......................... 34

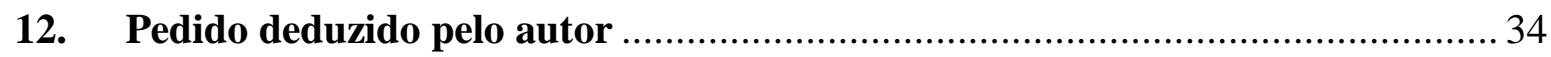

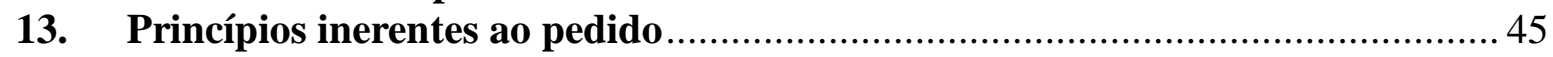

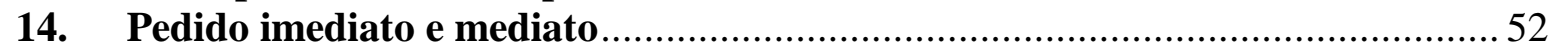

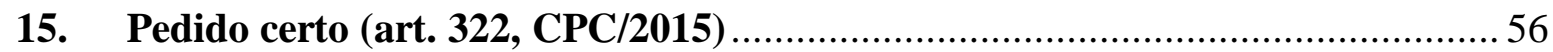

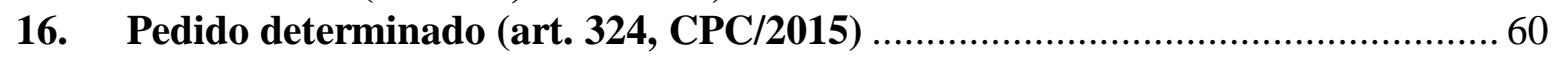

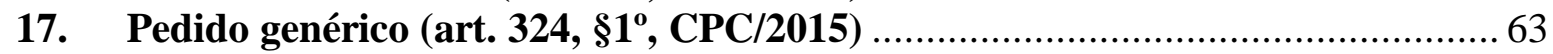

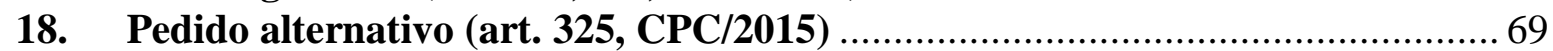

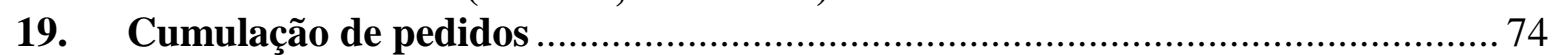

20. Cumulação subsidiária de pedidos (art. 326, CPC/2015) …………………...... 76

21. Cumulação alternativa de pedidos (art. 326, parágrafo único, CPC/2015) ....... 81

22. Cumulação simples de pedidos (art. 327, CPC/2015) …………........................ 88

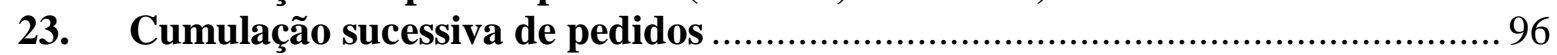

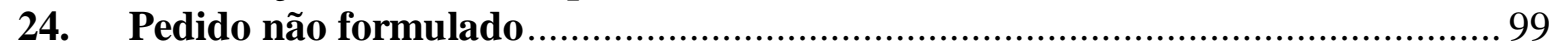

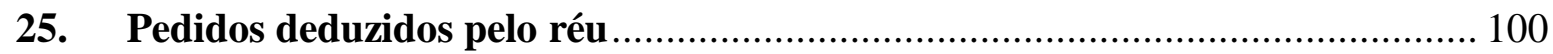

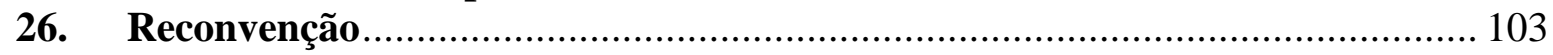

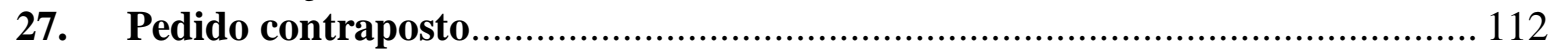

28. Relação entre pedido e o contraditório do demandado ................................... 119

29. Pedido, condições e elementos da ação ………........................................ 128

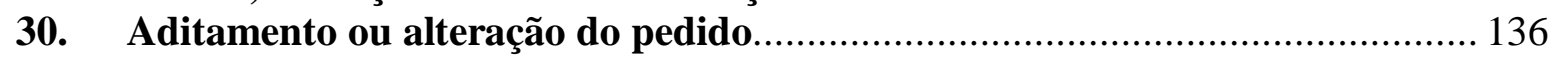

$\$ 4^{0}$ Princípio da congruência no processo civil ............................................ 149

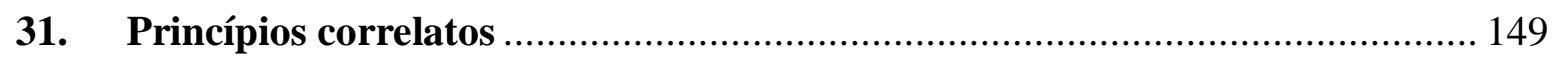

32. Pretensão, ação, demanda e tutela jurisdicional ........................................... 153

33. Objeto do processo e objeto litigioso do processo ………………………........... 161

34. Correlação entre o pedido e o dispositivo da sentença ……………………....... 165

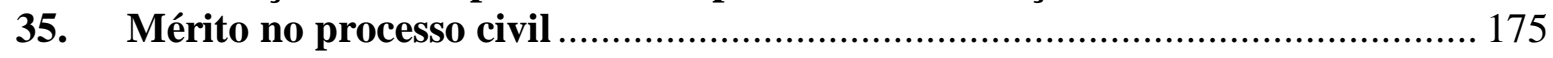

36. Patologias da congruência. Decisões ultra, extra e citra ou infra petita ............. 181 §5 ${ }^{\circ}$ Exceções ao princípio da congruência e interpretação do pedido no

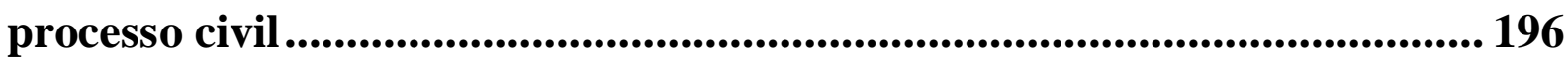

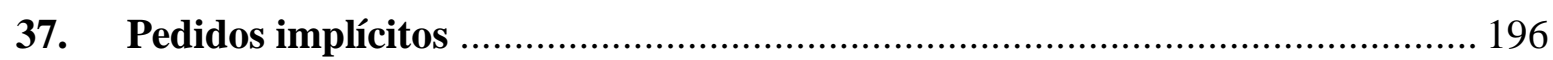

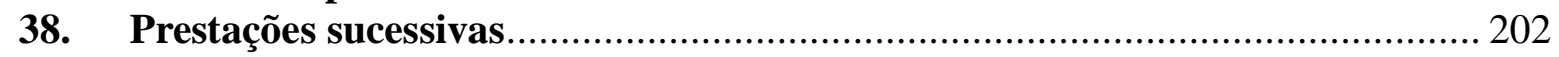




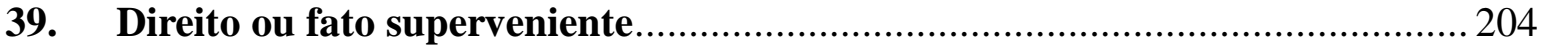

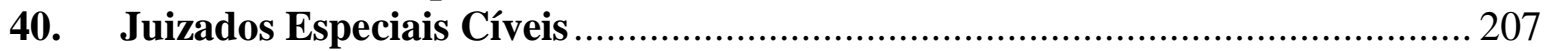

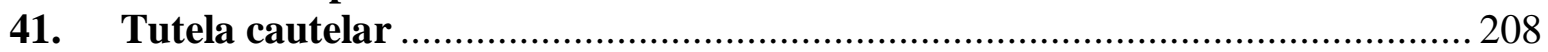

42. Medidas que assegurem o resultado prático equivalente da demanda ............ 211

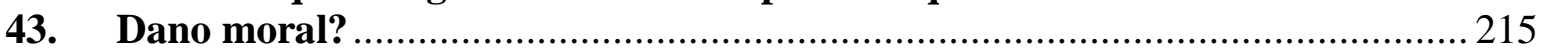

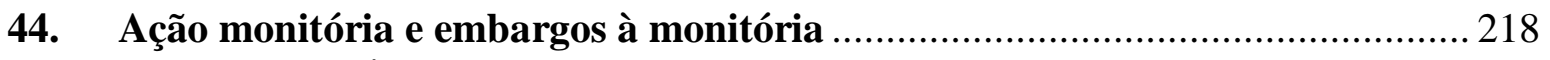

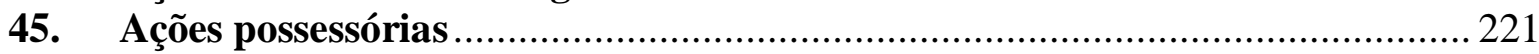

46. Ações dúplices ..................................................................................... 223

47. Pedido unitário em demanda decorrente de obrigação alternativa ................ 229

48. Ações de controle concentrado de constitucionalidade................................ 231

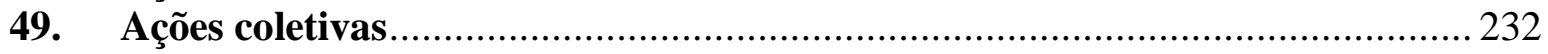

50. Questões de ordem pública .................................................................... 238

51. Contraditório legitimador de pedido não formulado? Pedido interpretado?.. 240

$\$^{\circ}$ Interpretação do pedido e o Superior Tribunal de Justiça ................. 243

52. Considerações iniciais e delimitação da proposta ......................................... 243

53. Análise empírica dos julgados que admitem a interpretação do pedido.......... 245

54. Posições pretorianas favoráveis a interpretação restritiva do pedido.............. 262

$\$ 7^{\circ}$ Interpretação do pedido e o Código de Processo Civil ......................... 269

55. O pedido extraído a partir do processo interpretativo .................................. 269

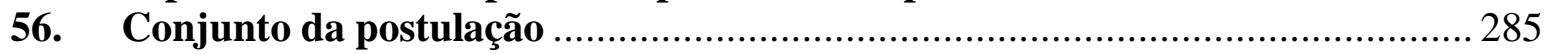

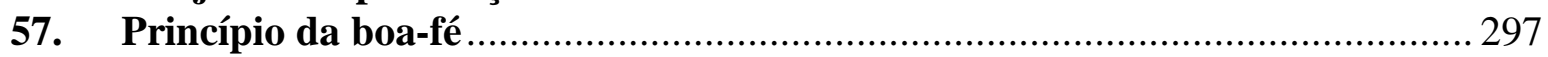

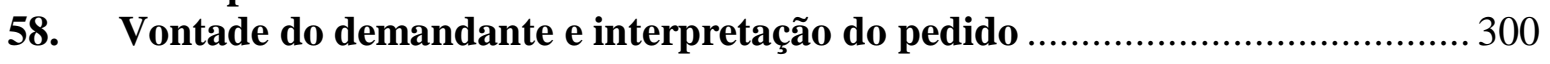

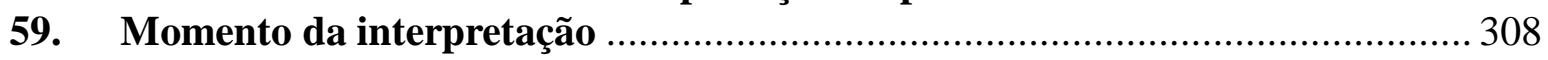



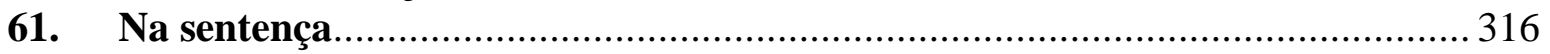

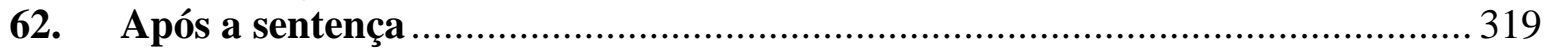

63. No Superior Tribunal de Justiça e no Supremo Tribunal Federal ................. 322

$\$ 8^{0}$ Conclusão .............................................................................. 325

Referências ............................................................................................... 330

ANEXO A - Decisões favoráveis à interpretação lógico-sistemática do pedido e suas variantes .......................................................................... 341

ANEXO B - Outras decisões favoráveis à interpretação do pedido.......... 362 ANEXO C - Decisões favoráveis à interpretação restritiva do pedido ..... 365 


\section{§ 1º INTRODUÇÃO}

Para a ciência jurídica o processo "é uma série de atos interligados e coordenados ao objetivo de produzir tutela jurisdicional mediante o julgamento da

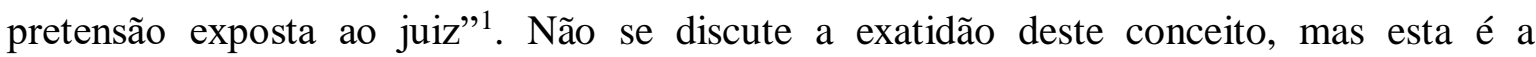
definição mais adequada feita pelos e para os atores do Direito, os quais o estudam e o operam.

Já para as partes envolvidas na relação jurídica processual, o processo vai além da explicação técnica. Para estes indivíduos o processo é o local no qual será traçada uma parcela do seu destino. Enquanto o demandante cria a expectativa de obter pela via litigiosa aquilo que não alcançou pela via consensual, o demandado, em regra, almeja apenas a manutenção do status quo.

Se o processo é definido doutrinariamente como uma série de atos, o primeiro e mais importante ato processual é o postulatório, pelo qual o demandante retira o Poder Judiciário da inércia, apresenta ao magistrado os fatos e os fundamentos jurídicos que dão suporte ao resultado que se esperar obter, bem como indica quem deverá suportar os efeitos do referido resultado, tudo isso sintetizado no pedido.

Não se ignora o fato de que a linguagem está sujeita a interpretações, notadamente em nosso sistema processual, que é predominantemente escrito.

O pedido, formulado no bojo da petição inicial, nem sempre será dotado de clareza suficiente para que os interlocutores do processo possam compreendê-lo de maneira uniforme. Daí surge a primeira problemática deste trabalho, entender se o pedido pode ou não ser interpretado.

Entretanto, conforme já mencionado, o pedido formulado é a síntese do resultado esperado do processo. E o pedido em si é polivalente, pois é dele o papel de indicar qual é a tutela jurisdicional que o demandante requer ao magistrado, por meio da qual se pretende obter um bem da vida, assim como se presta para especificar, definir, quantificar e qualificar referido bem da vida desejado pelo demandante.

Deste modo, caso seja admitida a possibilidade de se interpretar o pedido, surgirá uma segunda problemática destinada a compreender se o pedido pode ser interpretado total ou parcialmente, ou seja, se todas as suas funções podem ser objeto de interpretação. A interpretação do pedido pode definir a tutela jurisdicional, o bem da vida,

\footnotetext{
${ }^{1}$ DINAMARCO, Cândido Rangel. Instituições de Direito Processual Civil - Volume III. 7. ed. São Paulo:
} Malheiros, 2017, p. 29. 
a especificação e definição do bem da vida, ou a qualificação e quantificação do bem da vida? É por meio da interpretação que os interlocutores do processo conseguirão delimitar todas estas funções do pedido?

Como terceira problemática destacamos o "como" interpretar. O art. 293 do CPC/1973 definia que "os pedidos são interpretados restritivamente". Em que pese a clara redação do mencionado dispositivo, na égide do diploma processual anterior se constatava a existência de decisões judiciais admitindo a "interpretação lógico-sistemática do pedido". Por sua vez, o art. 322, §2 , do CPC/2015 determina que "a interpretação do pedido considerará o conjunto da postulação e observará o princípio da boa-fé”. Necessário, portanto, definir o escopo de cada um destes modelos de interpretação do pedido.

Ademais, enquanto o caput do art. 322 do CPC/2015 determina que o pedido deve ser certo, seu $\S 2^{\circ}$ possibilita a interpretação do pedido, devendo ser considerado o "conjunto da postulação" e observado o "princípio da boa-fé". Ambos os requisitos da regra legal de interpretação do pedido merecem ser analisados de maneira detida.

A quarta problemática a ser enfrentada por este trabalho é saber o "quando" interpretar o pedido. Se o processo é uma série de atos processuais concatenados para se atingir um fim, se mostra importante saber qual é o momento adequado para se interpretar o pedido.

Além das problemáticas anteriores, existe ainda outro ponto a ser enfrentado. A norma processual determina que a sentença de mérito deverá se ater aos limites o pedido formulado pelo demandante, em respeito ao princípio da congruência. Não pode o magistrado decidir mais, menos ou diferente daquilo que foi pedido. Portanto, resta saber o alcance da interpretação do pedido. Se é a partir do pedido que o magistrado irá delimitar sua atuação é necessário definir como interpretá-lo sem dilatar ou alterar o objeto litigioso do processo. Nesta linha, importante atribuir ao pedido o verdadeiro valor que este elemento da ação possui dentro, fora e no curso da demanda, bem como todas as implicações que a sua delineação, deficiência ou não formulação podem gerar para os demandantes.

E, dentro deste contexto, necessário definir o papel da vontade do demandante na interpretação do pedido. No CC/2002 o art. 112 determina que "Nas declarações de vontade se atenderá mais à intenção nelas consubstanciada do que ao sentido literal da linguagem". Portanto, é de fundamental importância analisar se referida regra de direito material se aplica para o direito processual. 
Por fim, se o pedido é formulado pelo demandante e será julgado pelo magistrado, a sétima problemática consiste em saber qual é o papel do demandado dentro deste contexto. A indagação a ser respondida é se o contraditório exercido pelo demandado pode ou não influenciar na interpretação do pedido e, se positivo, em que medida.

Daí o motivo pelo qual o objeto do presente estudo se mostra rico e merecedor de reflexão, dada a amplitude da problemática.

Entretanto, antes de iniciarmos o trabalho necessário registrar que este não tratará especificamente da ação de execução, pois o pedido de satisfação e a interpretação de título executivo demandaria abordagem e pesquisa diversas das adotadas neste estudo, bem como não será analisada a defesa do executado, haja vista que "os Embargos à Execução são impropriamente uma ação, pois não apresentam efetivamente um pedido, mas sim representam instrumento para o devedor resistir à pretensão executiva" ${ }^{2}$.

Necessário também registrar que este trabalho tratará da interpretação do pedido apenas no processo de conhecimento na seara civil, exclusivamente sobre o enfoque da ação individual.

O escopo deste estudo é analisar as problemáticas elencadas acima de maneira crítica, a partir da perspectiva e dos atos processuais do demandante, do demandado e do magistrado, bem como apresentar soluções práticas e concretas para a interpretação do pedido, no intuito de atribuir previsibilidade e racionalidade a este ato processual, atualmente regido pelo art. $322, \S 2^{\circ}$, do CPC/2015. Nada contra eventuais posicionamentos filosóficos e abstratos que possam vir a ser apresentados em outros estudos sobre o presente tema, mas entendemos não ser este o caminho para se concretizar a segurança jurídica esperada pelo jurisdicionado, enquanto destinatário final do processo ${ }^{3}$.

\footnotetext{
${ }^{2}$ STJ - EDcl no AgRg no AREsp no 150035/DF - Min. Relator: Herman Benjamin - Publicação: 02/02/2017.

3 "Filosofar por filosofar interessa à filosofia. Para o direito, porém, o conhecimento das teorias filosóficas somente é útil ou relevante na medida em que o jurista consiga utilizá-lo para produzir resultados no plano de sua ciência, que é, sabidamente, ávida de resultados práticos para a disciplina normativa da convivência social. Sem tais resultados, na esfera própria dos fenômenos jurídicos, o trabalho filosófico não atende os objetivos do direito, por mais bonito e convincente que seja no plano das abstrações sintetizantes da filosofia." (THEODORO JÚNIOR, Humberto. Interpretação e aplicação das normas jurídicas. Revista de Processo, São Paulo, v. 150, ago/2007, p. 20)
} 


\section{$\S^{\circ}$ CONCLUSÃo}

E em síntese conclusiva, seguem abaixo os pontos que norteiam as constatações obtidas no curso deste trabalho, em razão da análise da lei, da doutrina e da jurisprudência ${ }^{962}$ :

1. O CPC/2015 tem como um de seus pilares uniformizar a jurisprudência (art. 926) e, consequentemente, tornar o resultado do processo mais previsível. Antes de decidir caberá ao magistrado observar se os Tribunais possuem posicionamento sobre a questão a ser decidida (art. 927).

2. Entretanto, para que o resultado do processo seja previsível não basta que o magistrado apenas observe as decisões proferidas pelos Tribunais em casos análogos. As regras processuais também devem ser obedecidas e a vontade expressada pelo demandante em seu pedido deve servir para delimitar o objeto litigioso do processo.

3. A demanda é inaugurada pelo demandante, ao qual incumbe formular pedido certo e determinado (ou genérico, nos casos previstos na lei).

4. Até o CPC/1973 vigorava a regra da interpretação restritiva do pedido. No entanto, após pesquisas realizadas junto ao banco de dados de jurisprudência do site do Superior Tribunal de Justiça, constatou-se a predileção do referido órgão jurisdicional para a interpretação lógico-sistemática do pedido e outras formas variadas deste posicionamento, todas destinadas a afastar a interpretação restritiva do pedido.

5. $\mathrm{O}$ do art. $322, \S 2^{\circ}$, do $\mathrm{CPC} / 2015$, revogou tacitamente a interpretação restritiva do pedido e trouxe para o sistema normativo a previsão de que "A interpretação do pedido considerará o conjunto da postulação e observará o princípio da boa-fé".

6. A interpretação do pedido está topologicamente dentro da regra do pedido certo (art. 322, caput e $\S 2^{\circ}$, do CPC/2015) e fora da previsão sobre o pedido determinado ou genérico (art. 324, caput e $\S 1^{\circ}$, do CPC/2015).

7. O pedido deve ser certo, mas em caso de deficiência na certeza do pedido expressamente formulado o magistrado pode interpretá-lo.

\footnotetext{
962 “A honestidade intelectual sugere ao estudioso que seja modesto em suas pretensões e não se atreva a oferecer como verdades dogmáticas o que não passa, nem pode passar, do plano das meras conjecturas. Dito isso, fica ele autorizado a formular algumas hipóteses, naturalmente sujeitas à confirmação ou ao desmentido da ciência e da experiência." (BARBOSA MOREIRA, José Carlos. O processo, as partes e a sociedade. Revista de Processo, São Paulo, v. 125, jul/2005, p. 285)
} 
8. O pedido genérico não deve ser interpretado. A interpretação não se presta para conferir liquidez. A ausência de liquidez do pedido requer a liquidação em momento posterior ao do ajuizamento da demanda, antes ou após a sentença.

9. O pedido mediato pode ser interpretado, com a finalidade de delimitar o bem da vida objetivado pelo demandante. O pedido imediato pode ser adequado, não se tratando necessariamente de interpretação do pedido. Se o pedido imediato for formulado de maneira incorreta, configurará falta de técnica processual e o juiz não está adstrito ao pedido imediato incorreto, desde que tenha como base o pedido mediato a ser alcançado.

10. Caso o magistrado entenda pela necessidade de interpretar o pedido para melhor delimitar a certeza e o bem da vida pleiteado, deverá considerar o conjunto da postulação e a boa-fé do demandante.

11. A interpretação do pedido não permite extrair da petição inicial - ou das manifestações do demandante no curso do processo - outros pedidos além dos formulados.

12. O magistrado não pode extrair da narrativa dos fatos todos os pedidos que o demandante poderia ter formulado. A simples narrativa de um fato pelo demandante não configura pedido, se destes fatos não sobrevier a formulação de uma demanda.

13. Pedido e causa de pedir não se confundem, mas se complementam. A interpretação do pedido pode ser extraída da causa de pedir, mas da causa de pedir o magistrado não pode extrair pedidos.

14. As demandas devem ser formuladas, aditadas ou alteradas no momento processual adequado, de acordo com as regras de postulação e de emenda do ato postulatório, todas previstas no $\mathrm{CPC} / 2015$.

15. O conjunto da postulação não está limitado aos fatos narrados pelo demandante em sua petição inicial ou em posterior emenda. A narrativa fática apresentada pelo demandante será o primeiro elemento analisado, caso seja necessário interpretar o pedido, mas nunca o único. Além da narrativa fática o magistrado também deverá se ater aos demais requisitos do art. 319 do CPC/2015, dentre os quais destacamos o valor da causa e as provas.

16. O valor da causa deve estar de acordo com o pedido cuja interpretação se busca alcançar. Se o valor da causa não compreender referido pedido, este deve ser tido por não formulado. Não se pode confundir pedido formulado com pedido que poderia ter sido formulado. A narrativa fática é subjetiva e o valor da causa, enquanto critério objetivo, confere segurança quando da aferição sobre a existência ou não de determinado pedido. 
17. Em alguns Tribunais o valor da causa é a base de cálculo para o recolhimento das custas judiciárias iniciais. Nestas hipóteses, as custas judiciárias iniciais também irão compor o conjunto da postulação, para fim de se aferir a existência do pedido e delimitar a certeza do bem da vida pleiteado. Ambos (valor da causa e custas judiciais) são critérios objetivos e devem ser considerados em uma primeira análise, logo após a leitura da narrativa fática.

18. As provas produzidas e/ou requeridas pelo demandante também podem ser consideradas para se aferir a existência de pedido e, se positivo, a delimitação do bem da vida.

19. O diploma processual não prevê a necessidade de capítulo próprio na exordial denominado “dos pedidos". Os pedidos podem ser extraídos do corpo da petição inicial como um todo. Entretanto, o princípio da cooperação e da boa-fé processual exigem que o pedido seja formulado da maneira mais clara e expressa possível (certa e determinada), a fim de possibilitar ao magistrado e ao demandado aferirem de plano a existência e extensão da demanda.

20. Em que pese a lei não determinar que o(s) pedido(s) formulado(s) conste $(m)$ em capítulo próprio da petição inicial, a técnica do patrono do demandante (boa ou má) deve ser considerada pelo magistrado, inclusive para fins de arbitramento dos honorários de sucumbência. Boas práticas devem ser premiadas e más práticas devem ser desprestigiadas.

21. A interpretação do pedido não é regra de julgamento. É dever do demandante postular em juízo apresentando pedido certo. Caso o pedido tenha sido formulado de maneira deficiente, quando do recebimento da petição inicial o magistrado deverá determinar a sua emenda, garantido ao demandante o direito de aditar ou alterar livremente sua exordial. Mesmo após a citação o demandante deverá ser diligente e delimitar a certeza do seu pedido, caso necessário e de acordo com as regras do momento processual em que sua manifestação for apresentada. No momento em que o magistrado for proferir a sentença ele não terá plena liberdade para interpretar o pedido, pois deverá se ater apenas ao conjunto da postulação (regra objetiva) e à boa-fé (regra subjetiva), de maneira cumulada e motivada.

22. A vontade do demandante não é um dos requisitos legais para a interpretação do pedido. Não basta que o demandante tenha a intenção de formular um pedido. O pedido só poderá ser julgado se tiver sido formulado e da maneira como foi formulado. Também não basta a possibilidade de se formular determinado pedido em 
determinado tipo de processo. Ressalte-se novamente que apenas o pedido formulado pode ser apreciado e julgado no mérito. Ressalvadas as exceções legais, o magistrado deve decidir de acordo e na medida da provocação do demandante. O pedido não pode ser extraído da vontade, ele precisa ser expresso. O querer do demandante deve ser transportado para o dentro do processo, em forma de pedido. Em caso de dúvida o conjunto da postulação e a boa-fé serão os guias do magistrado, para fins de se aferir a existência e a extensão do pedido. Entender de maneira diversa significa violar a regra da congruência e os princípios que lhe são inerentes.

23. Em grau recursal o Tribunal pode corrigir vício na congruência com (efeito devolutivo) ou sem (efeito translativo) provocação no recurso interposto, bem como poderá - mediante provocação do recorrente - interpretar o pedido para zelar pela consideração ao conjunto da postulação e pela observância ao princípio da boa-fé.

24. O Superior Tribunal de Justiça e o Supremo Tribunal Federal podem interpretar o pedido, desde que demonstrada, respectivamente, a contrariedade ou a negativa de vigência de norma infraconstitucional (recurso especial), ou a contrariedade de dispositivo constitucional (recurso extraordinário), bem como se for respeitado o prequestionamento para ambos os casos. A análise das provas e de circunstâncias fáticas restará prejudicada.

25. Incumbe ao demandante delimitar o objeto litigioso do processo e ao magistrado fiscalizar a adequada formulação do pedido. Já ao demandado incumbe apresentar toda a matéria de defesa (ônus da impugnação específica), ainda que contraditória (princípio da eventualidade). A defesa não se presta para delimitar e nem para esclarecer o objeto litigioso do processo.

26. Todas as considerações feitas neste trabalho têm por escopo analisar o pedido e a sua interpretação em ações individuais, notadamente no processo de conhecimento. As ações coletivas possuem outra estrutura e objeto, sendo necessária a adoção de outros critérios para a interpretação do pedido.

27. Com o advento da interpretação do pedido prevista no $\S 2^{\circ}$, art. 322 , do CPC/2015, não existe mais justificativa para que o Poder Judiciário permaneça utilizando a interpretação lógico-sistemática do pedido (e suas variantes) em ações individuais. A segurança jurídica ${ }^{963}$ deve ser preservada e, para isso, o magistrado deve se ater ao objeto litigioso do processo, limitando-se a decidir de acordo com a provocação do demandante.

963 “Sem a lei, a Justiça seria apenas uma ideia ou um ideal. A segurança jurídica é a certeza que se tem de atos, coisas e situações na incerteza da vida. $\mathrm{O}$ acatamento à lei dá a segurança de que precisa o cidadão. 
28. Este trabalho não se limitou a expor uma problemática. Antes disso, a real intenção deste estudo é apresentar propostas práticas para solucionar e tornar mais objetiva a interpretação do pedido no processo civil, quando do julgamento de ações individuais.

Na resposta judicial serena, impessoal e imparcial para a solução de um conflito repousa a confiança no direito e no Judiciário." (ROCHA, Cármen Lúcia Antunes. (In)segurança jurídica. Disponível em: https://oglobo.globo.com/opiniao/inseguranca-juridica-22880449 - Acessado em: 21/07/2018) 


\section{REFERÊNCIAS}

ALMEIDA FILHO, José Carlos de Araújo. O pedido no sistema da common law e o princípio da adstrição. Revista de Processo, São Paulo, v. 118, nov-dez/2004, p. 89-108.

ÁVILA, Humberto. Teoria dos princípios - da definição à aplicação dos princípios jurídicos. 16. ed. São Paulo: Malheiros, 2015.

ALVIM, Arruda. Manual de direito processual civil. 17. ed. São Paulo: Editora Revista dos Tribunais, 2017.

ALVIM, Eduardo Arruda. Direito processual civil. 5. ed. São Paulo: Editora Revista dos Tribunais, 2013.

ALVIM, Thereza. Questões prévias e os limites objetivos da coisa julgada. São Paulo: Revista dos Tribunais, 1977.

AMENDOEIRA JÚNIOR, Sidnei. Manual de direito processual civil, Volume 1: teoria geral do processo e fase de conhecimento em primeiro grau de jurisdição. 2. ed. São Paulo: Saraiva, 2012.

Poderes do juiz e tutela jurisdicional: a utilização racional dos poderes do juiz, como forma de obtenção da tutela jurisdicional efetiva, justa e tempestiva. São Paulo: Atlas, 2006.

ARENHART, Sérgio Cruz. Reflexões sobre o Princípio da Demanda. In: FUX, Luiz; NERY JÚNIOR, Nelson; WAMBIER, Tereza Arruda Alvim (Coord.). Processo e Constituição: estudos em homenagem ao Professor José Carlos Barbosa Moreira. São Paulo: Revista dos Tribunais, 2006. p. 587-603.

ARRUDA ALVIM, Teresa. Embargos de declaração. Como se motiva uma decisão judicia? 3. ed. São Paulo: Editora Revista dos Tribunais, 2017.

Tribunais, 2017.

. Nulidades do processo e da sentença. 8. ed. São Paulo: Editora Revista dos

ASSIS, Araken de. Cumulação de ações. 4. ed. São Paulo: Editora Revista dos Tribunais, 2002.

. Questão de princípio. Revista do Advogado. São Paulo, v. 40, jul/1993, p. 30-34.

Processo Civil brasileiro, Volume I: parte geral, fundamentos e distribuição de conflitos. São Paulo: Editora Revista dos Tribunais, 2015.

BADARÓ, Gustavo Henrique Righi Ivahy. Correlação entre a acusação e a sentença. 3. ed. São Paulo: Editora Revista dos Tribunais, 2013.

BARBOSA MOREIRA, José Carlos. Ação de revisão de aluguel - pedido e sentença (parecer). Revista Forense, v. 328. out-nov-dez/1994, p. 128-133. 
Correlação entre o pedido e a sentença. Revista de Processo, São Paulo, v. 83. julset /1996, p. 207-215.

185.

. Duelo e processo. Revista de Processo, São Paulo, v. 112, out-dez/2003, p. 177-

O processo, as partes e a sociedade. Revista de Processo, São Paulo, v. 125, jul/2005, p. 279-288.

BARIONI, Rodrigo Otávio. A emenda da petição inicial após a citação do réu. Revista de Processo, São Paulo, v. 121, mar/2005, p. 51-68.

BEDAQUE, José Roberto dos Santos. Direito e Processo. A influência do direito material sobre o processo. 6. ed. São Paulo: Malheiros, 2011.

. Efetividade do processo e técnica processual. 3. ed. São Paulo: Malheiros, 2010.

. Os elementos objetivos da demanda à luz do contraditório, In: CRUZ E TUCCI, José Rogério, BEDAQUE, José Roberto dos Santos (Coord.). Causa de pedir e pedido no processo civil (questões polêmicas). São Paulo: Revista dos Tribunais, 2002, p. 13-52.

2011.

Poderes instrutórios do juiz. 6. ed. São Paulo: Editora Revista dos Tribunais,

BETIOLI, Antônio Bento. Introdução ao Direito. 14. ed. São Paulo: Saraiva, 2015.

BONICIO, Marcelo José Magalhães. Ensaio sobre o dever de colaboração previsto no projeto do novo Código de Processo Civil brasileiro. Revista de Processo, São Paulo, v. 190, dez/2010, p. 210-230.

2016.

Princípios do processo no novo Código de Processo Civil. São Paulo: Saraiva,

BUZAID, Alfredo. Da lide: estudos sobre o objeto litigioso. Estudos e pareceres de direito processual civil. Notas de adaptação ao direito vigente de Ada Pellegrini Grinover e Flávio Luiz Yarshell. São Paulo: Editora Revista dos Tribunais, 2002, p. 72-132.

. Processo e verdade no direito brasileiro. Revista de Processo, São Paulo, v. 47, jul-set/1987, p. 92-99.

CABRAL, Antônio do Passo. O contraditório como dever e a boa-fé processual objetiva. Revista de Processo, São Paulo, v. 126, ago/2005, p. 59 - 81.

CAHALI, Yussef Said. Dano moral. 2. ed. São Paulo: Editora Revista dos Tribunais, 1998.

CALAMANDREI, Piero. Eles, os juízes, vistos por nós, os advogados. (tradução Ivo de Paula). São Paulo: Editora Pilares, 2013.

CATALAN, Marcos Jorge. O princípio da congruência e o acesso à ordem jurídica justa: reflexões sobre o tema na legalidade constitucional. Revista de Processo, São Paulo, v. 147. mai/2007, p. 73-95. 
CARACIOLA, Andrea Boari. Princípio da congruência no Código de Processo Civil. São Paulo: LTr, 2010.

CARMONA, Carlos Alberto. Em torno da petição inicial. Revista de Processo, São Paulo, v. 119, jan/2005, p. 11-34.

CARNELUTTI, Francesco. Como nasce o direito. São Paulo: Editora Pillares: 2015.

. Como se faz um processo. Campinas: Servanda Editora, 2015.

. Instituições do Processo Civil. Volume 1. São Paulo: Classic Book, 2000.

CARVALHO, Milton Paulo de. Do pedido no processo civil. Porto Alegre: Sérgio Antônio Fabris Editor, 1992.

Pedido novo e aditamento do pedido. O art. 294 do Código de Processo Civil na sua nova redação. In: CRUZ E TUCCI, José Rogério (Coord.). Processo civil: estudo em comemoração aos 20 anos de vigência do Código de Processo Civil. São Paulo: Saraiva, 1995, p. 169-177.

CINTRA, Antônio Carlos de Araújo; GRINOVER, Ada Pellegrini e DINAMARCO, Cândido Rangel. Teoria geral do processo. 27. ed. São Paulo: Malheiros, 2011.

CINTRA. Lia Carolina Batista. Relevância da vontade no processo, interpretação do ato postulatório e pedido "meramente" declaratório. Revista de Processo, São Paulo, v. 239, jan/2015, p. 35-62.

CORRÊA, Fábio Peixinho Gomes. O objeto litigioso no processo civil. São Paulo: Quartier Latin, 2009.

COSTA, Susana Henriques da. Condições da Ação. São Paulo: Quartier Latin, 2005.

. Arts. 318 a 333. Comentários ao novo Código de Processo Civil. Coord. Antônio do Passo Cabral, Ronaldo Cramer. 2. ed. Rio de Janeiro: Forense, 2016, p. 501-528.

COSTA, Susana Henriques da. FERNANDES, Débora Chaves Martines. Processo coletivo e controle judicial de políticas públicas - relatório Brasil. in. Ada Pellegrini Grinover, Kazuo Watanabe, e Susana Henriques da Costa (Coord.). O processo para solução de conflitos de interesse público. Salvador: Editora Juspodivm, 2017, p. 359-382.

COSTA E SILVA, Paula. Acto e Processo - o dogma da irrelevância da vontade na interpretação e nos vícios do acto postulativo. Coimbra: Coimbra Editora, 2003.

COUTURE, Eduardo Juan. Interpretação das leis processuais. São Paulo: Max Limonad, 1956.

CRUZ E TUCCI, José Rogério. A causa petendi no processo civil. 3. ed. São Paulo: Editora Revista dos Tribunais, 2009.

A denominada "situação substancial" como objeto do processo na obra de Fazzalari. Revista de Processo, São Paulo, v. 68, out-dez/1992, p. 271-281. 
A regra da eventualidade como pressuposto da denominada teoria da substanciação. Revista do Advogado. São Paulo, v. 40, jul/1993, p. 39-43.

. Art. $2^{o}$. Código de Processo Civil anotado. Coord. José Rogério Cruz e Tucci et al. Rio de Janeiro: GZ Editora, 2016, p. 2-4.

. Contornos da causa petendi da demanda civil perante o juizado especial. Revista dos Tribunais. vol. 745. Nov/ 1997. p. 11. p. $47-65$.

Contra o processo autoritário. Revista de Processo, São Paulo, v. 242, Abr / 2015,

. Espírito do processo civil moderno na obra de Rudolf von Ihering. Revista de Processo, São Paulo, v. 66, abr-jun/1992, p. 285-294.

. Reflexões sobre a cumulação subsidiária de pedidos. Revista dos Tribunais. vol. 786/2001. Abr/2001. p. 57-67.

CRUZ E TUCCI, José Rogério; AZEVEDO, Luiz Carlos de. Lições de história do processo civil romano. 2. ed. São Paulo: Editora Revista dos Tribunais, 2013.

DIDIER JR., Fredie. Arts. 502 a 508. Comentários ao novo Código de Processo Civil. Coord. Antônio do Passo Cabral, Ronaldo Cramer. 2. ed. Rio de Janeiro: Forense, 2016, p. 751-783

DINAMARCO, Cândido Rangel. A Instrumentalidade do Processo. 15. ed. São Paulo: Malheiros, 2013.

2017.. Instituições de Direito Processual Civil - Volume II. 7. ed. São Paulo: Malheiros,

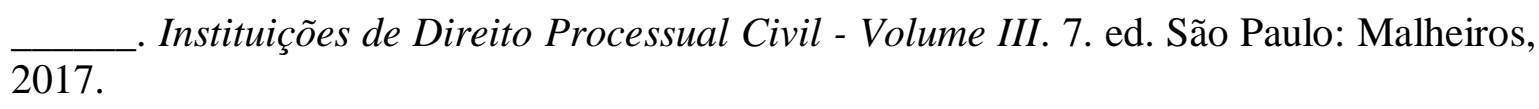
. O conceito de mérito em processo civil. Revista de Processo, São Paulo, v. 34, abr-jun/1984, p. 20-46.

Ônus de afirmar e causa petendi - Os documentos indispensáveis a propositura da demanda - Ônus de afirmar e ônus de impugnação específica (CPC, art. 302 - Pedido determinado e sentença ilíquida - Confissões de dívida como declarações de vontade constitutivas - Honorários advocatícios (parecer). Revista Forense, v. 341, jan-mar/1998, p. $215-238$.

. Nova era do processo civil. 4. ed. São Paulo: Malheiros, 2013.

. Superior Tribunal de Justiça e acesso a ordem jurídica justa. Revista de Processo, São Paulo, v. 59, jul-set/1991, p. 14-21.

DINIZ, Maria Helena. Curso de direito civil brasileiro: teoria geral do direito civil. Vol. 1. 33. ed. São Paulo: Saraiva, 2016. 
. Compêndio de introdução à ciência do Direito. 26. ed. São Paulo: Saraiva, 2017.

DIP, Ricardo. Tópicos inaugurais da interpretação jurídica. Revista Forense, Rio de Janeiro, v. 413, jan-jun/2011, p. 663-667.

ELIAS, Carlos Eduardo Stefen. As reformas processuais e o princípio da congruência entre sentença e pedido. Revista de Processo, São Paulo, v. 158, abr/2008, p. 38-64.

Arts. 700 a 702. Código de Processo Civil anotado. Coord. José Rogério Cruz e Tucci et al. Rio de Janeiro: GZ Editora, 2016, p. 964-971.

FERRARA, Francesco. Interpretação e aplicação das leis. 2. ed. São Paulo: Saraiva, 1940.

FERRAZ JÚNIOR, Tercio Sampaio. Introdução ao estudo do direito: técnica, decisão, dominação. 9. ed. São Paulo: Editora Atlas, 2016.

FORNACIARI JÚNIOR. Clito. Art. 343. Código de Processo Civil anotado. Coord. José Rogério Cruz e Tucci et al. Rio de Janeiro: GZ Editora, 2016, p. 505-508.

FREITAS, Juarez. A interpretação sistemática do Direito. São Paulo: Malheiros, 2010.

GABBAY, Daniela Monteiro. Arts. 318 a 331. Código de Processo Civil anotado. Coord. José Rogério Cruz e Tucci et al. Rio de Janeiro: GZ Editora, 2016, p. 471-482.

. Pedido e causa de pedir. São Paulo: Saraiva, 2010.

GODOY, Arnaldo Sampaio de Moraes. Introdução ao Realismo Jurídico NorteAmericano. Brasília: edição do autor, 2013.

GOMES, Danilo Heber. Ato processual (in)existente. Curitiba: Juruá, 2013.

GOMES, Luiz Roldão de Freitas. Norma jurídica. Interpretação e aplicação. Aspectos atuais. Revista Forense, Rio de Janeiro, v. 316, out-dez/1991, p. 65-71.

GRAU, Eros Roberto. O Direito Posto e o Direito Pressuposto. 9. ed. São Paulo: Malheiros, 2014.

p. 21-26.

O direito pressuposto e o direito posto. Revista dos Tribunais. vol. 673. Nov/1991.

Por que tenho medo dos juízes (interpretação/ aplicação do direito e os princípios). 8. ed. São Paulo: Malheiros, 2017.

. Nota sobre os conceitos jurídicos. Doutrinas Essenciais de Direito Civil. vol. 1. out/2010, p. 259.

GRINOVER, Ada Pellegrini. Ensaio sobre a processualidade: fundamentos de uma nova teoria geral do processo. Brasília: Gazeta Jurídica, 2016.

57.

O direito de ação. Doutrinas Essenciais de Processo Civil. vol. 2. out/2011, p. 45- 
JORGE, Flávio Cheim. Sentença cível. Revista de Processo, São Paulo, v. 104, outdez/2001, p. 111-132.

Teoria geral dos recursos cíveis. Rio de Janeiro: Forense, 2003.

LANES, Júlio Cesar Goulart. Fato e direito no processo civil cooperativo. São Paulo: Revista dos Tribunais, 2014.

LEONEL, Ricardo de Barros. Causa de Pedir e Pedido: o direito superveniente. São Paulo: Método, 2006.

LIEBMAN, Enrico Tullio. A força criativa da jurisprudência e os limites impostos pelo texto da lei. Revista de Processo, São Paulo, v. 43, jul-set/1986, p. 57-60.

Do arbítrio à razão reflexões sobre a motivação da sentença. Revista de Processo, São Paulo, v. 29, jan-mar/1983, p. 79-81.

- Eficácia e autoridade da sentença e outros escritos sobre a coisa julgada (tradução de Alfredo Buzaid e Benvindo Aires, tradução dos textos posteriores à edição de 1945 com notas relativas ao direito brasileiro vigente de Ada Pellegrini Grinover). Rio de Janeiro: Forense, 2007.

. Manual de Direito Processual Civil. Vol. I, 3. ed. São Paulo: Malheiros, 2005.

. O despacho saneador e o julgamento do mérito. Revista dos Tribunais. vol. 767. Set/1999. p. 737 - 753.

LOPES, Bruno Vasconcelos Carrilho. A extensão da coisa julgada às questões apreciadas na motivação da sentença. Revista de Processo, São Paulo, v. 216, fev/2013, p. 431-438.

LUCON, Paulo Henrique dos Santos. Relação entre demandas. Brasília: Gazeta Jurídica, 2016.

LUCON, Paulo Henrique dos Santos; GABBAY, Daniela Monteiro; ALVES, Rafael Francisco; ANDRADE, Tathyana Chaves de. Interpretação do pedido e da causa de pedir nas demandas coletivas (conexão, continência e litispendência). In: Paulo Henrique dos Santos Lucon. (Org.). Tutela Coletiva - 20 anos da Lei da Ação Civil Pública e do Fundo de Defesa de Direitos Difusos - 15 anos do Código de Defesa do Consumidor. São Paulo: Atlas, 2006, p. 184-199.

LUCON, Paulo Henrique dos Santos; RODRIGUES, Rafael Ribeiro. Recursos Extraordinário e Especial Repetitivos: antecedentes e novidades no CPC/2015. Aspectos polêmicos dos recursos cíveis e assuntos afins. Volume 14. Coord. Nelson Nery Júnior, Teresa Arruda Alvim e Pedro Miranda de Oliveira. São Paulo: Thomson Reuters, 2018, p. 345-374.

LOPES, Mônica Sette. O realismo jurídico: O discurso jurídico e a apreensão da realidade pontual. Revista da Faculdade de Direito da Universidade Federal de Minas Gerais. Minas Gerais, v. 45, 2004, p. 297-340.

MACHADO, Hugo de Brito. Introdução ao estudo do direito. 3. ed. São Paulo: Atlas, 2012. 
MACHADO. Marcelo Pacheco. A correlação no processo civil: relações entre demanda e tutela jurisdicional. Salvador: JusPodivm, 2015.

. Causa de pedir e teoria da relatividade do fato essencial. Revista de Processo, São Paulo, v. 237, nov/2014, p. 89-113.

. Demanda, reconvenção e defesa: o que é o que é? Revista de Processo, São Paulo, v. 236, out/2014, p. 71-96.

. Incerteza e processo. São Paulo: Saraiva, 2013.

Simplificação, autonomia e estabilização das tutelas de urgência: análise da proposta do Projeto de novo Código de Processo Civil. Revista de Processo, São Paulo. v. 202. dez/2011, p. 233-267.

MALACHINI. Edson Ribas. Da conversibilidade de um processo em outro, por emenda à petição inicial. Revista de Processo, São Paulo, v. 54, abr-jun/1989, p. 7-16.

MALLET, Estêvão. Notas sobre o problema da chamada "decisão-surpresa". Revista de Processo, São Paulo, v. 233, jul/2014, p. 43-64.

MARCATO, Antonio Carlos. Preclusões: limitação ao contraditório? Revista de Processo, São Paulo, v. 17, jan-mar/1980, p. 105-114.

Procedimentos especiais. 17. ed. São Paulo: Atlas, 2017.

MARINONI, Luiz Guilherme. O direito de ação como direito fundamental (consequiências teóricas e práticas). Revista dos Tribunais. vol. 873. Jul/2008. p. 11-30.

MARINONI, Luiz Guilherme; ARENHART, Sérgio Cruz; MITIDIERO, Daniel. Novo curso de processo civil: teoria do processo civil, volume I. 2. ed. São Paulo: Editora Revista dos Tribunais, 2016.

. Novo curso de processo civil: tutela dos direitos mediante procedimento comum, volume II. 2. ed. São Paulo: Editora Revista dos Tribunais, 2016.

- Novo curso de processo civil: tutela dos direitos mediante procedimentos diferenciados, volume III. 2. ed. São Paulo: Editora Revista dos Tribunais, 2016.

MARKY, Thomas. Curso Elementar de Direito Romano. 8. ed. São Paulo: Saraiva, 1995

MAXIMILIANO, Carlos. Hermenêutica e aplicação do direito. 20. ed. Rio de Janeiro: Forense, 2011.

MEDINA, José Miguel Garcia; WAMBIER, Teresa Arruda Alvim. Parte geral e processo de conhecimento. 3. ed. São Paulo: Editora Revista dos Tribunais, 2013.

MEIRELLES, Hely Lopes. Direito administrativo brasileiro. 41. ed. São Paulo: Malheiros, 2015.

MEIRELLES, Hely Lopes. WALD, Arnoldo. MENDES, Gilmar Ferreira. Mandado de segurança e ações constitucionais. 36. ed. São Paulo: Malheiros, 2014. 
MESQUITA, José Ignácio Botelho de. A 'causa petendi' nas ações reivindicatórias. Revista da Ajuris, Rio Grande do Sul, v. 20, nov/1980, p. 166-180.

MESQUITA, José Ignácio Botelho de; LOMBARDI, Mariana Capela; AMADEO, Rodolfo da Costa Manso Real; DELLORE, Luiz Guilherme Pennacchi; ZVEIBIL, Daniel Guimarães. O colapso das condições da ação?: um breve ensaio sobre os efeitos da carência de ação. Revista de Processo, São Paulo, v. 152, out/2007, p. 11-35.

MITIDIERO, Daniel Francisco. Cortes Superiores e Cortes Supremas - Do Controle à Interpretação, da Jurisprudência ao Precedente. 2. ed. São Paulo: Revista dos Tribunais, 2015.

MONTEIRO NETO. João Pereira. Pedido genérico: reflexões à luz do novo Código de Processo Civil. Revista de Processo, São Paulo, v. 243, mai/2015, p. 59-80.

MONTORO, André Franco. Introdução à ciência do direito. 25. ed. São Paulo: Editora Revista dos Tribunais, 2000.

NERY JÚNIOR, Nelson. Condições da ação. Revista de Processo, São Paulo, v. 64, outdez/1991, p. 33-38.

. Decisão extra petita. Soluções Práticas de Direito. vol. 9. Set/2014. p. 125-153.

. Princípios do processo civil na constituição federal. 13. ed. São Paulo: Revista dos Tribunais, 2017.

NERY JÚNIOR, Nelson. NERY, Rosa Maria de Andrade. Comentários ao Código de Processo Civil. São Paulo: Editora Revista dos Tribunais, 2015.

NERY, Rosa Maria de Andrade. Fatos processuais. Atos jurídicos processuais simples. Negócio jurídico processual (unilateral e bilateral). Transação. Revista de Direito Privado. vol. 64, out-dez/2015, p. 261-274.

NUSDEO, Fábio. Curso de economia: introdução ao direito econômico. 7. ed. São Paulo: Editora Revista dos Tribunais, 2013.

OLIVEIRA, Bruno Silveira de. O juízo de identificação de demandas e de recursos no processo civil brasileiro (contribuição ao estudo dos atos postulatórios). Tese (Doutorado) - Faculdade de Direito da Universidade de São Paulo, São Paulo, 2009.

OLIVEIRA NETO. Olavo de. OLIVEIRA. Patrícia Elias Cozzolino de. A necessidade de pedido específico na ação de indenização por dano moral. Revista do Instituto dos Advogados de São Paulo. vol. 23. Jan-Jun/2009. p. 250-263.

PINHEIRO, Guilherme César. O novo código de processo civil e as alterações não explícitas sobre a petição inicial. Revista de Processo, São Paulo, v. 258, ago/2016. p. 85102.

PINTO, Teresa Celina Arruda Alvim. A sentença e a coisa julgada. Revista de Processo, São Paulo, v. 41, jan-mar/1986, p. 177-184. 
. Existe a "discricionariedade" judicial? Revista de Processo, São Paulo, v. 70, abrjun/1993, p. 232-234.

PONTES DE MIRANDA, Francisco Cavalcanti. Comentários ao Código de Processo Civil. Tomo II, arts. 80 a 160. 2. ed. Rio de Janeiro: Revista Forense, 1958.

. Comentários ao Código de Processo Civil, Tomo I, arts 1 a 45. 2. ed. Rio de Janeiro: Forense, 1979.

. Comentários ao Código de Processo Civil, Tomo II, arts 46 a 153. Rio de Janeiro: Forense, 1974.

. Comentários ao Código de Processo Civil, Tomo IV, arts 282 a 443. 2. ed. Rio de Janeiro: Forense, 1979.

. Comentários ao Código de Processo Civil, Tomo V, arts 444 a 475. Rio de Janeiro: Forense, 1974.

. Comentários ao Código de Processo Civil, Tomo XII, arts 796 a 889. Rio de Janeiro: Forense, 1976.

PUOLI, José Carlos Baptista. Os Poderes do Juiz e as Reformas do Processo Civil. São Paulo: Editora Juarez de Oliveira, 2001.

ROCHA, Cármen Lúcia Antunes. (In)segurança jurídica. Disponível em: https://oglobo.globo.com/opiniao/inseguranca-juridica-22880449 - Acessado em: 21/07/2018.

RODRIGUES, Marco Antônio dos Santos. A modificação do pedido e da causa de pedir no processo civil. Rio de Janeiro: GZ Editora, 2014.

RODRIGUES, Rafael Ribeiro. Honorários recursais. Do Anteprojeto ao CPC/15. Requisitos e Funções. Questões problemáticas. Revista Forense, Rio de Janeiro, v. 426, jul-dez/2017, p. 161-187.

RODRIGUES, Rafael Ribeiro; THAMAY, Rennan F. K. Estabilização e pedido incontroverso. Revista de Processo, São Paulo, v. 268, jun/2017, p. 377 - 404.

. O efeito translativo na barca de Caronte. Revista de Processo, São Paulo, v. 255, maio/2016, p. 253-274.

- Uma primeira análise constitucional sobre os princípios no Novo Código de Processo Civil. Coleção Novo CPC: doutrina selecionada. Vol. 1: parte geral. 2. ed. Fredie Didier Júnior (Coord.). Salvador: Juspodivm, 2016, p. 351-367.

RODRIGUES, Silvio. Direito Civil: parte geral. 28. ed. São Paulo: Saraiva, 2002.

SANCHES, Sydney. Objeto do processo e objeto litigioso do processo. Revista de Jurisprudência do Tribunal de Justiça do Estado de São Paulo, nov-dez/1978, p. 13-26.

SANTOS, Silas Silva. Litisconsórcio eventual, alternativo e sucessivo. São Paulo: Atlas, 2013. 
SCARPINELLA BUENO, Cassio. Curso sistematizado de direito processual civil: procedimento comum ordinário e sumário. Vol. 2. Tomo I. 7. ed. São Paulo: Saraiva, 2014.

- Curso sistematizado de direito processual civil: procedimentos especiais do

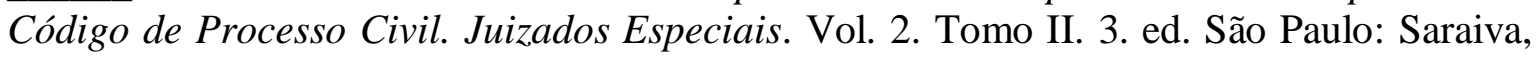
2014.

Curso sistematizado de direito processual civil: tutela antecipada, tutela cautelar, procedimentos cautelares específicos. Vol. 4. 6. ed. São Paulo: Saraiva, 2014.

. Direito, interpretação e norma jurídica: uma aproximação musical do direito. Revista de Processo, São Paulo, v. 111, jul-set/2003, p. 223-242.

SICA, Heitor Vitor Mendonça. O Direito de Defesa No Processo Civil Brasileiro - Um Estudo Sobre a Posição do Réu. São Paulo: Editora Atlas, 2011.

Preclusão Processual Civil. 2. ed. São Paulo: Atlas, 2008.

SILVA, De Plácido e. Vocabulário Jurídico. 20. ed. Rio de Janeiro: Editora Forense, 2002.

SILVA, João Paulo Hecker da. Processo societário: tutelas de urgência e da evidência. Brasília: Gazeta Jurídica, 2014.

SILVA, José Afonso da. Curso de direito constitucional positivo. 37. ed. São Paulo: Malheiros, 2014.

SILVA, Ovídio Araujo Baptista da. Limites objetivos da coisa julgada no direito brasileiro atual. Revista de Processo, São Paulo, v. 14, abr-set/1979, p. 45-71.

36.

. Processo e ideologia. Revista de Processo, São Paulo, v. 110, abr-jun/2003, p. 19-

SOBRINHO, Elicio de Cresci. Objeto litigioso no processo civil. Porto Alegre: Editora Sergio Antônio Fabris, 2008.

THEODORO JÚNIOR, Humberto. Curso de direito processual civil. Vol. I. 58. ed. Rio de Janeiro: Forense, 2017.

Estabilização da demanda no novo Código de Processo Civil. Revista de Processo, São Paulo, v. 244, jun/2015, p. 195-208.

. Interpretação e aplicação das normas jurídicas. Revista de Processo, São Paulo, v. 150, ago/2007, p. $11-23$.

- Notas sobre sentença, coisa julgada e interpretação. Revista de Processo, São Paulo, v. 167, jan/2009. p. 9-24.

O juiz e a revelação do Direito in concreto. Revista Forense, Rio de Janeiro, v. 360, mar-abr/2002, p. 23-33. 
TUCCI, Rogério Lauria. Aspectos modernos do conceito de ação. Doutrinas Essenciais de Processo Civil. vol. 2, out / 2011, p. 59 - 80.

TUNALA, Larissa Gaspar. Comportamento processual contraditório. Salvador: Juspodivm, 2015.

VENOSA, Sílvio de Salvo. Direito Civil: parte geral. 15. ed. São Paulo: Atlas, 2015.

. Direito Civil: teoria geral das obrigações e teoria geral dos contratos. 15. ed. São Paulo: Atlas, 2015.

. Introdução ao estudo do direito: primeiras linhas. 5. ed. São Paulo: Atlas, 2016.

VIEIRA, Luíta Maria Ourém Sabóia. O princípio da correlação aplicado ao processo civil e ao processo penal. Revista de Processo, São Paulo, v. 211, set/2012, p. 391-415.

VIGLIAR, José Marcelo Menezes. Tutela jurisdicional coletiva. 4. ed. São Paulo: Atlas, 2013.

WAMBIER, Luiz Rodrigues; TALAMINI, Eduardo. Curso Avançado de Processo Civil: teoria geral do processo e processo de conhecimento. Volume 1. 15. ed. São Paulo: Editora Revista dos Tribunais, 2015.

WAMBIER, Teresa Arruda Alvim, et al. Primeiros Comentários ao Novo Código de Processo Civil. São Paulo: Saraiva, 2015.

WAMBIER, Teresa Arruda Alvim. A tutela específica do art. 461, do Código de Processo Civil. Revista de Processo, São Paulo, v. 80, out-dez/1995, p. 103-110.

. O juiz aplica a lei à verdade dos fatos? Revista de Processo, São Paulo, v. 216, fev/2013, p. 425-430.

WATANABE, Kazuo. Ação dúplice. Revista de Processo, São Paulo, v. 31, jul-set/1983, p. 138-143.

. Cognição no Processo Civil. 4. ed. São Paulo: Saraiva, 2012.

YARSHELL, Flávio Luiz. Antecipação da prova sem o requisito da urgência e direito autônomo à prova. São Paulo: Malheiros, 2009.

. Curso de Direito Processual Civil. Vol. 1. São Paulo: Editora Marcial Pons, 2014.

. Tutela Jurisdicional. 2. ed. São Paulo: Editora DPJ. 2006. 


\section{ANEXO A - DECISÕES FAVORÁVEIS À INTERPRETAÇÃO LÓGICO- SISTEMÁTICA DO PEDIDO E SUAS VARIANTES}

\begin{tabular}{|c|c|c|c|}
\hline $\begin{array}{c}\text { ÓRGÃO } \\
\text { JULGADOR }\end{array}$ & MINISTRO(A) & PROCESSO & PUBLICAÇÃO \\
\hline $\begin{array}{l}\text { QUARTA } \\
\text { TURMA }\end{array}$ & $\begin{array}{l}\text { SÁLVIO DE FIGUEIREDO } \\
\text { TEIXEIRA }\end{array}$ & REsp 76153 / SP & 05/02/1996 \\
\hline $\begin{array}{l}\text { PRIMEIRA } \\
\text { TURMA }\end{array}$ & JOSÉ DELGADO & REsp 105616 / PR & 16/12/1996 \\
\hline $\begin{array}{l}\text { QUARTA } \\
\text { TURMA }\end{array}$ & $\begin{array}{l}\text { SÁLVIO DE FIGUEIREDO } \\
\text { TEIXEIRA }\end{array}$ & $\begin{array}{c}\text { AgRg no Ag } 145729 / \\
\text { MG }\end{array}$ & 02/03/1998 \\
\hline $\begin{array}{l}\text { QUARTA } \\
\text { TURMA }\end{array}$ & $\begin{array}{l}\text { SÁLVIO DE FIGUEIREDO } \\
\text { TEIXEIRA }\end{array}$ & REsp 120299 / ES & 21/09/1998 \\
\hline $\begin{array}{l}\text { QUARTA } \\
\text { TURMA }\end{array}$ & $\begin{array}{l}\text { SÁLVIO DE FIGUEIREDO } \\
\text { TEIXEIRA }\end{array}$ & REsp 284480 / RJ & 02/04/2001 \\
\hline $\begin{array}{l}\text { QUARTA } \\
\text { TURMA }\end{array}$ & $\begin{array}{l}\text { SÁLVIO DE FIGUEIREDO } \\
\text { TEIXEIRA }\end{array}$ & REsp 233446 / RJ & 07/05/2001 \\
\hline $\begin{array}{l}\text { QUINTA } \\
\text { TURMA }\end{array}$ & FELIX FISCHER & REsp 306761 / DF & 04/06/2001 \\
\hline $\begin{array}{c}\text { TERCEIRA } \\
\text { TURMA }\end{array}$ & NANCY ANDRIGHI & REsp 337785 / RJ & $25 / 03 / 2002$ \\
\hline $\begin{array}{c}\text { PRIMEIRA } \\
\text { TURMA }\end{array}$ & LUIZ FUX & AgRg no Ag 468472 / RJ & $02 / 06 / 2003$ \\
\hline $\begin{array}{l}\text { PRIMEIRA } \\
\text { TURMA }\end{array}$ & DENISE ARRUDA & AgRg no Ag 567773 / RJ & $20 / 09 / 2004$ \\
\hline $\begin{array}{l}\text { QUARTA } \\
\text { TURMA }\end{array}$ & FERNANDO GONÇALVES & REsp 440211 / ES & $11 / 10 / 2004$ \\
\hline $\begin{array}{l}\text { QUARTA } \\
\text { TURMA }\end{array}$ & FERNANDO GONÇALVES & AgRg no Ag 594865 / RS & $16 / 11 / 2004$ \\
\hline $\begin{array}{l}\text { QUINTA } \\
\text { TURMA }\end{array}$ & LAURITA VAZ & REsp 646909 / MT & $13 / 12 / 2004$ \\
\hline $\begin{array}{l}\text { QUARTA } \\
\text { TURMA }\end{array}$ & JORGE SCARTEZZINI & AgRg no Ag 596323 / RJ & $17 / 12 / 2004$ \\
\hline $\begin{array}{l}\text { SEGUNDA } \\
\text { TURMA }\end{array}$ & FRANCIULLI NETTO & $\begin{array}{c}\text { AgRg no REsp } 511670 \text { / } \\
\text { MG }\end{array}$ & 08/08/2005 \\
\hline $\begin{array}{l}\text { PRIMEIRA } \\
\text { TURMA }\end{array}$ & DENISE ARRUDA & AgRg no Ag $625911 / \mathrm{GO}$ & $20 / 06 / 2005$ \\
\hline $\begin{array}{l}\text { TERCEIRA } \\
\text { TURMA }\end{array}$ & CASTRO FILHO & REsp 586474 / RS & $23 / 05 / 2005$ \\
\hline $\begin{array}{c}\text { PRIMEIRA } \\
\text { TURMA }\end{array}$ & DENISE ARRUDA & $\begin{array}{c}\text { AgRg no Ag 627423 / } \\
\text { MG }\end{array}$ & $20 / 06 / 2005$ \\
\hline $\begin{array}{l}\text { QUARTA } \\
\text { TURMA }\end{array}$ & BARROS MONTEIRO & AgRg no Ag 643032 / ES & 03/04/2006 \\
\hline $\begin{array}{l}\text { QUARTA } \\
\text { TURMA }\end{array}$ & ALDIR PASSARINHO JUNIOR & AgRg no Ag $738250 / \mathrm{GO}$ & $05 / 11 / 2007$ \\
\hline $\begin{array}{c}\text { PRIMEIRA } \\
\text { TURMA }\end{array}$ & LUIZ FUX & REsp 807863 / RJ & $01 / 08 / 2006$ \\
\hline $\begin{array}{l}\text { PRIMEIRA } \\
\text { TURMA }\end{array}$ & JOSÉ DELGADO & REsp 716468 / RJ & $31 / 08 / 2006$ \\
\hline $\begin{array}{l}\text { TERCEIRA } \\
\text { TURMA }\end{array}$ & CASTRO FILHO & REsp 772185 / MT & $13 / 11 / 2006$ \\
\hline $\begin{array}{l}\text { QUARTA } \\
\text { TURMA }\end{array}$ & JORGE SCARTEZZINI & AgRg no Ag 668909 / SP & $20 / 11 / 2006$ \\
\hline
\end{tabular}




\begin{tabular}{|c|c|c|c|}
\hline $\begin{array}{c}\text { ÓRGÃO } \\
\text { JULGADOR }\end{array}$ & MINISTRO(A) & PROCESSO & PUBLICAÇÃO \\
\hline $\begin{array}{l}\text { TERCEIRA } \\
\text { TURMA }\end{array}$ & CASTRO FILHO & REsp 712293 / RJ & $04 / 12 / 2006$ \\
\hline $\begin{array}{l}\text { QUARTA } \\
\text { TURMA }\end{array}$ & JORGE SCARTEZZINI & AgRg no Ag 819912 / DF & $26 / 02 / 2007$ \\
\hline $\begin{array}{l}\text { TERCEIRA } \\
\text { TURMA }\end{array}$ & $\begin{array}{c}\text { HUMBERTO GOMES DE } \\
\text { BARROS }\end{array}$ & REsp 445413 / DF & $18 / 06 / 2007$ \\
\hline $\begin{array}{l}\text { QUINTA } \\
\text { TURMA }\end{array}$ & ARNALDO ESTEVES LIMA & REsp 767845 / GO & $07 / 05 / 2007$ \\
\hline $\begin{array}{l}\text { PRIMEIRA } \\
\text { TURMA }\end{array}$ & LUIZ FUX & AgRg no Ag 865880 / RJ & 09/08/2007 \\
\hline $\begin{array}{l}\text { SEGUNDA } \\
\text { TURMA }\end{array}$ & HERMAN BENJAMIN & AgRg no Ag $819800 /$ DF & $17 / 10 / 2008$ \\
\hline $\begin{array}{l}\text { QUINTA } \\
\text { TURMA }\end{array}$ & ARNALDO ESTEVES LIMA & REsp 734509 / BA & $06 / 08 / 2007$ \\
\hline $\begin{array}{l}\text { SEGUNDA } \\
\text { TURMA }\end{array}$ & HERMAN BENJAMIN & AgRg no Ag 844050 / SP & 08/02/2008 \\
\hline $\begin{array}{l}\text { SEGUNDA } \\
\text { SEÇÃO }\end{array}$ & FERNANDO GONÇALVES & CC $62402 / \mathrm{MG}$ & $11 / 10 / 2007$ \\
\hline $\begin{array}{l}\text { QUARTA } \\
\text { TURMA }\end{array}$ & MASSAMI UYEDA & $\begin{array}{c}\text { AgRg no Ag } 632742 \text { / } \\
\text { MA }\end{array}$ & $22 / 10 / 2007$ \\
\hline $\begin{array}{c}\text { TERCEIRA } \\
\text { TURMA }\end{array}$ & $\begin{array}{c}\text { HUMBERTO GOMES DE } \\
\text { BARROS } \\
\end{array}$ & REsp 985084 / BA & $19 / 12 / 2007$ \\
\hline $\begin{array}{l}\text { QUINTA } \\
\text { TURMA }\end{array}$ & ARNALDO ESTEVES LIMA & RMS 23353 / RS & $19 / 05 / 2008$ \\
\hline $\begin{array}{l}\text { QUINTA } \\
\text { TURMA }\end{array}$ & FELIX FISCHER & $\begin{array}{c}\text { EDcl no REsp } 895655 / \\
\text { SP }\end{array}$ & $28 / 04 / 2008$ \\
\hline $\begin{array}{l}\text { TERCEIRA } \\
\text { TURMA }\end{array}$ & SIDNEI BENETI & AgRg no Ag 886219/RS & $07 / 05 / 2008$ \\
\hline $\begin{array}{l}\text { QUINTA } \\
\text { TURMA }\end{array}$ & ARNALDO ESTEVES LIMA & REsp 906644 / RJ & $01 / 09 / 2008$ \\
\hline $\begin{array}{l}\text { TERCEIRA } \\
\text { TURMA }\end{array}$ & MASSAMI UYEDA & REsp 1045351 / MT & 05/08/2008 \\
\hline $\begin{array}{l}\text { TERCEIRA } \\
\text { TURMA }\end{array}$ & SIDNEI BENETI & $\begin{array}{c}\text { AgRg no REsp } 714159 / \\
\text { SC }\end{array}$ & 01/07/2008 \\
\hline $\begin{array}{l}\text { QUINTA } \\
\text { TURMA }\end{array}$ & ARNALDO ESTEVES LIMA & AgRg no Ag 948786 / SP & $01 / 12 / 2008$ \\
\hline $\begin{array}{l}\text { QUINTA } \\
\text { TURMA }\end{array}$ & ARNALDO ESTEVES LIMA & REsp 907087 / DF & $01 / 12 / 2008$ \\
\hline $\begin{array}{c}\text { SEGUNDA } \\
\text { TURMA }\end{array}$ & CASTRO MEIRA & REsp 1022798 / ES & $28 / 11 / 2008$ \\
\hline $\begin{array}{l}\text { QUINTA } \\
\text { TURMA }\end{array}$ & ARNALDO ESTEVES LIMA & REsp 948732 / RS & $03 / 11 / 2008$ \\
\hline $\begin{array}{l}\text { QUINTA } \\
\text { TURMA }\end{array}$ & ARNALDO ESTEVES LIMA & REsp 925534 / RN & $03 / 11 / 2008$ \\
\hline $\begin{array}{l}\text { QUINTA } \\
\text { TURMA }\end{array}$ & LAURITA VAZ & $\begin{array}{c}\text { AgRg no REsp } 737941 / \\
\text { CE }\end{array}$ & $01 / 12 / 2008$ \\
\hline $\begin{array}{l}\text { PRIMEIRA } \\
\text { TURMA }\end{array}$ & DENISE ARRUDA & $\begin{array}{c}\text { AgRg no Ag } 1038295 \text { / } \\
\text { RS } \\
\end{array}$ & $03 / 12 / 2008$ \\
\hline $\begin{array}{l}\text { PRIMEIRA } \\
\text { TURMA }\end{array}$ & DENISE ARRUDA & $\begin{array}{l}\text { EDcl nos EDcl no REsp } \\
911520 / \text { SP }\end{array}$ & $03 / 12 / 2008$ \\
\hline
\end{tabular}




\begin{tabular}{|c|c|c|c|}
\hline $\begin{array}{l}\text { ÓRGÃO } \\
\text { JULGADOR }\end{array}$ & $\mathbf{O}(\mathrm{A})$ & PROCESSO & PUBLICAÇÃO \\
\hline $\begin{array}{l}\text { QUINTA } \\
\text { TURMA }\end{array}$ & ARNALDO ESTEVES LIMA & REsp 996621 / BA & $09 / 12 / 2008$ \\
\hline $\begin{array}{l}\text { TERCEIRA } \\
\text { TURMA } \\
\end{array}$ & SIDNEI BENETI & $\begin{array}{c}\text { AgRg no REsp } 1032716 / \\
\text { MG }\end{array}$ & $19 / 12 / 2008$ \\
\hline $\begin{array}{l}\text { QUINTA } \\
\text { TURMA }\end{array}$ & ARNALDO ESTEVES LIMA & REsp 880163 / GO & $09 / 03 / 2009$ \\
\hline $\begin{array}{l}\text { PRIMEIRA } \\
\text { TURMA }\end{array}$ & TEORI ALBINO ZAVASCKI & REsp 775475 / DF & $28 / 05 / 2009$ \\
\hline $\begin{array}{l}\text { TERCEIRA } \\
\text { TURMA } \\
\end{array}$ & SIDNEI BENETI & REsp 1021688 / RJ & $01 / 07 / 2009$ \\
\hline $\begin{array}{l}\text { QUARTA } \\
\text { TURMA }\end{array}$ & FERNANDO GONÇALVES & REsp 671964 / BA & $29 / 06 / 2009$ \\
\hline $\begin{array}{l}\text { TERCEIRA } \\
\text { TURMA }\end{array}$ & NANCY ANDRIGHI & REsp 907350 / PR & $09 / 09 / 2009$ \\
\hline $\begin{array}{l}\text { SEGUNDA } \\
\text { TURMA } \\
\end{array}$ & HUMBERTO MARTINS & REsp 973686 / PR & $30 / 09 / 2009$ \\
\hline $\begin{array}{l}\text { SEGUNDA } \\
\text { TURMA }\end{array}$ & HUMBERTO MARTINS & $\begin{array}{c}\text { AgRg no REsp } 1118704 \text { / } \\
\text { RJ }\end{array}$ & $22 / 09 / 2009$ \\
\hline $\begin{array}{l}\text { SEGUNDA } \\
\text { TURMA }\end{array}$ & HUMBERTO MARTINS & REsp $1115916 / \mathrm{MG}$ & $18 / 09 / 2009$ \\
\hline $\begin{array}{l}\text { QUINTA } \\
\text { TURMA }\end{array}$ & LAURITA VAZ & $\begin{array}{c}\text { AgRg no Ag } 1170562 / \\
\text { SP } \\
\end{array}$ & $03 / 11 / 2009$ \\
\hline $\begin{array}{l}\text { TERCEIRA } \\
\text { TURMA } \\
\end{array}$ & SIDNEI BENETI & $\begin{array}{c}\text { AgRg no Ag } 1172526 / \\
\text { PR } \\
\end{array}$ & $07 / 10 / 2009$ \\
\hline $\begin{array}{l}\text { QUINTA } \\
\text { TURMA }\end{array}$ & ARNALDO ESTEVES LIMA & REsp 1040579 / GO & $16 / 11 / 2009$ \\
\hline $\begin{array}{l}\text { TERCEIRA } \\
\text { TURMA }\end{array}$ & $\begin{array}{c}\text { PAULO FURTADO (DES. } \\
\text { CONV. TJ/BA) }\end{array}$ & $\begin{array}{c}\text { AgRg no REsp } 788361 \text { / } \\
\text { SC }\end{array}$ & $13 / 11 / 2009$ \\
\hline $\begin{array}{l}\text { TERCEIRA } \\
\text { TURMA }\end{array}$ & SIDNEI BENETI & $\begin{array}{c}\text { AgRg no REsp } 737069 \text { / } \\
\text { RJ }\end{array}$ & 24/11/2009 \\
\hline $\begin{array}{l}\text { TERCEIRA } \\
\text { TURMA }\end{array}$ & MASSAMI UYEDA & RMS 27589 / PA & $16 / 12 / 2009$ \\
\hline $\begin{array}{l}\text { SEGUNDA } \\
\text { TURMA }\end{array}$ & $\begin{array}{l}\text { MAURO CAMPBELL } \\
\text { MARQUES }\end{array}$ & $\begin{array}{l}\text { AgRg no REsp } 1104430 \text { / } \\
\text { AL }\end{array}$ & $16 / 04 / 2010$ \\
\hline $\begin{array}{l}\text { TERCEIRA } \\
\text { TURMA } \\
\end{array}$ & NANCY ANDRIGHI & $\begin{array}{c}\text { AgRg no REsp } 914981 / \\
\text { RN } \\
\end{array}$ & $27 / 04 / 2010$ \\
\hline $\begin{array}{l}\text { SEGUNDA } \\
\text { TURMA }\end{array}$ & ELIAN & REsp 1159409 / AC & 21/05/2010 \\
\hline $\begin{array}{l}\text { TERCEIRA } \\
\text { TURMA }\end{array}$ & $\begin{array}{l}\text { VASCO DELLA GIUSTINA } \\
\text { (DES. CONV. TJ/RS) }\end{array}$ & $\begin{array}{c}\text { AgRg no REsp } 872990 / \\
\text { SP }\end{array}$ & 27/05/2010 \\
\hline $\begin{array}{l}\text { QUARTA } \\
\text { TURMA }\end{array}$ & LUIS FELIPE SALOMÃO & $\begin{array}{c}\text { AgRg no REsp } 1190060 \text { / } \\
\text { RS }\end{array}$ & $28 / 06 / 2010$ \\
\hline SEXTA TURMA & $\begin{array}{c}\text { MARIA THEREZA DE ASSIS } \\
\text { MOURA }\end{array}$ & $\begin{array}{c}\text { AgRg no REsp } 827527 \text { / } \\
\text { RS }\end{array}$ & $16 / 08 / 2010$ \\
\hline $\begin{array}{l}\text { QUARTA } \\
\text { TURMA }\end{array}$ & ALDIR PASSARINHO JUNIOR & $\begin{array}{c}\text { AgRg no REsp } 1007935 / \\
\text { MG }\end{array}$ & $10 / 09 / 2010$ \\
\hline $\begin{array}{l}\text { TERCEIRA } \\
\text { TURMA }\end{array}$ & $\begin{array}{l}\text { PAULO DE TARSO } \\
\text { SANSEVERINO }\end{array}$ & AgRg no Ag $732711 /$ SP & $15 / 09 / 2010$ \\
\hline $\begin{array}{l}\text { PRIMEIRA } \\
\text { TURMA }\end{array}$ & TEO & $\begin{array}{c}\text { AgRg no REsp 835091 / } \\
\text { ES }\end{array}$ & 13/09/2010 \\
\hline
\end{tabular}




\begin{tabular}{|c|c|c|c|}
\hline $\begin{array}{c}\text { ÓRGÃO } \\
\text { JULGADOR }\end{array}$ & MINISTRO(A) & PROCESSO & PUBLICAÇÃO \\
\hline $\begin{array}{l}\text { QUINTA } \\
\text { TURMA }\end{array}$ & $\begin{array}{l}\text { NAPOLEÃO NUNES MAIA } \\
\text { FILHO } \\
\end{array}$ & $\begin{array}{c}\mathrm{AgRg} \text { no } \mathrm{AgRg} \text { no } \mathrm{Ag} \\
1136475 / \mathrm{DF}\end{array}$ & $11 / 10 / 2010$ \\
\hline $\begin{array}{l}\text { TERCEIRA } \\
\text { TURMA }\end{array}$ & $\begin{array}{l}\text { VASCO DELLA GIUSTINA } \\
\text { (DES. CONV. TJ/RS) }\end{array}$ & $\begin{array}{c}\text { AgRg nos EDcl no REsp } \\
805265 / \mathrm{AL}\end{array}$ & $21 / 09 / 2010$ \\
\hline $\begin{array}{l}\text { PRIMEIRA } \\
\text { TURMA }\end{array}$ & LUIZ FUX & REsp 1107219 / SP & $23 / 09 / 2010$ \\
\hline $\begin{array}{l}\text { SEGUNDA } \\
\text { TURMA }\end{array}$ & ELIANA CALMON & REsp 967375 / RJ & $20 / 09 / 2010$ \\
\hline $\begin{array}{l}\text { TERCEIRA } \\
\text { TURMA } \\
\end{array}$ & $\begin{array}{l}\text { PAULO DE TARSO } \\
\text { SANSEVERINO } \\
\end{array}$ & AgRg no Ag 784710 / RJ & $06 / 10 / 2010$ \\
\hline $\begin{array}{l}\text { TERCEIRA } \\
\text { TURMA }\end{array}$ & $\begin{array}{l}\text { VASCO DELLA GIUSTINA } \\
\text { (DES. CONV. TJ/RS) }\end{array}$ & $\begin{array}{c}\text { AgRg no REsp } 241996 / \\
\text { ES }\end{array}$ & $13 / 10 / 2010$ \\
\hline $\begin{array}{l}\text { TERCEIRA } \\
\text { TURMA }\end{array}$ & $\begin{array}{l}\text { VASCO DELLA GIUSTINA } \\
\text { (DES. CONV. TJ/RS) }\end{array}$ & $\begin{array}{c}\text { AgRg no REsp } 243718 \text { / } \\
\text { RS }\end{array}$ & $13 / 10 / 2010$ \\
\hline $\begin{array}{l}\text { QUINTA } \\
\text { TURMA }\end{array}$ & LAURITA VAZ & REsp 1070929 / RJ & $1 / 10 / 2010$ \\
\hline $\begin{array}{l}\text { PRIMEIRA } \\
\text { TURMA }\end{array}$ & HAMILTON CARVALHIDO & $\begin{array}{c}\text { AgRg no REsp } 994827 \text { / } \\
\text { RS }\end{array}$ & $04 / 11 / 2010$ \\
\hline $\begin{array}{l}\text { QUINTA } \\
\text { TURMA }\end{array}$ & $\begin{array}{c}\text { NAPOLEÃO NUNES MAIA } \\
\text { FILHO }\end{array}$ & $\begin{array}{c}\text { AgRg no REsp } 976306 / \\
\text { ES }\end{array}$ & $25 / 10 / 2010$ \\
\hline $\begin{array}{l}\text { PRIMEIRA } \\
\text { TURMA }\end{array}$ & BENEDITO GONÇALVES & RMS 32442 / RJ & $26 / 10 / 2010$ \\
\hline $\begin{array}{l}\text { PRIMEIRA } \\
\text { TURMA }\end{array}$ & ARNALDO ESTEVES LIMA & $\begin{array}{c}\text { AgRg no REsp } 1198331 / \\
\text { DF }\end{array}$ & $20 / 10 / 2010$ \\
\hline $\begin{array}{l}\text { TERCEIRA } \\
\text { TURMA }\end{array}$ & NANCY ANDRIGHI & REsp 1049560 / MG & $16 / 11 / 2010$ \\
\hline $\begin{array}{l}\text { SEGUNDA } \\
\text { TURMA }\end{array}$ & $\begin{array}{c}\text { MAURO CAMPBELL } \\
\text { MARQUES }\end{array}$ & REsp 1210068 / RS & $08 / 02 / 2011$ \\
\hline $\begin{array}{l}\text { QUINTA } \\
\text { TURMA }\end{array}$ & GII & $\begin{array}{c}\text { AgRg no REsp } 1122901 / \\
\text { RS }\end{array}$ & 09/03/2011 \\
\hline $\begin{array}{l}\text { TERCEIRA } \\
\text { TURMA }\end{array}$ & NANCY ANDRIGHI & REsp 863890 / SC & $17 / 02 / 2011$ \\
\hline $\begin{array}{l}\text { TERCEIRA } \\
\text { TURMA }\end{array}$ & SIDNEI BENETI & $\begin{array}{c}\text { AgRg no REsp 995528 / } \\
\text { RS }\end{array}$ & $28 / 02 / 2011$ \\
\hline $\begin{array}{l}\text { TERCEIRA } \\
\text { TURMA }\end{array}$ & $\begin{array}{l}\text { VASCO DELLA GIUSTINA } \\
\text { (DES. CONV. TJ/RS) }\end{array}$ & $\begin{array}{l}\text { AgRg nos EDcl no Ag } \\
762469 / \text { MS }\end{array}$ & $13 / 0$ \\
\hline $\begin{array}{l}\text { SEGUNDA } \\
\text { TURMA }\end{array}$ & CASTRO MEIRA & $\begin{array}{l}\text { AgRg no REsp } 416937 \text { / } \\
\text { SC }\end{array}$ & $28 / 04 / 2011$ \\
\hline $\begin{array}{l}\text { TERCEIRA } \\
\text { TURMA }\end{array}$ & NANCY ANDRIGHI & $\begin{array}{c}\text { AgRg no Ag } 1343635 / \\
\text { SP }\end{array}$ & $11 / 05 / 2011$ \\
\hline $\begin{array}{l}\text { SEGUNDA } \\
\text { TURMA }\end{array}$ & HUMBI & $\begin{array}{c}\text { AgRg no REsp } 1198808 / \\
\text { ES }\end{array}$ & $01 / 06 / 2011$ \\
\hline $\begin{array}{l}\text { PRIMEIRA } \\
\text { TURMA }\end{array}$ & ARNALDO ESTEVES LIMA & $\begin{array}{c}\text { AgRg no Ag } 1380926 \text { / } \\
\text { DF }\end{array}$ & $25 / 05 / 2011$ \\
\hline $\begin{array}{c}\text { TERCEIRA } \\
\text { TURMA }\end{array}$ & DRIGHI & $\begin{array}{c}\text { AgRg no Ag } 1343032 \text { / } \\
\text { SC }\end{array}$ & $19 / 06 / 2012$ \\
\hline $\begin{array}{l}\text { QUARTA } \\
\text { TURMA }\end{array}$ & JOÃO OTÁVIO DE NORONHA & $\begin{array}{c}\text { AgRg no Ag } 1332176 / \\
\text { PR }\end{array}$ & 09/08/2011 \\
\hline $\begin{array}{l}\text { TERCEIRA } \\
\text { TURMA }\end{array}$ & GHI & $\begin{array}{c}\text { AgRg nos EDcl no REsp } \\
1161797 / \text { RJ }\end{array}$ & $24 / 08 / 2011$ \\
\hline
\end{tabular}




\begin{tabular}{|c|c|c|c|}
\hline $\begin{array}{l}\text { ÓRGÃO } \\
\text { JULGADOR }\end{array}$ & MINISTRO(A) & PROCESSO & PUBLICAÇÃO \\
\hline $\begin{array}{l}\text { TERCEIRA } \\
\text { TURMA }\end{array}$ & MASSAMI UYEDA & REsp 1195656/ BA & $30 / 08 / 2011$ \\
\hline $\begin{array}{l}\text { TERCEIRA } \\
\text { TURMA }\end{array}$ & NANCY ANDRIGHI & REsp 1097955 / MG & 03/10/2011 \\
\hline SEXTA TURMA & $\begin{array}{l}\text { MARIA THEREZA DE ASSIS } \\
\text { MOURA }\end{array}$ & $\begin{array}{c}\text { AgRg no RMS } 28542 / \\
\text { AP }\end{array}$ & 28/09/2011 \\
\hline $\begin{array}{l}\text { PRIMEIRA } \\
\text { TURMA }\end{array}$ & BENEDITO GONÇALVES & $\begin{array}{c}\text { AgRg no Ag } 1236080 / \\
\text { RS }\end{array}$ & $11 / 10 / 2011$ \\
\hline $\begin{array}{l}\text { SEGUNDA } \\
\text { SEÇÃO }\end{array}$ & NANCY ANDRIGHI & AR 3682 / RN & 19/10/2011 \\
\hline $\begin{array}{l}\text { TERCEIRA } \\
\text { TURMA }\end{array}$ & IGHI & REsp 1071158 / RJ & $07 / 11 / 2011$ \\
\hline $\begin{array}{l}\text { PRIMEIRA } \\
\text { TURMA }\end{array}$ & BENEDITO GONÇALVES & $\begin{array}{l}\text { AgRg no REsp } 1168551 / \\
\text { MG }\end{array}$ & 28/10/2011 \\
\hline $\begin{array}{l}\text { QUARTA } \\
\text { TURMA }\end{array}$ & RAUL ARAÚJO & REsp 874430 / MA & $07 / 12 / 2011$ \\
\hline $\begin{array}{l}\text { TERCEIRA } \\
\text { TURMA }\end{array}$ & NANCY ANDRIGHI & $\begin{array}{l}\text { AgRg no Ag } 1388277 / \\
\text { RS }\end{array}$ & $25 / 11 / 2011$ \\
\hline $\begin{array}{l}\text { PRIMEIRA } \\
\text { TURMA }\end{array}$ & $\begin{array}{l}\text { NAPOLEÃO NUNES MAIA } \\
\text { FILHO }\end{array}$ & $\begin{array}{c}\text { AgRg no REsp } 1197200 \text { / } \\
\text { RJ }\end{array}$ & $24 / 11 / 2011$ \\
\hline $\begin{array}{l}\text { PRIMEIRA } \\
\text { TURMA }\end{array}$ & $\begin{array}{l}\text { NAPOLEÃO NUNES MAIA } \\
\text { FILHO }\end{array}$ & $\begin{array}{c}\text { AgRg no REsp } 1195680 \text { / } \\
\text { RN }\end{array}$ & $24 / 11 / 2011$ \\
\hline $\begin{array}{l}\text { QUARTA } \\
\text { TURMA }\end{array}$ & MARIA ISABEL GALLOTTI & $\begin{array}{c}\mathrm{AgRg} \text { no } \mathrm{Ag} 1088411 / \\
\mathrm{SP}\end{array}$ & $16 / 11 / 2011$ \\
\hline $\begin{array}{l}\text { TERCEIRA } \\
\text { TURMA }\end{array}$ & SID & $\begin{array}{c}\text { AgRg no AREsp 4513 / } \\
\text { MG }\end{array}$ & 2/2011 \\
\hline $\begin{array}{l}\text { SEGUNDA } \\
\text { TURMA }\end{array}$ & CESAR ASFOR ROCHA & $\begin{array}{c}\text { AgRg no REsp } 1236161 / \\
\text { DF }\end{array}$ & 29/11/2011 \\
\hline $\begin{array}{l}\text { TERCEIRA } \\
\text { TURMA }\end{array}$ & MASSAMI UYEDA & REsp 1120631 / RJ & $01 / 02 / 2012$ \\
\hline SEXTA TURMA & $\begin{array}{l}\text { VASCO DELLA GIUSTINA } \\
\text { (DES. CONV. TJ/RS) }\end{array}$ & $\begin{array}{c}\text { AgRg no REsp } 674710 \text { / } \\
\text { SP }\end{array}$ & $06 / 02 / 2012$ \\
\hline SEXTA TURMA & $\begin{array}{l}\text { VASCO DELLA GIUSTINA } \\
\text { (DES. CONV. TJ/RS) }\end{array}$ & $\begin{array}{c}\text { AgRg no REsp } 891600 \text { / } \\
\text { RJ }\end{array}$ & $06 / 02 / 2012$ \\
\hline $\begin{array}{l}\text { TERCEIRA } \\
\text { TURMA }\end{array}$ & NANCY A & REsp 1093648 / SP & $01 / 02 / 2012$ \\
\hline $\begin{array}{l}\text { PRIMEIRA } \\
\text { TURMA }\end{array}$ & ENEDITO GONÇALVES & $\begin{array}{l}\text { AgRg no Ag } 1298321 / \\
\text { DF }\end{array}$ & $10 / 02 / 2012$ \\
\hline $\begin{array}{l}\text { PRIMEIRA } \\
\text { TURMA }\end{array}$ & BENEDITO GONÇALVES & $\begin{array}{c}\text { AgRg no RMS } 33646 \text { / } \\
\text { SP }\end{array}$ & $10 / 02 / 2012$ \\
\hline $\begin{array}{l}\text { SEGUNDA } \\
\text { TURMA }\end{array}$ & CASTRO N & $\begin{array}{l}\text { AgRg no REsp } 1253140 \text { / } \\
\text { SC }\end{array}$ & $05 / 03 / 2012$ \\
\hline $\begin{array}{l}\text { QUINTA } \\
\text { TURMA }\end{array}$ & LAURITA VAZ & REsp 1104357 / RS & 05/03/2012 \\
\hline $\begin{array}{l}\text { SEGUNDA } \\
\text { TURMA }\end{array}$ & HERMAN BENJAMIN & $\begin{array}{c}\text { AgRg no Ag } 1344486 / \\
\text { DF }\end{array}$ & 2012 \\
\hline $\begin{array}{l}\text { TERCEIRA } \\
\text { TURMA }\end{array}$ & NANCY ANDRIGHI & $\begin{array}{c}\text { AgRg nos EDcl no REsp } \\
1198380 \text { / SC }\end{array}$ & 09/03/2012 \\
\hline SEXTA TURMA & $\begin{array}{l}\text { VASCO DELLA GIUSTINA } \\
\text { (DES. CONV. TJ/RS) }\end{array}$ & $\begin{array}{c}\text { AgRg no REsp } 1115942 \text { / } \\
\text { RJ }\end{array}$ & $12 / 03 / 2012$ \\
\hline
\end{tabular}




\begin{tabular}{|c|c|c|c|}
\hline $\begin{array}{c}\text { ÓRGÃO } \\
\text { JULGADOR }\end{array}$ & MINISTRO(A) & PROCESSO & PUBLICAÇÃO \\
\hline $\begin{array}{l}\text { TERCEIRA } \\
\text { TURMA }\end{array}$ & $\begin{array}{l}\text { RICARDO VILLAS BÔAS } \\
\text { CUEVA }\end{array}$ & AgRg no Ag 666835 / MS & $21 / 03 / 2012$ \\
\hline $\begin{array}{l}\text { TERCEIRA } \\
\text { TURMA } \\
\end{array}$ & $\begin{array}{c}\text { PAULO DE TARSO } \\
\text { SANSEVERINO } \\
\end{array}$ & $\begin{array}{c}\text { AgRg no REsp } 1115354 \text { / } \\
\text { RS }\end{array}$ & 03/04/2012 \\
\hline $\begin{array}{l}\text { QUINTA } \\
\text { TURMA }\end{array}$ & GILSON DIPP & $\begin{array}{c}\text { AgRg no Ag } 1351484 \text { / } \\
\text { RJ }\end{array}$ & $26 / 03 / 2012$ \\
\hline $\begin{array}{l}\text { TERCEIRA } \\
\text { TURMA }\end{array}$ & NANCY ANDRIGHI & REsp 1143962 / SP & 09/04/2012 \\
\hline $\begin{array}{l}\text { QUARTA } \\
\text { TURMA }\end{array}$ & MARIA ISABEL GALLOTTI & $\begin{array}{c}\text { AgRg no REsp } 756532 \text { / } \\
\text { RS }\end{array}$ & 23/03/2012 \\
\hline $\begin{array}{l}\text { TERCEIRA } \\
\text { TURMA }\end{array}$ & MASSAMI UYEDA & $\begin{array}{c}\text { AgRg no REsp } 1166904 \text { / } \\
\text { MG }\end{array}$ & $27 / 04 / 2012$ \\
\hline SEXTA TURMA & $\begin{array}{l}\text { MARIA THEREZA DE ASSIS } \\
\text { MOURA }\end{array}$ & $\begin{array}{c}\text { AgRg no REsp } 1149636 \text { / } \\
\text { PR }\end{array}$ & $23 / 04 / 2012$ \\
\hline $\begin{array}{l}\text { PRIMEIRA } \\
\text { TURMA }\end{array}$ & BENEDITO GONÇALVES & $\begin{array}{c}\text { EDcl no REsp } 1294238 / \\
\text { CE }\end{array}$ & $25 / 04 / 2012$ \\
\hline $\begin{array}{l}\text { SEGUNDA } \\
\text { TURMA }\end{array}$ & CESAR ASFOR ROCHA & $\begin{array}{c}\text { AgRg no Ag } 1423462 / \\
\text { CE }\end{array}$ & 26/04/2012 \\
\hline $\begin{array}{l}\text { TERCEIRA } \\
\text { TURMA } \\
\end{array}$ & SIDNEI BENETI & $\begin{array}{c}\text { AgRg no AREsp } 112675 \text { / } \\
\text { RS }\end{array}$ & $07 / 05 / 2012$ \\
\hline $\begin{array}{l}\text { TERCEIRA } \\
\text { TURMA } \\
\end{array}$ & NANCY ANDRIGHI & REsp 1155274 / PE & $15 / 05 / 2012$ \\
\hline $\begin{array}{l}\text { QUARTA } \\
\text { TURMA }\end{array}$ & RAUL ARAÚJO & REsp 876144 / SC & $20 / 08 / 2012$ \\
\hline $\begin{array}{l}\text { PRIMEIRA } \\
\text { TURMA }\end{array}$ & ARNALDO ESTEVES LIMA & $\begin{array}{c}\text { AgRg no REsp } 1031414 \text { / } \\
\text { RS }\end{array}$ & $10 / 05 / 2012$ \\
\hline $\begin{array}{l}\text { SEGUNDA } \\
\text { TURMA }\end{array}$ & CASTRO MEIRA & $\begin{array}{c}\text { AgRg no REsp } 1254227 \text { / } \\
\text { RS }\end{array}$ & $28 / 05 / 2012$ \\
\hline $\begin{array}{c}\text { TERCEIRA } \\
\text { TURMA }\end{array}$ & SIDNEI BENETI & $\begin{array}{c}\text { AgRg no REsp } 1302480 / \\
\text { SP }\end{array}$ & $30 / 05 / 2012$ \\
\hline $\begin{array}{l}\text { SEGUNDA } \\
\text { TURMA }\end{array}$ & HERMAN BENJAMIN & $\begin{array}{c}\text { AgRg no AREsp } 134264 \text { / } \\
\text { RS }\end{array}$ & 26/06/2012 \\
\hline $\begin{array}{l}\text { SEGUNDA } \\
\text { TURMA }\end{array}$ & HERMAN BENJAMIN & REsp $1186181 / \mathrm{MS}$ & $06 / 12 / 2013$ \\
\hline $\begin{array}{c}\text { SEGUNDA } \\
\text { TURMA }\end{array}$ & HUMBERTO MARTINS & $\begin{array}{c}\text { AgRg no AREsp } 156155 / \\
\text { RS }\end{array}$ & $14 / 06 / 2012$ \\
\hline $\begin{array}{c}\text { SEGUNDA } \\
\text { TURMA }\end{array}$ & CASTRO MEIRA & $\begin{array}{c}\text { AgRg no AREsp } 124010 / \\
\text { PA }\end{array}$ & $14 / 06 / 2012$ \\
\hline $\begin{array}{l}\text { TERCEIRA } \\
\text { TURMA } \\
\end{array}$ & SIDNEI BENETI & $\begin{array}{c}\text { AgRg no AREsp } 161113 / \\
\text { SP }\end{array}$ & $29 / 06 / 2012$ \\
\hline $\begin{array}{l}\text { QUINTA } \\
\text { TURMA }\end{array}$ & MARCO AURÉLIO BELLIZZE & $\begin{array}{c}\text { AgRg no REsp 969299 / } \\
\text { MG }\end{array}$ & $28 / 06 / 2012$ \\
\hline $\begin{array}{l}\text { SEGUNDA } \\
\text { TURMA }\end{array}$ & HUMBERTO MARTINS & $\begin{array}{c}\text { AgRg no AREsp } 166543 \text { / } \\
\text { ES }\end{array}$ & $28 / 06 / 2012$ \\
\hline $\begin{array}{l}\text { SEGUNDA } \\
\text { TURMA }\end{array}$ & HERMAN BENJAMIN & $\begin{array}{c}\text { AgRg no REsp } 1309733 \text { / } \\
\text { RJ }\end{array}$ & $23 / 08 / 2012$ \\
\hline $\begin{array}{l}\text { PRIMEIRA } \\
\text { TURMA }\end{array}$ & ARNALDO ESTEVES LIMA & $\begin{array}{c}\text { AgRg no REsp } 1218056 / \\
\text { DF }\end{array}$ & 02/08/2012 \\
\hline $\begin{array}{l}\text { QUARTA } \\
\text { TURMA }\end{array}$ & RAUL ARAÚJO & $\begin{array}{c}\text { AgRg no AREsp } 135685 / \\
\text { SP }\end{array}$ & 02/08/2012 \\
\hline
\end{tabular}




\begin{tabular}{|c|c|c|c|}
\hline $\begin{array}{l}\text { ÓRGÃO } \\
\text { JULGADOR }\end{array}$ & MINISTRO(A) & PROCESSO & PUBLICAÇÃ̃O \\
\hline SEXTA TURMA & SEBASTIÃO REIS JÚNIOR & $\begin{array}{c}\text { AgRg no REsp } 910503 / \\
\text { PR }\end{array}$ & $22 / 08 / 2012$ \\
\hline $\begin{array}{l}\text { TERCEIRA } \\
\text { TURMA }\end{array}$ & NANCY ANDRIGHI & REsp 1162643 / SC & $17 / 08 / 2012$ \\
\hline $\begin{array}{l}\text { TERCEIRA } \\
\text { TURMA }\end{array}$ & NANCY ANDRIGHI & REsp 1316926 / SP & $15 / 08 / 2012$ \\
\hline $\begin{array}{l}\text { TERCEIRA } \\
\text { TURMA }\end{array}$ & MASSAMI UYEDA & REsp 1202238 / SC & $18 / 09 / 2012$ \\
\hline $\begin{array}{l}\text { TERCEIRA } \\
\text { TURMA }\end{array}$ & NANCY ANDRIGHI & REsp 1339242 / RJ & $25 / 09 / 2012$ \\
\hline $\begin{array}{l}\text { TERCEIRA } \\
\text { TURMA }\end{array}$ & NANCY ANDRIGHI & $\begin{array}{c}\text { AgRg no Ag } 1418171 / \\
\text { RJ }\end{array}$ & $10 / 09 / 2012$ \\
\hline $\begin{array}{l}\text { QUARTA } \\
\text { TURMA }\end{array}$ & LUIS FELIPE SALOMÃO & REsp 1294166 / GO & $22 / 10 / 2012$ \\
\hline $\begin{array}{l}\text { TERCEIRA } \\
\text { TURMA } \\
\end{array}$ & MASSAMI UYEDA & $\begin{array}{c}\text { AgRg no Ag } 1330187 / \\
\text { MS } \\
\end{array}$ & $05 / 10 / 2012$ \\
\hline $\begin{array}{l}\text { TERCEIRA } \\
\text { TURMA }\end{array}$ & SIDNEI BENETI & $\begin{array}{l}\text { AgRg nos EDcl no } \\
\text { AREsp 143102 / RJ }\end{array}$ & $29 / 10 / 2012$ \\
\hline $\begin{array}{l}\text { TERCEIRA } \\
\text { TURMA }\end{array}$ & SIDNEI BENETI & $\begin{array}{c}\text { AgRg no REsp } 1236431 / \\
\text { RJ }\end{array}$ & $08 / 11 / 2012$ \\
\hline $\begin{array}{l}\text { SEGUNDA } \\
\text { TURMA }\end{array}$ & $\begin{array}{c}\text { MAURO CAMPBELL } \\
\text { MARQUES }\end{array}$ & $\begin{array}{c}\text { AgRg no REsp } 1313899 / \\
\text { SC }\end{array}$ & $25 / 10 / 2012$ \\
\hline $\begin{array}{l}\text { SEGUNDA } \\
\text { TURMA } \\
\end{array}$ & RO MEIRA & $\begin{array}{c}\text { AgRg no AREsp } 220712 \text { / } \\
\text { RN }\end{array}$ & $29 / 11 / 2012$ \\
\hline $\begin{array}{l}\text { TERCEIRA } \\
\text { TURMA }\end{array}$ & SIDNEI BENETI & $\begin{array}{c}\text { AgRg no REsp } 1198488 / \\
\text { DF }\end{array}$ & $11 / 12 / 2012$ \\
\hline $\begin{array}{l}\text { PRIMEIRA } \\
\text { SEÇÃO }\end{array}$ & $\begin{array}{c}\text { NAPOLEÃO NUNES MAIA } \\
\text { FILHO }\end{array}$ & MS 18037 / DF & $01 / 02 / 2013$ \\
\hline $\begin{array}{l}\text { PRIMEIRA } \\
\text { TURMA }\end{array}$ & ARNALDO ESTEVES LIMA & $\begin{array}{c}\text { AgRg no REsp } 1297489 \text { / } \\
\text { RS }\end{array}$ & $15 / 02 / 2013$ \\
\hline $\begin{array}{l}\text { SEGUNDA } \\
\text { TURMA }\end{array}$ & CASTRO MEIRA & $\begin{array}{c}\text { EDcl no REsp } 968384 \text { / } \\
\text { RJ }\end{array}$ & $08 / 02 / 2013$ \\
\hline SEXTA TURMA & $\begin{array}{c}\text { ALDERITA RAMOS DE } \\
\text { OLIVEIRA (DES. CONV. } \\
\text { TJ/PE) }\end{array}$ & $\begin{array}{c}\text { AgRg no REsp } 445358 \text { / } \\
\text { AL }\end{array}$ & $12 / 03 / 2013$ \\
\hline $\begin{array}{l}\text { QUARTA } \\
\text { TURMA }\end{array}$ & MARIA ISABEL GALLOTTI & $\begin{array}{c}\text { AgRg no REsp } 526638 \text { / } \\
\text { SP }\end{array}$ & $27 / 02 / 2013$ \\
\hline $\begin{array}{l}\text { TERCEIRA } \\
\text { TURMA } \\
\end{array}$ & SIDNEI BENETI & $\begin{array}{c}\text { AgRg no REsp } 1288067 \text { / } \\
\text { RJ }\end{array}$ & $20 / 03 / 2013$ \\
\hline $\begin{array}{l}\text { TERCEIRA } \\
\text { TURMA }\end{array}$ & SIDNEI BENETI & REsp 1359558 / PB & $15 / 05 / 2013$ \\
\hline $\begin{array}{l}\text { QUINTA } \\
\text { TURMA }\end{array}$ & MARCO AURÉLIO BELLIZZE & $\begin{array}{c}\text { AgRg no RMS 25979 / } \\
\text { GO }\end{array}$ & $16 / 04 / 2013$ \\
\hline $\begin{array}{l}\text { TERCEIRA } \\
\text { TURMA }\end{array}$ & NANCY ANDRIGHI & REsp 1307131 / DF & $15 / 04 / 2013$ \\
\hline $\begin{array}{l}\text { SEGUNDA } \\
\text { TURMA }\end{array}$ & HERMAN BENJAMIN & REsp 1362297 / DF & $09 / 05 / 2013$ \\
\hline $\begin{array}{l}\text { TERCEIRA } \\
\text { TURMA }\end{array}$ & TI & $\begin{array}{l}\text { AgRg nos EDcl no } \\
\text { AREsp 229116 / RJ }\end{array}$ & $09 / 05 / 2013$ \\
\hline $\begin{array}{l}\text { TERCEIRA } \\
\text { TURMA }\end{array}$ & $\begin{array}{l}\text { RICARDO VILLAS BÔAS } \\
\text { CUEVA }\end{array}$ & REsp 647456 / SP & $25 / 04 / 2013$ \\
\hline
\end{tabular}




\begin{tabular}{|c|c|c|c|}
\hline $\begin{array}{c}\text { ÓRGÃO } \\
\text { JULGADOR }\end{array}$ & MINISTRO(A) & PROCESSO & PUBLICAÇÃO \\
\hline $\begin{array}{l}\text { SEGUNDA } \\
\text { TURMA }\end{array}$ & ELIANA CALMON & REsp 1284927 / PR & $15 / 05 / 2013$ \\
\hline $\begin{array}{l}\text { QUINTA } \\
\text { TURMA }\end{array}$ & JORGE MUSSI & $\begin{array}{c}\text { EDcl no AgRg no REsp } \\
1112291 / \text { PE }\end{array}$ & $16 / 05 / 2013$ \\
\hline $\begin{array}{l}\text { TERCEIRA } \\
\text { TURMA }\end{array}$ & SIDNEI BENETI & $\begin{array}{c}\text { AgRg no AREsp } 305191 / \\
\text { SP }\end{array}$ & $13 / 06 / 2013$ \\
\hline $\begin{array}{l}\text { TERCEIRA } \\
\text { TURMA } \\
\end{array}$ & NANCY ANDRIGHI & $\begin{array}{c}\text { AgRg no REsp } 1313696 / \\
\text { MS }\end{array}$ & $04 / 06 / 2013$ \\
\hline $\begin{array}{l}\text { TERCEIRA } \\
\text { TURMA }\end{array}$ & NANCY ANDRIGHI & REsp 1368210 / SP & $17 / 06 / 2013$ \\
\hline $\begin{array}{l}\text { SEGUNDA } \\
\text { TURMA }\end{array}$ & ELIANA CALMON & REsp 1234025 / MT & $11 / 06 / 2013$ \\
\hline $\begin{array}{l}\text { TERCEIRA } \\
\text { TURMA }\end{array}$ & SIDNEI BENETI & $\begin{array}{c}\text { AgRg no AREsp } 308921 / \\
\text { SP }\end{array}$ & $13 / 06 / 2013$ \\
\hline $\begin{array}{l}\text { SEGUNDA } \\
\text { TURMA }\end{array}$ & ELIANA CALMON & $\begin{array}{c}\text { AgRg no AREsp } 324927 / \\
\text { RJ }\end{array}$ & $26 / 06 / 2013$ \\
\hline $\begin{array}{l}\text { TERCEIRA } \\
\text { TURMA } \\
\end{array}$ & NANCY ANDRIGHI & REsp 1263234 / TO & $01 / 07 / 2013$ \\
\hline $\begin{array}{l}\text { QUARTA } \\
\text { TURMA }\end{array}$ & RAUL ARAÚJO & AgRg no Ag 838989 / DF & $01 / 07 / 2013$ \\
\hline $\begin{array}{l}\text { SEGUNDA } \\
\text { TURMA }\end{array}$ & HERMAN BENJAMIN & $\begin{array}{c}\text { AgRg no AREsp } 322510 / \\
\text { BA }\end{array}$ & $25 / 06 / 2013$ \\
\hline $\begin{array}{l}\text { SEGUNDA } \\
\text { TURMA }\end{array}$ & HERMAN BENJAMIN & $\begin{array}{c}\text { AgRg no AREsp 261861 / } \\
\text { RS }\end{array}$ & $13 / 09 / 2013$ \\
\hline $\begin{array}{l}\text { PRIMEIRA } \\
\text { TURMA }\end{array}$ & SÉRGIO KUKINA & $\begin{array}{c}\text { AgRg no AREsp 347218 / } \\
\text { BA }\end{array}$ & $19 / 08 / 2013$ \\
\hline $\begin{array}{l}\text { TERCEIRA } \\
\text { TURMA } \\
\end{array}$ & NANCY ANDRIGHI & $\begin{array}{c}\text { AgRg no AREsp } 328436 / \\
\text { SP }\end{array}$ & $12 / 08 / 2013$ \\
\hline $\begin{array}{l}\text { TERCEIRA } \\
\text { TURMA }\end{array}$ & $\begin{array}{l}\text { RICARDO VILLAS BÔAS } \\
\text { CUEVA }\end{array}$ & $\begin{array}{l}\text { AgRg no AgRg no } \\
\text { AREsp } 190378 \text { / ES }\end{array}$ & $27 / 08 / 2013$ \\
\hline SEXTA TURMA & $\begin{array}{c}\text { ALDERITA RAMOS DE } \\
\text { OLIVEIRA (DES. CONV. } \\
\text { TJ/PE) }\end{array}$ & $\begin{array}{c}\text { AgRg no REsp } 769765 \text { / } \\
\text { SP }\end{array}$ & $27 / 08 / 2013$ \\
\hline $\begin{array}{l}\text { SEGUNDA } \\
\text { TURMA }\end{array}$ & HERMAN BENJAMIN & $\begin{array}{c}\text { AgRg no AREsp } 337632 / \\
\text { BA }\end{array}$ & $17 / 09 / 2013$ \\
\hline $\begin{array}{l}\text { QUARTA } \\
\text { TURMA }\end{array}$ & RAUL ARAÚJO & $\begin{array}{c}\text { AgRg no AREsp } 35970 / \\
\text { RS } \\
\end{array}$ & $15 / 10 / 2013$ \\
\hline SEXTA TURMA & ASSUSETE MAGALHÃES & $\begin{array}{c}\text { AgRg nos EDcl no REsp } \\
651174 / \mathrm{MG}\end{array}$ & $08 / 05 / 2014$ \\
\hline $\begin{array}{c}\text { TERCEIRA } \\
\text { TURMA } \\
\end{array}$ & NANCY ANI & REsp 1286704 / SP & $28 / 10 / 2013$ \\
\hline $\begin{array}{l}\text { SEGUNDA } \\
\text { TURMA }\end{array}$ & HUMBERTO MARTINS & $\begin{array}{c}\text { AgRg no REsp } 1400223 \text { / } \\
\text { RN }\end{array}$ & $25 / 10 / 2013$ \\
\hline $\begin{array}{l}\text { QUINTA } \\
\text { TURMA }\end{array}$ & MARCO AURÉLIO BELLIZZE & $\begin{array}{c}\text { AgRg no Ag } 1314361 / \\
\text { MG }\end{array}$ & $23 / 10 / 2013$ \\
\hline $\begin{array}{l}\text { QUARTA } \\
\text { TURMA }\end{array}$ & MARIA ISABEL GALLOTTI & $\begin{array}{c}\text { AgRg no AREsp } 261422 / \\
\text { RS }\end{array}$ & $30 / 10 / 2013$ \\
\hline $\begin{array}{l}\text { TERCEIRA } \\
\text { TURMA }\end{array}$ & NANCY ANDRIGHI & REsp 1331115 / RJ & $22 / 04 / 2014$ \\
\hline $\begin{array}{c}\text { SEGUNDA } \\
\text { TURMA }\end{array}$ & HUMBERTO MARTINS & $\begin{array}{c}\text { AgRg no REsp } 1284020 / \\
\text { SP }\end{array}$ & $06 / 03 / 2014$ \\
\hline
\end{tabular}




\begin{tabular}{|c|c|c|c|}
\hline $\begin{array}{l}\text { ÓRGÃO } \\
\text { JULGADOR }\end{array}$ & MINISTRO(A) & PROCESSO & PUBLICAÇÃO \\
\hline $\begin{array}{l}\text { PRIMEIRA } \\
\text { TURMA }\end{array}$ & $\begin{array}{l}\text { NAPOLEÃO NUNES MAIA } \\
\text { FILHO }\end{array}$ & $\begin{array}{c}\text { EDcl no AgRg no REsp } \\
1137565 \text { / MG }\end{array}$ & $02 / 12 / 2013$ \\
\hline $\begin{array}{l}\text { QUARTA } \\
\text { TURMA }\end{array}$ & RAUL ARAÚJO & $\begin{array}{c}\text { AgRg no AREsp } 420451 / \\
\text { RJ }\end{array}$ & $19 / 12 / 2013$ \\
\hline $\begin{array}{l}\text { PRIMEIRA } \\
\text { TURMA }\end{array}$ & SÉRGIO KUKINA & $\begin{array}{c}\text { AgRg no REsp } 1323709 / \\
\text { SC }\end{array}$ & $17 / 12 / 2013$ \\
\hline $\begin{array}{l}\text { QUARTA } \\
\text { TURMA }\end{array}$ & MARCO BUZZI & $\begin{array}{c}\text { AgRg no REsp } 1155859 / \\
\text { MT }\end{array}$ & $04 / 02 / 2014$ \\
\hline $\begin{array}{l}\text { TERCEIRA } \\
\text { TURMA }\end{array}$ & $\begin{array}{l}\text { RICARDO VILLAS BÔAS } \\
\text { CUEVA }\end{array}$ & REsp 1215294 / SP & $11 / 02 / 2014$ \\
\hline $\begin{array}{l}\text { PRIMEIRA } \\
\text { TURMA }\end{array}$ & SÉRGIO KUKINA & $\begin{array}{c}\text { AgRg no AREsp } 377750 / \\
\text { DF }\end{array}$ & $25 / 02 / 2014$ \\
\hline $\begin{array}{l}\text { QUARTA } \\
\text { TURMA }\end{array}$ & MARCO BUZZI & $\begin{array}{c}\text { AgRg nos EDcl no Ag } \\
1415130 / \text { SC }\end{array}$ & t/02/2014 \\
\hline $\begin{array}{l}\text { SEGUNDA } \\
\text { TURMA }\end{array}$ & HERMAN BENJAMIN & $\begin{array}{c}\text { AgRg no AREsp } 426389 / \\
\text { CE }\end{array}$ & $07 / 03 / 2014$ \\
\hline $\begin{array}{l}\text { TERCEIRA } \\
\text { TURMA }\end{array}$ & NANCY ANDRIGHI & REsp 1342955 / RS & $31 / 03 / 2014$ \\
\hline $\begin{array}{l}\text { TERCEIRA } \\
\text { TURMA }\end{array}$ & JOÃO OTÁVIO DE NORONHA & REsp 1219329 / RJ & $29 / 04 / 2014$ \\
\hline $\begin{array}{l}\text { TERCEIRA } \\
\text { TURMA }\end{array}$ & NANCY ANDRIGHI & REsp 1363781 / SP & $26 / 03 / 2014$ \\
\hline $\begin{array}{l}\text { TERCEIRA } \\
\text { TURMA }\end{array}$ & NANCY ANDRIGHI & $\begin{array}{c}\text { AgRg no AREsp } 464922 / \\
\text { SP }\end{array}$ & $1 / 03 / 2014$ \\
\hline $\begin{array}{l}\text { SEGUNDA } \\
\text { TURMA }\end{array}$ & HERMAN BENJAMIN & $\begin{array}{c}\text { AgRg no AREsp } 358700 / \\
\text { SC }\end{array}$ & $22 / 04 / 2014$ \\
\hline $\begin{array}{l}\text { SEGUNDA } \\
\text { TURMA }\end{array}$ & HERMAN BEN. & $\begin{array}{c}\text { AgRg no REsp } 1425636 / \\
\text { PR }\end{array}$ & $28 / 11 / 2014$ \\
\hline $\begin{array}{l}\text { TERCEIRA } \\
\text { TURMA }\end{array}$ & SIDNEI BENETI & $\begin{array}{c}\text { AgRg no AREsp } 481632 / \\
\text { RS }\end{array}$ & $16 / 05 / 2014$ \\
\hline $\begin{array}{l}\text { SEGUNDA } \\
\text { TURMA }\end{array}$ & ASSUSETE MAG & $\begin{array}{c}\text { AgRg no AREsp } 258806 / \\
\text { PE }\end{array}$ & $05 / 05 / 2014$ \\
\hline $\begin{array}{l}\text { TERCEIRA } \\
\text { TURMA }\end{array}$ & NANCY ANDRIGHI & REsp 1255398 / SP & $30 / 05 / 2014$ \\
\hline $\begin{array}{l}\text { PRIMEIRA } \\
\text { SEÇÃO }\end{array}$ & BENEDITO GONÇALVES & Rcl 15624 / MG & $02 / 06 / 2014$ \\
\hline $\begin{array}{l}\text { TERCEIRA } \\
\text { TURMA }\end{array}$ & NANCY ANDRIGHI & $\begin{array}{c}\text { AgRg no REsp } 1439300 / \\
\text { RS }\end{array}$ & 08/09/2014 \\
\hline SEXTA TURMA & ROGERIO SCHIETTI CRUZ & $\begin{array}{c}\text { RCDESP no Ag } 1099977 \\
\text { / RJ }\end{array}$ & $02 / 09 / 2014$ \\
\hline $\begin{array}{l}\text { SEGUNDA } \\
\text { TURMA }\end{array}$ & HUMBERTO MARTINS & $\begin{array}{c}\text { EDcl no AgRg no AREsp } \\
483037 \text { / PE }\end{array}$ & $26 / 08 / 2014$ \\
\hline $\begin{array}{l}\text { SEGUNDA } \\
\text { TURMA }\end{array}$ & HERMAN BENJAMIN & $\begin{array}{c}\text { AgRg no REsp } 1456844 \text { / } \\
\text { RJ }\end{array}$ & $25 / 09 / 2014$ \\
\hline $\begin{array}{l}\text { TERCEIRA } \\
\text { TURMA }\end{array}$ & NANCY ANDRIGHI & REsp 1349788 / RS & 29/08/2014 \\
\hline $\begin{array}{l}\text { SEGUNDA } \\
\text { TURMA }\end{array}$ & HUMBERTO MARTINS & REsp 1420003 / RS & $15 / 09 / 2014$ \\
\hline $\begin{array}{l}\text { SEGUNDA } \\
\text { TURMA }\end{array}$ & HUMBERTO MARTINS & $\begin{array}{c}\text { AgRg nos EDcl no REsp } \\
1446516 \text { / SP }\end{array}$ & $16 / 09 / 2014$ \\
\hline
\end{tabular}




\begin{tabular}{|c|c|c|c|}
\hline $\begin{array}{c}\text { ÓRGÃO } \\
\text { JULGADOR }\end{array}$ & MINISTRO(A) & PROCESSO & PUBLICAÇÃO \\
\hline $\begin{array}{l}\text { QUARTA } \\
\text { TURMA }\end{array}$ & MARCO BUZZI & $\begin{array}{c}\text { AgRg no AgRg no REsp } \\
961535 \text { / RS }\end{array}$ & 03/06/2015 \\
\hline $\begin{array}{l}\text { TERCEIRA } \\
\text { TURMA } \\
\end{array}$ & $\begin{array}{l}\text { RICARDO VILLAS BÔAS } \\
\text { CUEVA }\end{array}$ & REsp 1197476 / BA & $10 / 10 / 2014$ \\
\hline $\begin{array}{l}\text { SEGUNDA } \\
\text { TURMA }\end{array}$ & ASSUSETE MAGALHÃES & $\begin{array}{c}\text { AgRg nos EDcl no REsp } \\
1221399 \text { / PR }\end{array}$ & 23/10/2014 \\
\hline $\begin{array}{l}\text { SEGUNDA } \\
\text { TURMA }\end{array}$ & HUMBERTO MARTINS & REsp 1391789/ PR & $24 / 10 / 2014$ \\
\hline $\begin{array}{l}\text { QUINTA } \\
\text { TURMA }\end{array}$ & $\begin{array}{c}\text { WALTER DE ALMEIDA } \\
\text { GUILHERME (DES. CONV. } \\
\text { TJ/SP) }\end{array}$ & $\begin{array}{c}\text { AgRg no REsp } 1229473 \text { / } \\
\text { PE }\end{array}$ & 03/11/2014 \\
\hline $\begin{array}{l}\text { SEGUNDA } \\
\text { TURMA }\end{array}$ & $\begin{array}{c}\text { MAURO CAMPBELL } \\
\text { MARQUES }\end{array}$ & $\begin{array}{c}\text { AgRg no REsp } 1450470 / \\
\text { ES }\end{array}$ & $28 / 10 / 2014$ \\
\hline $\begin{array}{l}\text { SEGUNDA } \\
\text { TURMA }\end{array}$ & HERMAN BENJAMIN & $\begin{array}{l}\text { AgRg no REsp } 1465614 \text { / } \\
\text { SC }\end{array}$ & $28 / 11 / 2014$ \\
\hline $\begin{array}{l}\text { SEGUNDA } \\
\text { TURMA }\end{array}$ & $\begin{array}{c}\text { MAURO CAMPBELL } \\
\text { MARQUES } \\
\end{array}$ & $\begin{array}{c}\text { AgRg no REsp } 1463589 / \\
\text { SC }\end{array}$ & 28/10/2014 \\
\hline $\begin{array}{l}\text { TERCEIRA } \\
\text { TURMA } \\
\end{array}$ & JOÃO OTÁVIO DE NORONHA & $\begin{array}{c}\text { AgRg no REsp } 1276751 / \\
\text { SP }\end{array}$ & $19 / 11 / 2014$ \\
\hline SEXTA TURMA & ROGERIO SCHIETTI CRUZ & $\begin{array}{c}\text { AgRg nos EDcl no REsp } \\
1053648 / \text { DF }\end{array}$ & $24 / 11 / 2014$ \\
\hline $\begin{array}{l}\text { SEGUNDA } \\
\text { TURMA }\end{array}$ & HUMBERTO MARTINS & $\begin{array}{l}\text { AgRg no REsp } 1470591 / \\
\text { SC }\end{array}$ & $17 / 11 / 2014$ \\
\hline $\begin{array}{l}\text { QUARTA } \\
\text { TURMA }\end{array}$ & MARCO BUZZI & $\begin{array}{c}\text { AgRg no AREsp } 519410 / \\
\text { RJ }\end{array}$ & $17 / 11 / 2014$ \\
\hline $\begin{array}{l}\text { SEGUNDA } \\
\text { TURMA }\end{array}$ & $\begin{array}{c}\text { MAURO CAMPBELL } \\
\text { MARQUES }\end{array}$ & $\begin{array}{c}\text { AgRg no REsp } 1455713 \text { / } \\
\text { SC }\end{array}$ & $24 / 11 / 2014$ \\
\hline $\begin{array}{l}\text { PRIMEIRA } \\
\text { TURMA }\end{array}$ & SÉRGIO KUKINA & $\begin{array}{c}\text { AgRg no REsp } 1341242 \text { / } \\
\text { SP }\end{array}$ & $01 / 12 / 2014$ \\
\hline $\begin{array}{l}\text { PRIMEIRA } \\
\text { TURMA }\end{array}$ & SÉRGIO KUKINA & $\begin{array}{c}\text { AgRg no AREsp } 308674 \text { / } \\
\text { RJ }\end{array}$ & $01 / 12 / 2014$ \\
\hline $\begin{array}{l}\text { QUARTA } \\
\text { TURMA }\end{array}$ & MARIA ISABEL GALLOTTI & AgRg no Ag 938958 / SP & $27 / 04 / 2015$ \\
\hline SEXTA TURMA & ROGERIO SCHIETTI CRUZ & $\begin{array}{c}\text { AgRg nos EDcl no Ag } \\
862160 / \text { RJ }\end{array}$ & $04 / 02 / 2015$ \\
\hline $\begin{array}{l}\text { PRIMEIRA } \\
\text { TURMA }\end{array}$ & SÉRGIO KUKINA & $\begin{array}{c}\text { AgRg no REsp } 1384108 / \\
\text { RS }\end{array}$ & $03 / 02 / 2015$ \\
\hline $\begin{array}{l}\text { PRIMEIRA } \\
\text { TURMA }\end{array}$ & $\begin{array}{c}\text { NAPOLEÃO NUNES MAIA } \\
\text { FILHO }\end{array}$ & $\begin{array}{c}\text { AgRg no AREsp } 249092 / \\
\text { RS }\end{array}$ & $23 / 02 / 2015$ \\
\hline $\begin{array}{l}\text { TERCEIRA } \\
\text { TURMA }\end{array}$ & $\begin{array}{l}\text { RICARDO VILLAS BÔAS } \\
\text { CUEVA }\end{array}$ & $\begin{array}{c}\text { AgRg no REsp } 1351671 / \\
\text { PR }\end{array}$ & $12 / 02 / 2015$ \\
\hline $\begin{array}{l}\text { SEGUNDA } \\
\text { TURMA }\end{array}$ & ASSUSETE MAGALHÃES & $\begin{array}{l}\text { AgRg no REsp } 1452608 / \\
\text { SC }\end{array}$ & $05 / 03 / 2015$ \\
\hline $\begin{array}{l}\text { QUARTA } \\
\text { TURMA }\end{array}$ & MARIA ISABEL GALLOTTI & $\begin{array}{c}\text { AgRg no AREsp 644649 / } \\
\text { DF } \\
\end{array}$ & $23 / 03 / 2015$ \\
\hline $\begin{array}{l}\text { SEGUNDA } \\
\text { TURMA }\end{array}$ & HUMBERTO MARTINS & REsp 1299900 / RJ & $13 / 03 / 2015$ \\
\hline $\begin{array}{l}\text { QUARTA } \\
\text { TURMA }\end{array}$ & MARIA ISABEL GALLOTTI & $\begin{array}{c}\text { AgRg no AREsp } 637631 / \\
\text { SP }\end{array}$ & $10 / 03 / 2015$ \\
\hline $\begin{array}{l}\text { PRIMEIRA } \\
\text { TURMA }\end{array}$ & SÉRGIO KUKINA & $\begin{array}{c}\text { AgRg no AREsp 533421 / } \\
\text { PE }\end{array}$ & $13 / 03 / 2015$ \\
\hline
\end{tabular}




\begin{tabular}{|c|c|c|c|}
\hline $\begin{array}{l}\text { ÓRGÃO } \\
\text { JULGADOR }\end{array}$ & MINISTRO(A) & PROCESSO & PUBLICAÇÃOO \\
\hline $\begin{array}{l}\text { PRIMEIRA } \\
\text { TURMA }\end{array}$ & SÉRGIO KUKINA & $\begin{array}{c}\text { AgRg no AREsp } 405039 / \\
\text { PE }\end{array}$ & $13 / 03 / 2015$ \\
\hline $\begin{array}{l}\text { SEGUNDA } \\
\text { TURMA }\end{array}$ & HERMAN BENJAMIN & $\begin{array}{c}\text { AgRg no REsp } 1501728 / \\
\text { AL }\end{array}$ & $31 / 03 / 2015$ \\
\hline $\begin{array}{l}\text { TERCEIRA } \\
\text { TURMA }\end{array}$ & JOÃO OTÁVIO DE NORONHA & REsp 1454264 / PR & $17 / 03 / 2015$ \\
\hline $\begin{array}{l}\text { SEGUNDA } \\
\text { TURMA }\end{array}$ & HUMBERTO MARTINS & $\begin{array}{c}\text { AgRg no AREsp } 633975 / \\
\text { SP }\end{array}$ & $12 / 03 / 2015$ \\
\hline $\begin{array}{c}\text { SEGUNDA } \\
\text { TURMA }\end{array}$ & OG FERNANDES & $\begin{array}{l}\text { AgRg no REsp } 1276663 / \\
\text { GO }\end{array}$ & $12 / 03 / 2015$ \\
\hline $\begin{array}{c}\text { SEGUNDA } \\
\text { TURMA }\end{array}$ & $\begin{array}{c}\text { MAURO CAMPBELL } \\
\text { MARQUES }\end{array}$ & $\begin{array}{c}\text { AgRg no REsp } 1500557 / / \\
\text { SC }\end{array}$ & $11 / 03 / 2015$ \\
\hline $\begin{array}{l}\text { TERCEIRA } \\
\text { TURMA }\end{array}$ & $\begin{array}{l}\text { PAULO DE TARSO } \\
\text { SANSEVERINO }\end{array}$ & $\begin{array}{c}\text { AgRg no REsp } 1462616 / \\
\text { RS }\end{array}$ & $11 / 03 / 2015$ \\
\hline $\begin{array}{c}\text { SEGUNDA } \\
\text { TURMA }\end{array}$ & HERMAN BENJAMIN & $\begin{array}{c}\text { AgRg no AREsp } 620663 / \\
\text { DF }\end{array}$ & $06 / 04 / 2015$ \\
\hline $\begin{array}{l}\text { TERCEIRA } \\
\text { TURMA }\end{array}$ & MOURA RI & REsp 1482953 / RJ & $17 / 03 / 2015$ \\
\hline $\begin{array}{c}\text { TERCEIRA } \\
\text { TURMA }\end{array}$ & JOÃO OTÁVIO DE NORONHA & REsp 1208207 / RN & $27 / 03 / 2015$ \\
\hline $\begin{array}{l}\text { QUARTA } \\
\text { TURMA }\end{array}$ & MARIA ISABEI & $\begin{array}{c}\text { AgRg no AREsp } 18908 / \\
\text { RS }\end{array}$ & t/2015 \\
\hline $\begin{array}{l}\text { SEGUNDA } \\
\text { TURMA }\end{array}$ & HERMAN BENJAMIN & $\begin{array}{c}\text { AgRg no AREsp 634136 / } \\
\text { RS }\end{array}$ & $06 / 04 / 2015$ \\
\hline $\begin{array}{l}\text { TERCEIRA } \\
\text { TURMA }\end{array}$ & $\begin{array}{l}\text { RICARDO VILLAS BÔAS } \\
\text { CUEVA }\end{array}$ & $\begin{array}{c}\text { AgRg no AREsp } 484257 \text { / } \\
\text { RN }\end{array}$ & $31 / 03 / 2015$ \\
\hline $\begin{array}{l}\text { TERCEIRA } \\
\text { TURMA }\end{array}$ & $\begin{array}{l}\text { RICARDO VILLAS BÔAS } \\
\text { CUEVA }\end{array}$ & $\begin{array}{c}\text { AgRg no REsp } 1385134 \text { / } \\
\text { RN }\end{array}$ & $31 / 03 / 2015$ \\
\hline $\begin{array}{c}\text { TERCEIRA } \\
\text { TURMA }\end{array}$ & JOÃO OTÁVIO DE NORONHA & REsp 1424164 / SC & $16 / 04 / 2015$ \\
\hline $\begin{array}{l}\text { QUARTA } \\
\text { TURMA }\end{array}$ & MARIA ISABEL GALLOTTI & $\begin{array}{c}\text { AgRg no AREsp 650036 / } \\
\text { MG }\end{array}$ & $10 / 04 / 2015$ \\
\hline $\begin{array}{l}\text { SEGUNDA } \\
\text { TURMA }\end{array}$ & OG FERNANDES & $\begin{array}{c}\text { AgRg no REsp } 1324787 / \\
\text { SP }\end{array}$ & $09 / 04 / 2015$ \\
\hline $\begin{array}{c}\text { SEGUNDA } \\
\text { TURMA }\end{array}$ & HUMBERTO MARTINS & REsp 1365999 / PR & $17 / 04 / 2015$ \\
\hline $\begin{array}{l}\text { SEGUNDA } \\
\text { TURMA }\end{array}$ & HUMBERTO MARTINS & $\begin{array}{c}\text { AgRg no REsp } 1366327 / \\
\text { PE }\end{array}$ & $11 / 05 / 2015$ \\
\hline $\begin{array}{l}\text { SEGUNDA } \\
\text { TURMA }\end{array}$ & HERMAN BENJ & $\begin{array}{c}\text { AgRg no REsp } 1484395 / \\
\text { PR }\end{array}$ & $01 / 07 / 2015$ \\
\hline $\begin{array}{l}\text { TERCEIRA } \\
\text { TURMA }\end{array}$ & MARCO AURÉLIO BELLIZZE & REsp 1319526 / SP & $18 / 05 / 2015$ \\
\hline $\begin{array}{c}\text { SEGUNDA } \\
\text { TURMA }\end{array}$ & HUMBERTO N & $\begin{array}{c}\text { AgRg no REsp } 1174853 / \\
\text { TO }\end{array}$ & $26 / 05 / 2015$ \\
\hline $\begin{array}{l}\text { QUARTA } \\
\text { TURMA }\end{array}$ & MARCO BUZZI & $\begin{array}{c}\text { AgRg no Ag } 1182834 \text { / } \\
\text { RS }\end{array}$ & $20 / 05 / 2015$ \\
\hline $\begin{array}{l}\text { SEGUNDA } \\
\text { TURMA }\end{array}$ & HUMBERTO MARTINS & $\begin{array}{c}\text { AgRg no AREsp } 255845 / \\
\text { SP }\end{array}$ & $10 / 08 / 2015$ \\
\hline $\begin{array}{l}\text { PRIMEIRA } \\
\text { TURMA }\end{array}$ & BENEDITO GONÇALVES & $\begin{array}{c}\text { AgRg no AREsp } 242962 / \\
\text { PR }\end{array}$ & $14 / 05 / 2015$ \\
\hline
\end{tabular}




\begin{tabular}{|c|c|c|c|}
\hline $\begin{array}{c}\text { ÓRGÃO } \\
\text { JULGADOR }\end{array}$ & MINISTRO(A) & PROCESSO & PUBLICAÇÃO \\
\hline $\begin{array}{l}\text { TERCEIRA } \\
\text { TURMA }\end{array}$ & JOÃO OTÁVIO DE NORONHA & REsp 1293490 / ES & $29 / 05 / 2015$ \\
\hline $\begin{array}{l}\text { TERCEIRA } \\
\text { TURMA }\end{array}$ & MOURA RIBEIRO & $\begin{array}{c}\text { AgRg no REsp } 1435413 / \\
\text { SC }\end{array}$ & $28 / 05 / 2015$ \\
\hline $\begin{array}{l}\text { QUARTA } \\
\text { TURMA }\end{array}$ & MARIA ISABEL GALLOTTI & REsp 1134709 / MG & $03 / 06 / 2015$ \\
\hline $\begin{array}{l}\text { SEGUNDA } \\
\text { TURMA }\end{array}$ & $\begin{array}{l}\text { MAURO CAMPBELL } \\
\text { MARQUES }\end{array}$ & $\begin{array}{c}\text { AgRg no REsp } 1427522 / \\
\text { AM }\end{array}$ & $16 / 06 / 2015$ \\
\hline $\begin{array}{l}\text { SEGUNDA } \\
\text { TURMA }\end{array}$ & OG FERNANDES & $\begin{array}{c}\text { AgRg no REsp } 1462355 / \\
\text { SC }\end{array}$ & $25 / 06 / 2015$ \\
\hline $\begin{array}{l}\text { TERCEIRA } \\
\text { TURMA }\end{array}$ & $\begin{array}{l}\text { PAULO DE TARSO } \\
\text { SANSEVERINO }\end{array}$ & $\begin{array}{c}\text { AgRg no REsp } 1392983 / \\
\text { DF }\end{array}$ & $22 / 06 / 2015$ \\
\hline $\begin{array}{l}\text { QUINTA } \\
\text { TURMA }\end{array}$ & $\begin{array}{l}\text { REYNALDO SOARES DA } \\
\text { FONSECA }\end{array}$ & $\begin{array}{l}\text { AgRg no REsp } 1247847 / \\
\text { SC }\end{array}$ & $25 / 06 / 2015$ \\
\hline $\begin{array}{l}\text { QUARTA } \\
\text { TURMA }\end{array}$ & MARIA ISABEL GALLOTTI & $\begin{array}{c}\text { AgRg no AREsp } 124613 / \\
\text { PR }\end{array}$ & $25 / 06 / 2015$ \\
\hline $\begin{array}{l}\text { TERCEIRA } \\
\text { TURMA }\end{array}$ & MARCO AURÉLIO BELLIZZE & $\begin{array}{c}\text { AgRg no AREsp } 690054 \text { / } \\
\text { SP }\end{array}$ & $30 / 06 / 2015$ \\
\hline $\begin{array}{l}\text { QUARTA } \\
\text { TURMA }\end{array}$ & RAUL ARAÚJO & $\begin{array}{l}\text { AgRg nos EDcl no } \\
\text { AREsp 551162 / SP }\end{array}$ & $18 / 08 / 2015$ \\
\hline $\begin{array}{l}\text { SEGUNDA } \\
\text { TURMA }\end{array}$ & OG FERNANDES & $\begin{array}{l}\text { AgRg no REsp } 1530191 / \\
\text { GO }\end{array}$ & $12 / 08 / 2015$ \\
\hline $\begin{array}{l}\text { SEGUNDA } \\
\text { SEÇÃOO }\end{array}$ & $\begin{array}{l}\text { RICARDO VILLAS BÔAS } \\
\text { CUEVA }\end{array}$ & AR 4176 / PR & $01 / 07 / 2015$ \\
\hline $\begin{array}{l}\text { QUARTA } \\
\text { TURMA }\end{array}$ & MARIA ISABEL GALLOTTI & $\begin{array}{c}\text { AgRg no AREsp 697818 / } \\
\text { DF }\end{array}$ & $14 / 08 / 2015$ \\
\hline $\begin{array}{l}\text { QUARTA } \\
\text { TURMA }\end{array}$ & MARIA ISABEL GALLOTTI & $\begin{array}{l}\text { AgRg nos EDcl no } \\
\text { AREsp } 640497 \text { / RS }\end{array}$ & $28 / 08 / 2015$ \\
\hline $\begin{array}{l}\text { QUARTA } \\
\text { TURMA }\end{array}$ & MARIA ISABEL GALLOTTI & $\begin{array}{c}\text { AgRg no AREsp 135791 / } \\
\text { MS }\end{array}$ & $27 / 08 / 2015$ \\
\hline $\begin{array}{c}\text { SEGUNDA } \\
\text { TURMA } \\
\end{array}$ & $\begin{array}{c}\text { MAURO CAMPBELL } \\
\text { MARQUES } \\
\end{array}$ & REsp $1384106 / \mathrm{SP}$ & $24 / 11 / 2015$ \\
\hline $\begin{array}{l}\text { SEGUNDA } \\
\text { TURMA }\end{array}$ & $\begin{array}{c}\text { MAURO CAMPBELL } \\
\text { MARQUES }\end{array}$ & $\begin{array}{c}\mathrm{AgRg} \text { nos EDcl nos EDcl } \\
\text { no REsp } 1464842 \text { / SP }\end{array}$ & $03 / 09 / 2015$ \\
\hline $\begin{array}{l}\text { TERCEIRA } \\
\text { TURMA }\end{array}$ & JOÃO OTÁVIO DE NORONHA & $\begin{array}{c}\text { AgRg no AREsp } 31519 / \\
\text { DF }\end{array}$ & $11 / 09 / 2015$ \\
\hline $\begin{array}{l}\text { SEGUNDA } \\
\text { TURMA }\end{array}$ & HERMAN BENJAMIN & REsp 1545518 / PR & $11 / 11 / 2015$ \\
\hline $\begin{array}{l}\text { QUARTA } \\
\text { TURMA }\end{array}$ & MARIA ISABEL GALLOTTI & $\begin{array}{c}\text { AgRg no AREsp } 729099 / \\
\text { RJ }\end{array}$ & $10 / 09 / 2015$ \\
\hline $\begin{array}{l}\text { TERCEIRA } \\
\text { TURMA }\end{array}$ & $\begin{array}{l}\text { RICARDO VILLAS BÔAS } \\
\text { CUEVA }\end{array}$ & $\begin{array}{c}\text { AgRg no AREsp 506601 / } \\
\text { RS }\end{array}$ & $08 / 09 / 2015$ \\
\hline $\begin{array}{l}\text { QUARTA } \\
\text { TURMA }\end{array}$ & MARCO BUZZI & $\begin{array}{c}\text { AgRg no AREsp } 456533 / \\
\text { SC }\end{array}$ & $25 / 09 / 2015$ \\
\hline $\begin{array}{l}\text { TERCEIRA } \\
\text { TURMA } \\
\end{array}$ & MARCO AURÉLIO BELLIZZE & $\begin{array}{c}\text { AgRg no AREsp 527202/ } \\
\text { SP }\end{array}$ & $30 / 09 / 2015$ \\
\hline $\begin{array}{l}\text { PRIMEIRA } \\
\text { TURMA }\end{array}$ & $\begin{array}{l}\text { NAPOLEÃO NUNES MAIA } \\
\text { FILHO }\end{array}$ & $\begin{array}{c}\text { AgRg no Ag } 1327010 \text { / } \\
\text { RJ }\end{array}$ & $29 / 09 / 2015$ \\
\hline $\begin{array}{l}\text { QUARTA } \\
\text { TURMA }\end{array}$ & MARCO BUZZI & $\begin{array}{c}\text { AgRg no AREsp } 354070 / \\
\text { RS }\end{array}$ & $21 / 10 / 2015$ \\
\hline
\end{tabular}




\begin{tabular}{|c|c|c|c|}
\hline $\begin{array}{l}\text { ÓRGÃO } \\
\text { JULGADOR }\end{array}$ & MINISTRO(A) & PROCESSO & PUBLICAÇÃO \\
\hline $\begin{array}{l}\text { SEGUNDA } \\
\text { TURMA }\end{array}$ & HERMAN BENJAMIN & $\begin{array}{c}\text { AgRg no AREsp } 713329 / \\
\text { PE }\end{array}$ & $03 / 02 / 2016$ \\
\hline $\begin{array}{l}\text { SEGUNDA } \\
\text { TURMA }\end{array}$ & HUMBERTO MARTINS & $\begin{array}{c}\text { AgRg no AREsp 690450 / } \\
\text { RJ }\end{array}$ & $16 / 10 / 2015$ \\
\hline $\begin{array}{l}\text { QUARTA } \\
\text { TURMA }\end{array}$ & LUIS FELIPE SALOMÃO & $\begin{array}{c}\text { AgRg no AREsp } 757147 / \\
\text { GO }\end{array}$ & $06 / 10 / 2015$ \\
\hline $\begin{array}{l}\text { SEGUNDA } \\
\text { TURMA }\end{array}$ & HERMAN BENJAMIN & $\begin{array}{c}\text { AgRg no REsp 1547276 / } \\
\text { RS }\end{array}$ & $03 / 02 / 2016$ \\
\hline $\begin{array}{l}\text { SEGUNDA } \\
\text { TURMA }\end{array}$ & HERMAN BENJAMIN & $\begin{array}{c}\text { AgRg no REsp } 1539796 / \\
\text { CE }\end{array}$ & $03 / 02 / 2016$ \\
\hline $\begin{array}{l}\text { QUARTA } \\
\text { TURMA }\end{array}$ & RAUL ARAÚJO & $\begin{array}{c}\text { AgRg no AREsp 546537 / } \\
\text { SP }\end{array}$ & $04 / 11 / 2015$ \\
\hline $\begin{array}{l}\text { QUARTA } \\
\text { TURMA }\end{array}$ & MARIA ISABEL GALLOTTI & $\begin{array}{c}\text { AgRg no AREsp } 478095 / \\
\text { PR }\end{array}$ & $20 / 10 / 2015$ \\
\hline $\begin{array}{l}\text { TERCEIRA } \\
\text { TURMA }\end{array}$ & MARCO AURÉLIO BELLIZZE & REsp 1520500 / SP & $13 / 11 / 2015$ \\
\hline $\begin{array}{l}\text { TERCEIRA } \\
\text { TURMA }\end{array}$ & $\begin{array}{c}\text { RICARDO VILLAS BÔAS } \\
\text { CUEVA }\end{array}$ & REsp 1550255 / RJ & $13 / 11 / 2015$ \\
\hline $\begin{array}{l}\text { QUARTA } \\
\text { TURMA }\end{array}$ & RAUL ARAÚJO & $\begin{array}{c}\text { AgRg nos EDcl no AgRg } \\
\text { no AREsp } 710780 / \text { RS }\end{array}$ & $25 / 11$ \\
\hline $\begin{array}{l}\text { QUARTA } \\
\text { TURMA }\end{array}$ & MARCO BUZZI & REsp 1056837 / RN & $10 / 11 / 2015$ \\
\hline $\begin{array}{l}\text { PRIMEIRA } \\
\text { TURMA }\end{array}$ & SÉRGIO KUKINA & $\begin{array}{c}\text { AgRg no AREsp } 770344 / \\
\text { RS }\end{array}$ & $01 / 12 / 2015$ \\
\hline $\begin{array}{l}\text { SEGUNDA } \\
\text { TURMA }\end{array}$ & $\begin{array}{l}\text { MAURO CAMPBELL } \\
\text { MARQUES }\end{array}$ & \begin{tabular}{|c|} 
AgRg no REsp $1455680 /$ \\
RS
\end{tabular} & 15 \\
\hline $\begin{array}{l}\text { SEGUNDA } \\
\text { TURMA }\end{array}$ & ASSUSETE MAGALHÃES & $\begin{array}{c}\text { AgRg no AREsp 484423/ } \\
\text { MS }\end{array}$ & $14 / 12 / 2015$ \\
\hline $\begin{array}{l}\text { SEGUNDA } \\
\text { TURMA }\end{array}$ & $\begin{array}{l}\text { DIVA MALERBI (DES. CONV. } \\
\text { TRF } 3^{\mathrm{a}} \text { REGIÃO) }\end{array}$ & $\begin{array}{c}\text { EDcl no REsp } 1334437 \text { / } \\
\text { PR }\end{array}$ & $17 / 12 / 2015$ \\
\hline $\begin{array}{l}\text { QUARTA } \\
\text { TURMA }\end{array}$ & $\begin{array}{l}\text { ANTONIO CARLOS } \\
\text { FERREIRA } \\
\end{array}$ & $\begin{array}{c}\text { AgRg no REsp } 1405409 / \\
\text { PR }\end{array}$ & $04 / 02 / 2016$ \\
\hline $\begin{array}{l}\text { TERCEIRA } \\
\text { TURMA }\end{array}$ & MARCO AURÉLIO BELLIZZE & $\begin{array}{l}\text { AgRg nos EDcl no } \\
\text { AREsp } 708465 \text { / RJ }\end{array}$ & $02 / 02 / 2016$ \\
\hline $\begin{array}{l}\text { TERCEIRA } \\
\text { TURMA }\end{array}$ & $\begin{array}{l}\text { RICARDO VILLAS BÔAS } \\
\text { CUEVA }\end{array}$ & $\begin{array}{c}\text { AgRg no AREsp } 793536 / \\
\text { SP }\end{array}$ & $02 / 02 / 2016$ \\
\hline $\begin{array}{l}\text { SEGUNDA } \\
\text { TURMA }\end{array}$ & HUMBERTO MARTINS & $\begin{array}{c}\text { AgRg no REsp } 1533758 \text { / } \\
\text { RJ }\end{array}$ & $10 / 02 / 2016$ \\
\hline $\begin{array}{l}\text { SEGUNDA } \\
\text { TURMA }\end{array}$ & HERMAN BENJAMIN & $\begin{array}{c}\text { AgRg no AREsp } 173860 / \\
\text { MS }\end{array}$ & $18 / 05 / 2016$ \\
\hline $\begin{array}{l}\text { TERCEIRA } \\
\text { TURMA }\end{array}$ & MARCO AURÉLIO BELLIZZE & $\begin{array}{c}\text { AgRg no REsp } 1432595 / \\
\text { MG }\end{array}$ & $05 / 02 / 2016$ \\
\hline $\begin{array}{l}\text { SEGUNDA } \\
\text { TURMA }\end{array}$ & HERMAN BENJAMIN & $\begin{array}{c}\text { EDcl no REsp } 1334703 \text { / } \\
\text { DF } \\
\end{array}$ & $20 / 05 / 2016$ \\
\hline $\begin{array}{l}\text { TERCEIRA } \\
\text { TURMA }\end{array}$ & MARCO AURÉLIO BELLIZZE & $\begin{array}{c}\text { AgRg nos EDcl no REsp } \\
1478946 / \mathrm{MT}\end{array}$ & $11 / 03 / 2016$ \\
\hline $\begin{array}{l}\text { SEGUNDA } \\
\text { TURMA }\end{array}$ & ASSUSETE MAGALHÃES & $\begin{array}{c}\text { AgRg no REsp } 1469086 / \\
\text { AC }\end{array}$ & $09 / 03 / 2016$ \\
\hline $\begin{array}{l}\text { QUARTA } \\
\text { TURMA }\end{array}$ & MARIA ISABEL GALLOTTI & $\begin{array}{c}\text { EDcl no AREsp } 280160 / \\
\text { MT }\end{array}$ & $03 / 03 / 2016$ \\
\hline
\end{tabular}




\begin{tabular}{|c|c|c|c|}
\hline $\begin{array}{l}\text { ÓRGÃO } \\
\text { JULGADOR }\end{array}$ & MINISTRO(A) & PROCESSO & PUBLICAÇÃO \\
\hline $\begin{array}{l}\text { QUARTA } \\
\text { TURMA }\end{array}$ & LUIS FELIPE SALOMÃO & $\begin{array}{c}\text { AgRg no AREsp } 809875 / \\
\text { RS }\end{array}$ & $01 / 03 / 2016$ \\
\hline $\begin{array}{l}\text { TERCEIRA } \\
\text { TURMA }\end{array}$ & JOÃO OTÁVIO DE NORONHA & REsp 1280261 / MG & 07/03/2016 \\
\hline $\begin{array}{l}\text { QUARTA } \\
\text { TURMA }\end{array}$ & MARCO BUZZI & $\begin{array}{c}\text { AgRg no AREsp } 793112 \text { / } \\
\text { RS }\end{array}$ & $10 / 03 / 2016$ \\
\hline $\begin{array}{l}\text { SEGUNDA } \\
\text { TURMA }\end{array}$ & HERMAN BENJAMIN & $\begin{array}{c}\text { AgRg nos EDcl no REsp } \\
1539203 / \text { RS } \\
\end{array}$ & $30 / 05 / 2016$ \\
\hline $\begin{array}{l}\text { SEGUNDA } \\
\text { TURMA }\end{array}$ & HERMAN BENJAMIN & $\begin{array}{c}\text { AgRg no AREsp 513685 / } \\
\text { SP }\end{array}$ & $24 / 05 / 2016$ \\
\hline $\begin{array}{l}\text { SEGUNDA } \\
\text { TURMA }\end{array}$ & ASSUSETE MAGALHÃES & $\begin{array}{c}\text { AgRg no AREsp } 789117 \text { / } \\
\text { RJ }\end{array}$ & $16 / 03 / 2016$ \\
\hline $\begin{array}{l}\text { SEGUNDA } \\
\text { TURMA }\end{array}$ & ASSUSETE MAGALHÃES & $\begin{array}{c}\text { EDcl no REsp } 1334203 / \\
\text { PR }\end{array}$ & $16 / 03 / 2016$ \\
\hline $\begin{array}{l}\text { QUARTA } \\
\text { TURMA }\end{array}$ & MARCO BUZZI & $\begin{array}{c}\text { AgRg no AREsp } 420691 / \\
\text { RJ }\end{array}$ & $22 / 03 / 2016$ \\
\hline $\begin{array}{l}\text { QUARTA } \\
\text { TURMA }\end{array}$ & MARIA ISABEL GALLOTTI & $\begin{array}{c}\text { AgRg no AREsp } 619504 / \\
\text { SP }\end{array}$ & $22 / 03 / 2016$ \\
\hline $\begin{array}{l}\text { QUARTA } \\
\text { TURMA }\end{array}$ & MARIA ISABEL GALLOTTI & REsp 1355901 / BA & $22 / 04 / 2016$ \\
\hline $\begin{array}{l}\text { SEGUNDA } \\
\text { TURMA }\end{array}$ & HERN & $\begin{array}{c}\text { AgRg no AREsp } 779165 / \\
\text { RS }\end{array}$ & 16 \\
\hline $\begin{array}{l}\text { SEGUNDA } \\
\text { TURMA } \\
\end{array}$ & ASSUSETE MAGALHÃES & $\begin{array}{c}\text { AgRg no AREsp } 392961 / \\
\text { GO }\end{array}$ & $18 / 04 / 2016$ \\
\hline $\begin{array}{l}\text { TERCEIRA } \\
\text { TURMA }\end{array}$ & $\begin{array}{l}\text { PAULO DE TARSO } \\
\text { SANSEVERINO }\end{array}$ & $\begin{array}{c}\text { AgRg no AREsp } 573264 \text { / } \\
\text { DF }\end{array}$ & /2016 \\
\hline $\begin{array}{l}\text { TERCEIRA } \\
\text { TURMA }\end{array}$ & $\begin{array}{c}\text { RICARDO VILLAS BÔAS } \\
\text { CUEVA }\end{array}$ & $\begin{array}{c}\text { AgRg no AREsp } 846804 \text { / } \\
\text { RS }\end{array}$ & $13 / 05 / 2016$ \\
\hline $\begin{array}{l}\text { TERCEIRA } \\
\text { TURMA }\end{array}$ & $\begin{array}{l}\text { RICARDO VILLAS BÔAS } \\
\text { CUEVA }\end{array}$ & REsp 1574377 / RJ & $09 / 05 / 2016$ \\
\hline $\begin{array}{l}\text { SEGUNDA } \\
\text { TURMA }\end{array}$ & HERMAN BENJAMIN & $\begin{array}{c}\text { AgRg no REsp } 1356449 / \\
\text { TO }\end{array}$ & $25 / 05 / 2016$ \\
\hline $\begin{array}{l}\text { QUARTA } \\
\text { TURMA }\end{array}$ & MARIA ISABEL GALLOTTI & $\begin{array}{c}\text { AgRg no AREsp } 747488 \text { / } \\
\text { MS }\end{array}$ & $12 / 05 / 2016$ \\
\hline $\begin{array}{l}\text { PRIMEIRA } \\
\text { SEÇÃO }\end{array}$ & $\begin{array}{c}\text { MAURO CAMPBELL } \\
\text { MARQUES } \\
\end{array}$ & REsp 1380931 / SP & $14 / 0$ \\
\hline $\begin{array}{l}\text { TERCEIRA } \\
\text { TURMA }\end{array}$ & JOÃO OTÁVIO DE NORONHA & REsp 1287458 / SP & $19 / 05 / 2016$ \\
\hline $\begin{array}{l}\text { SEGUNDA } \\
\text { TURMA }\end{array}$ & HERMAN BENJAMIN & $\begin{array}{c}\text { AgRg no AREsp 850024 / } \\
\text { RJ }\end{array}$ & $31 / 05 / 2016$ \\
\hline $\begin{array}{l}\text { QUARTA } \\
\text { TURMA }\end{array}$ & LUIS FELIPE SALOMÃO & $\begin{array}{c}\text { AgRg no AREsp } 549696 / \\
\text { ES }\end{array}$ & $11 / 05 / 2016$ \\
\hline $\begin{array}{l}\text { SEGUNDA } \\
\text { TURMA }\end{array}$ & HUMBE & $\begin{array}{c}\text { AgRg no REsp } 1434797 \text { / } \\
\text { PR }\end{array}$ & 07/06/2016 \\
\hline $\begin{array}{l}\text { TERCEIRA } \\
\text { TURMA }\end{array}$ & $\begin{array}{l}\text { RICARDO VILLAS BÔAS } \\
\text { CUEVA }\end{array}$ & REsp 1496018 / MA & $06 / 06 / 2016$ \\
\hline $\begin{array}{l}\text { QUINTA } \\
\text { TURMA }\end{array}$ & $\begin{array}{l}\text { REYNALDO SOARES DA } \\
\text { FONSECA }\end{array}$ & $\begin{array}{c}\text { AgRg no REsp } 1019714 \text { / } \\
\text { RS }\end{array}$ & $25 / 05 / 2016$ \\
\hline $\begin{array}{l}\text { PRIMEIRA } \\
\text { TURMA }\end{array}$ & $\begin{array}{c}\text { NAPOLEÃO NUNES MAIA } \\
\text { FILHO }\end{array}$ & $\begin{array}{c}\text { AgRg no AREsp } 143370 / \\
\text { RJ }\end{array}$ & $02 / 06 / 2016$ \\
\hline
\end{tabular}




\begin{tabular}{|c|c|c|c|}
\hline $\begin{array}{c}\text { ÓRGÃO } \\
\text { JULGADOR }\end{array}$ & MINISTRO(A) & PROCESSO & PUBLICAÇÃ̃O \\
\hline $\begin{array}{c}\text { TERCEIRA } \\
\text { TURMA }\end{array}$ & $\begin{array}{l}\text { PAULO DE TARSO } \\
\text { SANSEVERINO }\end{array}$ & $\begin{array}{c}\text { AgRg no AREsp 625605/ } \\
\text { GO }\end{array}$ & $01 / 06 / 2016$ \\
\hline $\begin{array}{c}\text { TERCEIRA } \\
\text { TURMA }\end{array}$ & JOÃO OTÁVIO DE NORONHA & REsp 1590479 / RJ & $16 / 06 / 2016$ \\
\hline $\begin{array}{l}\text { QUARTA } \\
\text { TURMA }\end{array}$ & RAUL ARAÚJO & $\begin{array}{c}\text { AgRg no REsp } 1263780 / \\
\text { SC }\end{array}$ & 03/08/2016 \\
\hline $\begin{array}{l}\text { TERCEIRA } \\
\text { TURMA }\end{array}$ & MARCO AURÉLIO BELLIZZE & $\begin{array}{l}\text { AgRg no AgRg no } \\
\text { AREsp } 695258 \text { / SC }\end{array}$ & $22 / 06 / 2016$ \\
\hline $\begin{array}{l}\text { QUARTA } \\
\text { TURMA }\end{array}$ & $\begin{array}{l}\text { ANTONIO CARLOS } \\
\text { FERREIRA }\end{array}$ & $\begin{array}{c}\text { AgRg no REsp } 1115572 / \\
\text { MG }\end{array}$ & $30 / 06 / 2016$ \\
\hline $\begin{array}{l}\text { PRIMEIRA } \\
\text { TURMA }\end{array}$ & SÉRGIO KUKINA & REsp 1122280 / MG & $28 / 06 / 2016$ \\
\hline $\begin{array}{c}\text { TERCEIRA } \\
\text { TURMA } \\
\end{array}$ & JOÃO OTÁVIO DE NORONHA & REsp $1537996 /$ DF & $28 / 06 / 2016$ \\
\hline $\begin{array}{c}\text { TERCEIRA } \\
\text { TURMA }\end{array}$ & $\begin{array}{c}\text { RICARDO VILLAS BÔAS } \\
\text { CUEVA }\end{array}$ & $\begin{array}{c}\text { AgInt no AREsp 647349/ } \\
\text { MG }\end{array}$ & $01 / 08 / 2016$ \\
\hline $\begin{array}{l}\text { TERCEIRA } \\
\text { TURMA }\end{array}$ & $\begin{array}{l}\text { RICARDO VILLAS BÔAS } \\
\text { CUEVA }\end{array}$ & REsp 1562641 / SP & 9/2016 \\
\hline $\begin{array}{l}\text { QUARTA } \\
\text { TURMA }\end{array}$ & RAUL ARAÚJO & $\begin{array}{c}\text { EDcl no REsp } 1331100 / \\
\text { BA }\end{array}$ & $10 / 08 / 2016$ \\
\hline $\begin{array}{l}\text { QUARTA } \\
\text { TURMA }\end{array}$ & RAUL ARAÚJO & $\begin{array}{c}\text { AgInt no REsp } 1088528 / \\
\text { ES }\end{array}$ & 03/08/2016 \\
\hline $\begin{array}{l}\text { QUARTA } \\
\text { TURMA }\end{array}$ & MARCO BUZZI & $\begin{array}{c}\text { AgRg no REsp } 1539794 / \\
\text { SP }\end{array}$ & $16 / 08 / 2016$ \\
\hline $\begin{array}{l}\text { SEGUNDA } \\
\text { TURMA }\end{array}$ & $\begin{array}{c}\text { DIVA MALERBI (DES. CONV. } \\
\text { TRF } 3^{\mathrm{a}} \text { REGIÃO) }\end{array}$ & REsp 1355574 / SE & 2016 \\
\hline $\begin{array}{l}\text { QUARTA } \\
\text { TURMA }\end{array}$ & LUIS FELIPE SALOMÃO & $\begin{array}{c}\text { AgInt no AREsp 777346/ } \\
\text { DF }\end{array}$ & $23 / 08 / 2016$ \\
\hline $\begin{array}{c}\text { TERCEIRA } \\
\text { TURMA }\end{array}$ & JOÃO OTÁVIO DE NORONHA & $\begin{array}{c}\text { EDcl no AREsp } 705078 \text { / } \\
\text { MG }\end{array}$ & 2016 \\
\hline $\begin{array}{c}\text { TERCEIRA } \\
\text { TURMA }\end{array}$ & $\begin{array}{l}\text { RICARDO VILLAS BÔAS } \\
\text { CUEVA }\end{array}$ & REsp 1605466 / SP & $28 / 10 / 2016$ \\
\hline $\begin{array}{l}\text { TERCEIRA } \\
\text { TURMA }\end{array}$ & JOÃO OTÁVIO DE NORONHA & $\begin{array}{c}\text { AgInt no AREsp 880008 / } \\
\text { SC }\end{array}$ & $26 / 08 / 2016$ \\
\hline $\begin{array}{l}\text { PRIMEIRA } \\
\text { TURMA }\end{array}$ & SÉRGIO KUKINA & $\begin{array}{c}\text { AgInt no AREsp 912511/ } \\
\text { RS }\end{array}$ & $22 / 09 / 2016$ \\
\hline $\begin{array}{l}\text { QUARTA } \\
\text { TURMA }\end{array}$ & MARIA ISABEL GALLOTTI & $\begin{array}{c}\text { AgInt no Ag } 1378294 \text { / } \\
\text { SP } \\
\end{array}$ & $22 / 09 / 2016$ \\
\hline $\begin{array}{l}\text { QUARTA } \\
\text { TURMA }\end{array}$ & MARIA ISABEL GALLOTTI & $\begin{array}{c}\text { AgRg no REsp } 1251517 / \\
\text { SE }\end{array}$ & $21 / 09 / 2016$ \\
\hline $\begin{array}{l}\text { QUARTA } \\
\text { TURMA }\end{array}$ & RAUL ARAÚJO & REsp 1536949 / SP & $04 / 11 / 2016$ \\
\hline $\begin{array}{l}\text { PRIMEIRA } \\
\text { TURMA }\end{array}$ & SÉRG & $\begin{array}{c}\text { AgInt no REsp } 1334477 \text { / } \\
\text { PR }\end{array}$ & $04 / 10 / 2016$ \\
\hline $\begin{array}{l}\text { SEGUNDA } \\
\text { TURMA }\end{array}$ & $\begin{array}{c}\text { MAURO CAMPBELL } \\
\text { MARQUES }\end{array}$ & $\begin{array}{c}\text { AgInt no AREsp 949166/ } \\
\text { PI }\end{array}$ & 03/10/2016 \\
\hline $\begin{array}{c}\text { TERCEIRA } \\
\text { TURMA }\end{array}$ & MARCO AURÉLIO BELLIZZE & $\begin{array}{c}\text { AgInt no REsp } 1355777 \text { / } \\
\text { MG }\end{array}$ & $13 / 10 / 2016$ \\
\hline $\begin{array}{l}\text { TERCEIRA } \\
\text { TURMA }\end{array}$ & & $\begin{array}{c}\text { AgRg no REsp } 1548506 / \\
\text { RJ }\end{array}$ & $07 / 10$ \\
\hline
\end{tabular}




\begin{tabular}{|c|c|c|c|}
\hline $\begin{array}{c}\text { ÓRGÃO } \\
\text { JULGADOR }\end{array}$ & MINISTRO(A) & PROCESSO & PUBLICAÇÃO \\
\hline $\begin{array}{l}\text { PRIMEIRA } \\
\text { TURMA }\end{array}$ & SÉRGIO KUKINA & $\begin{array}{c}\text { AgInt no REsp } 1528563 \text { / } \\
\text { PR }\end{array}$ & $19 / 10 / 2016$ \\
\hline $\begin{array}{l}\text { SEGUNDA } \\
\text { TURMA }\end{array}$ & ASSUSETE MAGALHÃES & $\begin{array}{c}\text { AgInt no AREsp 927829 / } \\
\text { SP }\end{array}$ & $04 / 11 / 2016$ \\
\hline $\begin{array}{l}\text { QUARTA } \\
\text { TURMA }\end{array}$ & LUIS FELIPE SALOMÃO & REsp 1327627 / RS & $01 / 12 / 2016$ \\
\hline $\begin{array}{l}\text { TERCEIRA } \\
\text { TURMA }\end{array}$ & $\begin{array}{l}\text { RICARDO VILLAS BÔAS } \\
\text { CUEVA }\end{array}$ & $\begin{array}{c}\text { AgRg no AREsp } 646488 \text { / } \\
\text { RJ }\end{array}$ & $14 / 11 / 2016$ \\
\hline $\begin{array}{l}\text { TERCEIRA } \\
\text { TURMA }\end{array}$ & MOURA RIBEIRO & $\begin{array}{c}\text { AgInt no REsp } 1523945 / \\
\text { BA }\end{array}$ & $19 / 12 / 2016$ \\
\hline $\begin{array}{l}\text { QUARTA } \\
\text { TURMA }\end{array}$ & MARIA ISABEL GALLOTTI & $\begin{array}{c}\text { AgInt no AREsp } 936344 \text { / } \\
\text { SP }\end{array}$ & $09 / 12 / 2016$ \\
\hline $\begin{array}{l}\text { TERCEIRA } \\
\text { TURMA }\end{array}$ & $\begin{array}{l}\text { RICARDO VILLAS BÔAS } \\
\text { CUEVA }\end{array}$ & $\begin{array}{c}\text { AgInt no REsp } 1593655 \text { / } \\
\text { BA }\end{array}$ & $10 / 02 / 2017$ \\
\hline $\begin{array}{l}\text { TERCEIRA } \\
\text { TURMA }\end{array}$ & NANCY ANDRIGHI & $\begin{array}{c}\text { AgInt no AREsp } 495704 \text { / } \\
\text { SP }\end{array}$ & $03 / 02 / 2017$ \\
\hline $\begin{array}{l}\text { QUARTA } \\
\text { TURMA }\end{array}$ & LUIS FELIPE SALOMÃO & $\begin{array}{c}\text { AgInt no AREsp 500889 / } \\
\text { RJ }\end{array}$ & $03 / 02 / 2017$ \\
\hline $\begin{array}{l}\text { QUARTA } \\
\text { TURMA }\end{array}$ & MARIA ISABEL GALLOTTI & $\begin{array}{c}\text { AgInt no AREsp } 933549 \text { / } \\
\text { PR }\end{array}$ & $02 / 02 / 2017$ \\
\hline $\begin{array}{l}\text { TERCEIRA } \\
\text { TURMA } \\
\end{array}$ & $\begin{array}{c}\text { RICARDO VILLAS BÔAS } \\
\text { CUEVA }\end{array}$ & $\begin{array}{c}\text { AgInt no AREsp } 735491 / \\
\text { DF }\end{array}$ & $20 / 02 / 2017$ \\
\hline $\begin{array}{l}\text { SEGUNDA } \\
\text { TURMA }\end{array}$ & HERMAN BENJAMIN & $\begin{array}{c}\text { AgInt nos EDcl no REsp } \\
1576291 / \text { PR }\end{array}$ & $07 / 03 / 2017$ \\
\hline $\begin{array}{l}\text { SEGUNDA } \\
\text { TURMA }\end{array}$ & OG FERNANDES & $\begin{array}{c}\text { AgInt no REsp } 1606719 / \\
\text { SC }\end{array}$ & $23 / 02 / 2017$ \\
\hline $\begin{array}{l}\text { SEGUNDA } \\
\text { TURMA }\end{array}$ & HERMAN BENJAMIN & REsp $1645856 /$ SP & $18 / 04 / 2017$ \\
\hline $\begin{array}{l}\text { SEGUNDA } \\
\text { TURMA }\end{array}$ & HERMAN BENJAMIN & REsp 1645223 / SP & $18 / 04 / 2017$ \\
\hline $\begin{array}{c}\text { TERCEIRA } \\
\text { TURMA }\end{array}$ & $\begin{array}{l}\text { RICARDO VILLAS BÔAS } \\
\text { CUEVA }\end{array}$ & $\begin{array}{c}\text { EDcl no REsp 1562641 / } \\
\text { SP }\end{array}$ & $24 / 03 / 2017$ \\
\hline $\begin{array}{l}\text { QUARTA } \\
\text { TURMA }\end{array}$ & RAUL ARAÚJO & $\begin{array}{l}\text { AgInt nos EDcl no } \\
\text { AREsp 449391 / PR }\end{array}$ & $22 / 03 / 2017$ \\
\hline $\begin{array}{l}\text { TERCEIRA } \\
\text { TURMA }\end{array}$ & $\begin{array}{l}\text { RICARDO VILLAS BÔAS } \\
\text { CUEVA }\end{array}$ & $\begin{array}{l}\text { AgRg no AgRg nos EDcl } \\
\text { no REsp 854158 / PR }\end{array}$ & $21 / 03 / 2017$ \\
\hline $\begin{array}{l}\text { PRIMEIRA } \\
\text { TURMA }\end{array}$ & REGINA HELENA COSTA & $\begin{array}{l}\text { AgInt no REsp } 1627683 \text { / } \\
\text { SC }\end{array}$ & $30 / 03 / 2017$ \\
\hline $\begin{array}{l}\text { QUARTA } \\
\text { TURMA }\end{array}$ & MARCO BUZZI & $\begin{array}{c}\text { AgInt no AREsp } 527706 / \\
\text { PR }\end{array}$ & $31 / 03 / 2017$ \\
\hline $\begin{array}{l}\text { QUARTA } \\
\text { TURMA }\end{array}$ & MARCO BUZZI & $\begin{array}{c}\text { AgInt no AREsp } 879069 \text { / } \\
\text { AM }\end{array}$ & $30 / 03 / 2017$ \\
\hline $\begin{array}{l}\text { TERCEIRA } \\
\text { TURMA }\end{array}$ & NANCY ANDRIGHI & REsp $1639016 /$ RJ & $04 / 04 / 2017$ \\
\hline $\begin{array}{l}\text { TERCEIRA } \\
\text { TURMA }\end{array}$ & MARCO AURÉLIO BELLIZZE & $\begin{array}{l}\text { AgInt nos EDcl no } \\
\text { AREsp } 776884 \text { / GO }\end{array}$ & $18 / 04 / 2017$ \\
\hline $\begin{array}{l}\text { SEGUNDA } \\
\text { TURMA }\end{array}$ & HERMAN BENJAMIN & REsp 1646998 / MG & $02 / 05 / 2017$ \\
\hline $\begin{array}{l}\text { SEGUNDA } \\
\text { TURMA }\end{array}$ & HERMAN BENJAMIN & REsp 1655395 / SP & 25/04/2017 \\
\hline
\end{tabular}




\begin{tabular}{|c|c|c|c|}
\hline $\begin{array}{c}\text { ÓRGÃO } \\
\text { JULGADOR }\end{array}$ & MINISTRO(A) & PROCESSO & PUBLICAÇÃO \\
\hline $\begin{array}{l}\text { SEGUNDA } \\
\text { TURMA }\end{array}$ & ASSUSETE MAGALHÃES & $\begin{array}{c}\text { AgInt no AREsp } 1000484 \\
\text { / PE }\end{array}$ & $04 / 05 / 2017$ \\
\hline $\begin{array}{l}\text { SEGUNDA } \\
\text { TURMA } \\
\end{array}$ & OG FERNANDES & $\begin{array}{l}\text { AgInt no AREsp } 1001801 \\
\text { / MG }\end{array}$ & $02 / 05 / 2017$ \\
\hline $\begin{array}{l}\text { QUARTA } \\
\text { TURMA }\end{array}$ & MARIA ISABEL GALLOTTI & $\begin{array}{c}\text { AgInt no AREsp } 492068 \text { / } \\
\text { SP }\end{array}$ & $03 / 05 / 2017$ \\
\hline $\begin{array}{l}\text { SEGUNDA } \\
\text { TURMA }\end{array}$ & HERMAN BENJAMIN & REsp 1662652 / RJ & 08/05/2017 \\
\hline $\begin{array}{l}\text { QUARTA } \\
\text { TURMA }\end{array}$ & RAUL ARAÚJO & $\begin{array}{c}\text { AgInt no REsp } 1387544 \text { / } \\
\text { AL }\end{array}$ & $19 / 05 / 2017$ \\
\hline $\begin{array}{l}\text { SEGUNDA } \\
\text { TURMA }\end{array}$ & OG FERNANDES & $\begin{array}{c}\text { AgInt no REsp } 1509165 / \\
\text { RJ }\end{array}$ & $08 / 05 / 2017$ \\
\hline $\begin{array}{l}\text { SEGUNDA } \\
\text { TURMA } \\
\end{array}$ & HERMAN BENJAMIN & REsp $1654980 / \mathrm{MG}$ & $12 / 05 / 2017$ \\
\hline $\begin{array}{l}\text { TERCEIRA } \\
\text { TURMA } \\
\end{array}$ & NANCY ANDRIGHI & REsp 1661482 / RJ & $16 / 05 / 2017$ \\
\hline $\begin{array}{l}\text { PRIMEIRA } \\
\text { TURMA }\end{array}$ & REGINA HELENA COSTA & $\begin{array}{c}\text { AgInt no REsp } 1538306 / \\
\text { PE }\end{array}$ & $11 / 05 / 2017$ \\
\hline $\begin{array}{l}\text { QUARTA } \\
\text { TURMA }\end{array}$ & LUIS FELIPE SALOMÃO & $\begin{array}{c}\text { AgInt no AREsp } 1054721 \\
\text { / MS }\end{array}$ & $17 / 05 / 2017$ \\
\hline $\begin{array}{l}\text { SEGUNDA } \\
\text { TURMA }\end{array}$ & ASSUSETE MAGALHÃES & $\begin{array}{c}\text { AgInt no AREsp } 909233 \text { / } \\
\text { PR }\end{array}$ & $23 / 05 / 2017$ \\
\hline $\begin{array}{c}\text { CORTE } \\
\text { ESPECIAL } \\
\end{array}$ & $\begin{array}{c}\text { MAURO CAMPBELL } \\
\text { MARQUES }\end{array}$ & $\begin{array}{l}\text { AgInt nos EREsp } \\
1208207 \text { / RN }\end{array}$ & $24 / 05 / 2017$ \\
\hline $\begin{array}{l}\text { PRIMEIRA } \\
\text { TURMA }\end{array}$ & SÉRGIO K & $\begin{array}{l}\text { AgInt no REsp } 1515711 / \\
\text { CE }\end{array}$ & $29 / 05 / 2017$ \\
\hline $\begin{array}{l}\text { SEGUNDA } \\
\text { TURMA }\end{array}$ & OG FERNANDES & $\begin{array}{l}\text { AgInt no REsp } 1356803 / \\
\text { SP }\end{array}$ & 29/05/2017 \\
\hline $\begin{array}{l}\text { SEGUNDA } \\
\text { TURMA } \\
\end{array}$ & HERMAN BENJAMIN & REsp 798679 / RJ & $20 / 06 / 2017$ \\
\hline $\begin{array}{l}\text { TERCEIRA } \\
\text { TURMA }\end{array}$ & MARCO AURÉLIO BELLIZZE & $\begin{array}{c}\text { AgInt no AREsp } 978024 \text { / } \\
\text { SC }\end{array}$ & $16 / 06 / 2017$ \\
\hline $\begin{array}{l}\text { QUARTA } \\
\text { TURMA }\end{array}$ & MARCO BUZZI & $\begin{array}{c}\text { AgInt no AREsp } 580725 / \\
\text { SP } \\
\end{array}$ & $22 / 06 / 2017$ \\
\hline $\begin{array}{l}\text { TERCEIRA } \\
\text { TURMA } \\
\end{array}$ & MARCO AURÉLIO BELLIZZE & $\begin{array}{c}\text { AgInt no AREsp } 1010409 \\
\text { / SP }\end{array}$ & $23 / 06 / 2017$ \\
\hline $\begin{array}{l}\text { TERCEIRA } \\
\text { TURMA }\end{array}$ & MARCO AURÉLIO BELLIZZE & REsp 1522142 / PR & $22 / 06 / 2017$ \\
\hline $\begin{array}{l}\text { PRIMEIRA } \\
\text { TURMA }\end{array}$ & $\begin{array}{c}\text { NAPOLEÃO NUNES MAIA } \\
\text { FILHO }\end{array}$ & $\begin{array}{c}\text { AgInt no AgInt no REsp } \\
1321804 \text { / PR }\end{array}$ & $03 / 08 / 2017$ \\
\hline $\begin{array}{l}\text { QUARTA } \\
\text { TURMA }\end{array}$ & RAUL ARAÚJO & $\begin{array}{c}\text { AgInt no AREsp } 1069068 \\
\text { / SP }\end{array}$ & $18 / 08 / 2017$ \\
\hline $\begin{array}{l}\text { SEGUNDA } \\
\text { TURMA } \\
\end{array}$ & OG FER & $\begin{array}{c}\text { AgInt no AREsp } 1063177 \\
\text { / SP }\end{array}$ & 017 \\
\hline $\begin{array}{l}\text { TERCEIRA } \\
\text { TURMA }\end{array}$ & $\begin{array}{l}\text { RICARDO VILLAS BÔAS } \\
\text { CUEVA }\end{array}$ & $\begin{array}{c}\text { AgInt no AREsp } 768589 / \\
\text { MG }\end{array}$ & $18 / 08 / 2017$ \\
\hline $\begin{array}{l}\text { QUARTA } \\
\text { TURMA }\end{array}$ & AÚJO & $\begin{array}{c}\text { AgInt nos EDcl no REsp } \\
1314067 / \text { PR }\end{array}$ & $14 / 08 / 2017$ \\
\hline $\begin{array}{l}\text { TERCEIRA } \\
\text { TURMA } \\
\end{array}$ & $\begin{array}{l}\text { PAULO DE TARSO } \\
\text { SANSEVERINO } \\
\end{array}$ & $\begin{array}{c}\text { AgInt no AREsp } 726996 / \\
\text { RJ }\end{array}$ & $31 / 08$ \\
\hline
\end{tabular}




\begin{tabular}{|c|c|c|c|}
\hline $\begin{array}{c}\text { ÓRGÃO } \\
\text { JULGADOR }\end{array}$ & MINISTRO(A) & PROCESSO & PUBLICAÇÃO \\
\hline $\begin{array}{l}\text { PRIMEIRA } \\
\text { TURMA }\end{array}$ & GURGEL DE FARIA & $\begin{array}{c}\text { AgInt no AREsp } 890822 \text { / } \\
\text { RJ }\end{array}$ & $04 / 10 / 2017$ \\
\hline $\begin{array}{l}\text { QUARTA } \\
\text { TURMA }\end{array}$ & MARCO BUZZI & $\begin{array}{c}\text { AgInt no AREsp } 489115 \text { / } \\
\text { SP }\end{array}$ & 29/08/2017 \\
\hline $\begin{array}{l}\text { SEGUNDA } \\
\text { TURMA }\end{array}$ & ASSUSETE MAGALHÃES & $\begin{array}{c}\text { AgRg no REsp } 1469193 / \\
\text { SC }\end{array}$ & $11 / 09 / 2017$ \\
\hline $\begin{array}{l}\text { QUARTA } \\
\text { TURMA }\end{array}$ & $\begin{array}{l}\text { ANTONIO CARLOS } \\
\text { FERREIRA }\end{array}$ & $\begin{array}{c}\text { AgInt no AREsp } 423304 \text { / } \\
\text { DF }\end{array}$ & 05/09/2017 \\
\hline $\begin{array}{l}\text { QUARTA } \\
\text { TURMA }\end{array}$ & MARIA ISABEL GALLOTTI & $\begin{array}{c}\text { AgInt no REsp } 1349336 \text { / } \\
\text { MG }\end{array}$ & 25/09/2017 \\
\hline $\begin{array}{l}\text { SEGUNDA } \\
\text { TURMA }\end{array}$ & $\begin{array}{c}\text { MAURO CAMPBELL } \\
\text { MARQUES }\end{array}$ & $\begin{array}{l}\text { AgInt no AREsp } 1074731 \\
\text { / GO }\end{array}$ & $25 / 09 / 2017$ \\
\hline $\begin{array}{l}\text { SEGUNDA } \\
\text { TURMA }\end{array}$ & ASSUSETE MAGALHÃES & $\begin{array}{c}\text { AgInt no REsp } 1217256 / \\
\text { SC }\end{array}$ & 28/09/2017 \\
\hline $\begin{array}{l}\text { QUARTA } \\
\text { TURMA }\end{array}$ & LUIS FELIPE SALOMÃO & $\begin{array}{c}\text { AgInt no AREsp } 1103681 \\
\text { / SP }\end{array}$ & $29 / 09 / 2017$ \\
\hline $\begin{array}{l}\text { QUARTA } \\
\text { TURMA }\end{array}$ & RAUL ARAÚJO & $\begin{array}{c}\text { AgInt no REsp } 1388080 \text { / } \\
\text { RJ }\end{array}$ & 20/10/2017 \\
\hline $\begin{array}{l}\text { SEGUNDA } \\
\text { TURMA }\end{array}$ & HERMAN BENJAMIN & REsp 1685852 / PE & $09 / 10 / 2017$ \\
\hline $\begin{array}{l}\text { SEGUNDA } \\
\text { TURMA }\end{array}$ & OG FERNANDES & $\begin{array}{c}\text { AgInt no REsp } 1348323 \text { / } \\
\text { PE }\end{array}$ & $28 / 09 / 2017$ \\
\hline $\begin{array}{l}\text { TERCEIRA } \\
\text { TURMA } \\
\end{array}$ & $\begin{array}{l}\text { RICARDO VILLAS BÔAS } \\
\text { CUEVA }\end{array}$ & $\begin{array}{c}\text { AgInt no REsp } 1599906 \text { / } \\
\text { MT }\end{array}$ & $10 / 10 / 2017$ \\
\hline $\begin{array}{l}\text { QUARTA } \\
\text { TURMA }\end{array}$ & MARIA ISABEL GALLOTTI & $\begin{array}{c}\text { AgInt no AREsp } 973657 \text { / } \\
\text { SP }\end{array}$ & 03/10/2017 \\
\hline $\begin{array}{l}\text { QUARTA } \\
\text { TURMA }\end{array}$ & MARIA ISABEL GALLOTTI & $\begin{array}{l}\text { AgInt nos EDcl no } \\
\text { AREsp 961376 / MS }\end{array}$ & 03/10/2017 \\
\hline $\begin{array}{l}\text { QUARTA } \\
\text { TURMA }\end{array}$ & MARCO BUZZI & $\begin{array}{c}\text { AgInt no AREsp } 906791 / \\
\text { SP }\end{array}$ & 03/10/2017 \\
\hline $\begin{array}{c}\text { SEGUNDA } \\
\text { TURMA }\end{array}$ & OG FERNANDES & $\begin{array}{c}\text { AgInt no REsp 1444911 / } \\
\text { SP }\end{array}$ & $29 / 09 / 2017$ \\
\hline $\begin{array}{l}\text { TERCEIRA } \\
\text { TURMA }\end{array}$ & $\begin{array}{l}\text { RICARDO VILLAS BÔAS } \\
\text { CUEVA }\end{array}$ & $\begin{array}{c}\text { AgInt no AgInt no AREsp } \\
1028373 / \mathrm{MG}\end{array}$ & $10 / 10 / 2017$ \\
\hline SEXTA TURMA & ROGERIO SCHIETTI CRUZ & REsp 1374938 / RS & $09 / 10 / 2017$ \\
\hline $\begin{array}{l}\text { SEGUNDA } \\
\text { TURMA }\end{array}$ & HERMAN BENJAMIN & REsp $1681089 / \mathrm{GO}$ & $17 / 10 / 2017$ \\
\hline $\begin{array}{l}\text { PRIMEIRA } \\
\text { TURMA }\end{array}$ & SÉRGIO KUKINA & $\begin{array}{c}\text { AgInt no REsp } 1308606 / \\
\text { SP }\end{array}$ & $19 / 10 / 2017$ \\
\hline $\begin{array}{c}\text { SEGUNDA } \\
\text { TURMA }\end{array}$ & HERMAN BENJAMIN & REsp 1685610 / SP & $16 / 10 / 2017$ \\
\hline $\begin{array}{c}\text { TERCEIRA } \\
\text { TURMA }\end{array}$ & $\begin{array}{c}\text { PAULO DE TARSO } \\
\text { SANSEVERINO }\end{array}$ & $\begin{array}{c}\text { AgInt no AREsp } 955407 \text { / } \\
\text { PR }\end{array}$ & $19 / 10 / 2017$ \\
\hline $\begin{array}{l}\text { SEGUNDA } \\
\text { TURMA }\end{array}$ & HERMAN BENJAMIN & REsp 1694677 / SP & $11 / 10 / 2017$ \\
\hline $\begin{array}{l}\text { SEGUNDA } \\
\text { TURMA }\end{array}$ & HERMAN BENJAMIN & REsp $1694460 / \mathrm{MG}$ & $11 / 10 / 2017$ \\
\hline $\begin{array}{l}\text { SEGUNDA } \\
\text { TURMA }\end{array}$ & HERMAN BENJAMIN & REsp 1692322 / RJ & $19 / 12 / 2017$ \\
\hline
\end{tabular}




\begin{tabular}{|c|c|c|c|}
\hline $\begin{array}{l}\text { ÓRGÃO } \\
\text { JULGADOR }\end{array}$ & MINISTRO(A) & PROCESSO & PUBLICAÇÃO \\
\hline $\begin{array}{l}\text { QUARTA } \\
\text { TURMA }\end{array}$ & $\begin{array}{l}\text { ANTONIO CARLOS } \\
\text { FERREIRA }\end{array}$ & $\begin{array}{l}\text { AgInt nos EDcl no } \\
\text { AREsp 986574 / AM }\end{array}$ & 09/10/2017 \\
\hline $\begin{array}{l}\text { SEGUNDA } \\
\text { TURMA }\end{array}$ & OG FERNANDES & $\begin{array}{c}\text { AgInt no AREsp 440450 / } \\
\text { RS }\end{array}$ & 20/10/2017 \\
\hline $\begin{array}{l}\text { SEGUNDA } \\
\text { TURMA }\end{array}$ & HERMAN BENJAMIN & $\begin{array}{c}\text { AgInt no AREsp 987196/ } \\
\text { RJ }\end{array}$ & 23/10/2017 \\
\hline $\begin{array}{l}\text { PRIMEIRA } \\
\text { TURMA }\end{array}$ & $\begin{array}{l}\text { NAPOLEÃO NUNES MAIA } \\
\text { FILHO }\end{array}$ & $\begin{array}{c}\text { AgInt no REsp } 1412645 \text { / } \\
\text { RS }\end{array}$ & $31 / 10 / 2017$ \\
\hline $\begin{array}{l}\text { TERCEIRA } \\
\text { TURMA }\end{array}$ & $\begin{array}{l}\text { PAULO DE TARSO } \\
\text { SANSEVERINO }\end{array}$ & $\begin{array}{c}\text { AgInt no REsp } 1436012 \text { / } \\
\text { MG }\end{array}$ & $13 / 11 / 2017$ \\
\hline $\begin{array}{l}\text { PRIMEIRA } \\
\text { TURMA }\end{array}$ & SÉRGIO KUKINA & \begin{tabular}{|c|} 
AgInt no REsp 1317594 / \\
MA
\end{tabular} & $21 / 11 / 2017$ \\
\hline $\begin{array}{l}\text { QUARTA } \\
\text { TURMA }\end{array}$ & $\begin{array}{l}\text { LÁZARO GUIMARÃES (DES. } \\
\text { CONV. TRF } 5^{\mathrm{a}} \text { REGIÃO) }\end{array}$ & $\begin{array}{c}\text { AgInt no REsp } 1531839 \text { / } \\
\text { DF }\end{array}$ & 2017 \\
\hline $\begin{array}{l}\text { SEGUNDA } \\
\text { TURMA }\end{array}$ & HERMAN BENJAMIN & REsp 1693611 / SP & $19 / 12 / 2017$ \\
\hline $\begin{array}{l}\text { QUARTA } \\
\text { TURMA }\end{array}$ & MARCO BUZZI & $\begin{array}{c}\text { AgInt no AgRg no AREsp } \\
345313 \text { / RS }\end{array}$ & $04 / 12 / 2017$ \\
\hline $\begin{array}{l}\text { SEGUNDA } \\
\text { TURMA }\end{array}$ & HERMAN BENJAMIN & REsp 1693656/ RJ & $19 / 12 / 2017$ \\
\hline $\begin{array}{l}\text { SEGUNDA } \\
\text { TURMA }\end{array}$ & HERMAN BENJAMIN & REsp 1701908 / SP & $19 / 12 / 2017$ \\
\hline $\begin{array}{l}\text { TERCEIRA } \\
\text { TURMA }\end{array}$ & MARCO AURÉLIO BELLIZZE & $\begin{array}{c}\text { AgInt no AREsp } 1057132 \\
\text { / SP }\end{array}$ & $15 / 12 / 2017$ \\
\hline $\begin{array}{l}\text { SEGUNDA } \\
\text { TURMA }\end{array}$ & OG FERNANDES & REsp $1512796 / \mathrm{RN}$ & $01 / 02 / 2018$ \\
\hline $\begin{array}{l}\text { QUARTA } \\
\text { TURMA }\end{array}$ & $\begin{array}{l}\text { LÁZARO GUIMARÃES (DES. } \\
\text { CONV. TRF 5 }{ }^{\mathrm{a}} \text { REGIÃO) }\end{array}$ & $\begin{array}{c}\text { AgInt no AREsp } 550641 \text { / } \\
\text { PR }\end{array}$ & $14 / 02 / 2018$ \\
\hline $\begin{array}{l}\text { TERCEIRA } \\
\text { TURMA }\end{array}$ & $\begin{array}{l}\text { RICARDO VILLAS BÔAS } \\
\text { CUEVA }\end{array}$ & REsp 1628700 / MG & $01 / 03 / 2018$ \\
\hline $\begin{array}{l}\text { TERCEIRA } \\
\text { TURMA }\end{array}$ & NANCY ANDRIGHI & $\begin{array}{c}\text { AgInt no REsp } 1551527 \text { / } \\
\text { SP }\end{array}$ & $12 / 03 / 2018$ \\
\hline $\begin{array}{l}\text { TERCEIRA } \\
\text { TURMA }\end{array}$ & NANCY ANDRIGHI & $\begin{array}{c}\text { AgInt no REsp } 1573984 \text { / } \\
\text { AL }\end{array}$ & $06 / 03 / 2018$ \\
\hline $\begin{array}{l}\text { SEGUNDA } \\
\text { TURMA }\end{array}$ & FRANCISCO FALCÃO & \begin{tabular}{|c|} 
AgInt no REsp 1628455 / \\
ES \\
\end{tabular} & $12 / 03 / 2018$ \\
\hline $\begin{array}{l}\text { QUARTA } \\
\text { TURMA }\end{array}$ & LUIS FELIPE SALOMÃO & $\begin{array}{c}\text { AgInt nos EDcl no } \\
\text { AREsp 1138645 / SP }\end{array}$ & $23 / 03 / 2018$ \\
\hline $\begin{array}{l}\text { TERCEIRA } \\
\text { TURMA }\end{array}$ & MOURA RIBEIRO & REsp 1658781 / CE & $12 / 03 / 2018$ \\
\hline $\begin{array}{l}\text { PRIMEIRA } \\
\text { TURMA }\end{array}$ & BENEDITO GONÇALVES & $\begin{array}{c}\text { AgInt no REsp } 1478367 / \\
\text { CE }\end{array}$ & $14 / 03 / 2018$ \\
\hline $\begin{array}{l}\text { QUARTA } \\
\text { TURMA }\end{array}$ & MARIA ISABEL GALLOTTI & $\begin{array}{c}\text { AgInt no AREsp } 970294 \text { / } \\
\text { SP }\end{array}$ & $12 / 03 / 2018$ \\
\hline $\begin{array}{l}\text { TERCEIRA } \\
\text { TURMA }\end{array}$ & NANCY ANDRIGHI & REsp 1641167 / RS & 20/03/2018 \\
\hline $\begin{array}{l}\text { TERCEIRA } \\
\text { TURMA }\end{array}$ & NANCY ANDRIGHI & $\begin{array}{c}\text { AgInt no AREsp } 1059679 \\
\text { / MG }\end{array}$ & $15 / 03 / 2018$ \\
\hline $\begin{array}{l}\text { QUARTA } \\
\text { TURMA }\end{array}$ & MARCO BUZZI & $\begin{array}{c}\text { AgInt no AREsp } 949752 / \\
\text { SP }\end{array}$ & $23 / 03 / 2018$ \\
\hline
\end{tabular}




\begin{tabular}{|c|c|c|c|}
\hline $\begin{array}{c}\text { ÓRGÃO } \\
\text { JULGADOR }\end{array}$ & MINISTRO(A) & PROCESSO & PUBLICAÇÃO \\
\hline $\begin{array}{l}\text { TERCEIRA } \\
\text { TURMA }\end{array}$ & $\begin{array}{l}\text { RICARDO VILLAS BÔAS } \\
\text { CUEVA }\end{array}$ & $\begin{array}{c}\text { AgInt no AREsp } 1172051 \\
\text { / SP }\end{array}$ & $23 / 03 / 2018$ \\
\hline $\begin{array}{l}\text { PRIMEIRA } \\
\text { TURMA }\end{array}$ & BENEDITO GONÇALVES & $\begin{array}{c}\text { AgInt no RMS } 43692 \text { / } \\
\text { GO }\end{array}$ & 03/04/2018 \\
\hline $\begin{array}{l}\text { QUARTA } \\
\text { TURMA }\end{array}$ & LUIS FELIPE SALOMÃO & $\begin{array}{c}\text { AgInt no AREsp } 1179037 \\
\text { / SP }\end{array}$ & $02 / 04 / 2018$ \\
\hline $\begin{array}{l}\text { SEGUNDA } \\
\text { TURMA }\end{array}$ & ASSUSETE MAGALHÃES & $\begin{array}{c}\text { AgInt nos EDcl no REsp } \\
1546432 \text { / SC } \\
\end{array}$ & $10 / 04 / 2018$ \\
\hline $\begin{array}{l}\text { SEGUNDA } \\
\text { TURMA }\end{array}$ & ASSUSETE MAGALHÃES & $\begin{array}{l}\text { AgInt no AREsp } 1102353 \\
\text { / MG }\end{array}$ & $17 / 04 / 2018$ \\
\hline $\begin{array}{l}\text { QUARTA } \\
\text { TURMA }\end{array}$ & MARCO BUZZI & $\begin{array}{c}\text { AgInt no AREsp } 215269 / \\
\text { ES }\end{array}$ & $16 / 04 / 2018$ \\
\hline $\begin{array}{l}\text { TERCEIRA } \\
\text { TURMA }\end{array}$ & MARCO AURÉLIO BELLIZZE & $\begin{array}{c}\text { AgInt no AREsp } 1178143 \\
\text { / SP }\end{array}$ & $17 / 04 / 2018$ \\
\hline $\begin{array}{l}\text { SEGUNDA } \\
\text { TURMA }\end{array}$ & HERMAN BENJAMIN & REsp 1725359 / SP & $23 / 05 / 2018$ \\
\hline $\begin{array}{l}\text { QUARTA } \\
\text { TURMA }\end{array}$ & LUIS FELIPE SALOMÃO & $\begin{array}{c}\text { AgInt no AREsp } 1233122 \\
\text { / SP }\end{array}$ & $02 / 05 / 2018$ \\
\hline $\begin{array}{l}\text { QUARTA } \\
\text { TURMA }\end{array}$ & $\begin{array}{c}\text { LÁZARO GUIMARÃES (DES. } \\
\text { CONV. TRF 5 }{ }^{\mathrm{a}} \text { REGIÃO) }\end{array}$ & $\begin{array}{c}\text { AgInt no AREsp } 667492 \text { / } \\
\text { MS }\end{array}$ & $30 / 04 / 2018$ \\
\hline $\begin{array}{l}\text { TERCEIRA } \\
\text { TURMA }\end{array}$ & NANCY ANDRIGHI & $\begin{array}{c}\text { AgInt no AREsp } 1063814 \\
\text { / SC }\end{array}$ & $02 / 05 / 2018$ \\
\hline $\begin{array}{l}\text { SEGUNDA } \\
\text { TURMA }\end{array}$ & OG FERNANDES & $\begin{array}{c}\text { AgInt no REsp } 1684284 \text { / } \\
\text { PR } \\
\end{array}$ & $09 / 05 / 2018$ \\
\hline $\begin{array}{l}\text { QUARTA } \\
\text { TURMA }\end{array}$ & LUIS FELIPE SALOMÃO & $\begin{array}{c}\text { AgInt no AREsp 930171 / } \\
\text { MG }\end{array}$ & $14 / 05 / 2018$ \\
\hline $\begin{array}{l}\text { TERCEIRA } \\
\text { TURMA }\end{array}$ & $\begin{array}{l}\text { PAULO DE TARSO } \\
\text { SANSEVERINO }\end{array}$ & $\begin{array}{c}\text { AgInt no AREsp 987491 / } \\
\text { SP }\end{array}$ & $14 / 05 / 2018$ \\
\hline $\begin{array}{l}\text { PRIMEIRA } \\
\text { TURMA }\end{array}$ & GURGEL DE FARIA & $\begin{array}{c}\text { AgInt no AREsp } 332844 \text { / } \\
\text { RS }\end{array}$ & 06/08/2018 \\
\hline $\begin{array}{l}\text { SEGUNDA } \\
\text { TURMA }\end{array}$ & OG FERNANDES & REsp $1134456 /$ TO & $13 / 06 / 2018$ \\
\hline $\begin{array}{l}\text { QUARTA } \\
\text { TURMA }\end{array}$ & LUIS FELIPE SALOMÃO & $\begin{array}{c}\text { AgInt no AREsp } 1152145 \\
\text { / DF }\end{array}$ & $13 / 06 / 2018$ \\
\hline $\begin{array}{l}\text { PRIMEIRA } \\
\text { TURMA }\end{array}$ & REGINA HELENA COSTA & $\begin{array}{c}\text { AgInt no REsp 1705251 / } \\
\text { SP }\end{array}$ & $14 / 06 / 2018$ \\
\hline $\begin{array}{l}\text { TERCEIRA } \\
\text { TURMA } \\
\end{array}$ & $\begin{array}{c}\text { RICARDO VILLAS BÔAS } \\
\text { CUEVA }\end{array}$ & $\begin{array}{c}\text { AgInt no AREsp } 178910 / \\
\text { MG }\end{array}$ & $25 / 06 / 2018$ \\
\hline $\begin{array}{l}\text { SEGUNDA } \\
\text { TURMA }\end{array}$ & ASSUSETE MAGALHÃES & $\begin{array}{c}\text { AgInt no AREsp } 1091420 \\
\text { / MG }\end{array}$ & $27 / 06 / 2018$ \\
\hline $\begin{array}{l}\text { PRIMEIRA } \\
\text { TURMA }\end{array}$ & BENEDITO GONÇALVES & $\begin{array}{c}\text { AgInt no REsp } 1576108 \text { / } \\
\text { DF }\end{array}$ & $10 / 08 / 2018$ \\
\hline $\begin{array}{l}\text { TERCEIRA } \\
\text { TURMA }\end{array}$ & MARCO AURÉLIO BELLIZZE & $\begin{array}{c}\text { AgInt no AREsp } 1263748 \\
\text { / MG }\end{array}$ & $13 / 08 / 2018$ \\
\hline $\begin{array}{l}\text { SEGUNDA } \\
\text { TURMA }\end{array}$ & FRANCISCO FALCÃO & $\begin{array}{c}\text { AgInt no REsp } 1589708 \text { / } \\
\text { SP }\end{array}$ & $14 / 08 / 2018$ \\
\hline $\begin{array}{l}\text { QUARTA } \\
\text { TURMA }\end{array}$ & LUIS FELIPE SALOMÃO & $\begin{array}{c}\text { AgInt no REsp } 1333200 \text { / } \\
\text { MS }\end{array}$ & $21 / 08 / 2018$ \\
\hline $\begin{array}{l}\text { SEGUNDA } \\
\text { TURMA }\end{array}$ & ASSUSETE MAGALHÃES & $\begin{array}{c}\text { AgInt no AREsp } 734824 \text { / } \\
\text { DF }\end{array}$ & $21 / 08 / 2018$ \\
\hline
\end{tabular}




\begin{tabular}{|c|c|c|c|}
\hline $\begin{array}{l}\text { ÓRGÃO } \\
\text { JULGADOR }\end{array}$ & MINISTRO(A) & PROCESSO & PUBLICAÇÃO \\
\hline $\begin{array}{l}\text { PRIMEIRA } \\
\text { TURMA }\end{array}$ & $\begin{array}{c}\text { NAPOLEÃO NUNES MAIA } \\
\text { FILHO } \\
\end{array}$ & $\begin{array}{c}\text { AgInt no REsp } 1326499 / \\
\text { SP } \\
\end{array}$ & $28 / 08 / 2018$ \\
\hline $\begin{array}{l}\text { TERCEIRA } \\
\text { TURMA }\end{array}$ & MARCO AURÉLIO BELLIZZE & $\begin{array}{c}\text { AgInt no REsp } 1741173 / \\
\text { CE }\end{array}$ & $03 / 09 / 2018$ \\
\hline $\begin{array}{l}\text { TERCEIRA } \\
\text { SEÇÃO } \\
\end{array}$ & JORGE MUSSI & AR 4152 / SP & 03/09/2018 \\
\hline $\begin{array}{l}\text { PRIMEIRA } \\
\text { TURMA }\end{array}$ & GURGEL DE FARIA & $\begin{array}{c}\text { AgInt no REsp } 1327487 / \\
\text { GO }\end{array}$ & $19 / 09 / 2018$ \\
\hline $\begin{array}{l}\text { QUARTA } \\
\text { TURMA }\end{array}$ & $\begin{array}{l}\text { ANTONIO CARLOS } \\
\text { FERREIRA }\end{array}$ & $\begin{array}{c}\text { AgInt no REsp } 1581691 / \\
\text { RS }\end{array}$ & $12 / 09 / 2018$ \\
\hline $\begin{array}{l}\text { PRIMEIRA } \\
\text { TURMA }\end{array}$ & GURGEL DE FARIA & RMS 52463 / RJ & $13 / 09 / 2018$ \\
\hline $\begin{array}{c}\text { SEGUNDA } \\
\text { TURMA }\end{array}$ & HERMAN BENJAMIN & REsp 1760160 / RJ & $21 / 11 / 2018$ \\
\hline $\begin{array}{c}\text { TERCEIRA } \\
\text { TURMA } \\
\end{array}$ & MARCO AURÉLIO BELLIZZE & REsp 1328457 / RS & $17 / 09 / 2018$ \\
\hline $\begin{array}{l}\text { QUARTA } \\
\text { TURMA }\end{array}$ & MARIA ISABEL GALLOTTI & $\begin{array}{c}\text { AgInt no AREsp } 1201898 \\
\text { / SP }\end{array}$ & $25 / 09 / 2018$ \\
\hline $\begin{array}{l}\text { PRIMEIRA } \\
\text { TURMA }\end{array}$ & SÉRGIO KUKINA & $\begin{array}{c}\text { AgInt no AREsp } 1292976 \\
\text { / RJ }\end{array}$ & $24 / 09 / 2018$ \\
\hline $\begin{array}{l}\text { QUARTA } \\
\text { TURMA }\end{array}$ & $\begin{array}{c}\text { LÁZARO GUIMARÃES (DES. } \\
\text { CONV. TRF 5 5 REGIÃO) }\end{array}$ & $\begin{array}{c}\text { AgInt no REsp } 1540423 \text { / } \\
\text { DF }\end{array}$ & $24 / 09 / 2018$ \\
\hline $\begin{array}{l}\text { SEGUNDA } \\
\text { TURMA }\end{array}$ & $\begin{array}{c}\text { MAURO CAMPBELL } \\
\text { MARQUES }\end{array}$ & $\begin{array}{c}\text { AgInt no AREsp } 1334513 \\
\text { / GO }\end{array}$ & $24 / 10 / 2018$ \\
\hline $\begin{array}{l}\text { TERCEIRA } \\
\text { TURMA }\end{array}$ & MARCO AURÉLIO BELLIZZE & $\begin{array}{c}\text { AgInt no AREsp } 1146033 \\
\text { / RS }\end{array}$ & $19 / 10 / 2018$ \\
\hline $\begin{array}{c}\text { TERCEIRA } \\
\text { TURMA } \\
\end{array}$ & MOURA RIBEIRO & $\begin{array}{c}\text { AgInt no AREsp } 1159975 \\
\text { / SP }\end{array}$ & $25 / 10 / 2018$ \\
\hline $\begin{array}{l}\text { SEGUNDA } \\
\text { TURMA }\end{array}$ & ASSUSETE MAGALHÃES & $\begin{array}{c}\text { AgInt no REsp } 1352245 / \\
\text { MS }\end{array}$ & $26 / 10 / 2018$ \\
\hline $\begin{array}{l}\text { SEGUNDA } \\
\text { TURMA }\end{array}$ & ASSUSETE MAGALHÃES & $\begin{array}{c}\text { AgInt no AREsp } 792207 / \\
\text { PR }\end{array}$ & $26 / 10 / 2018$ \\
\hline $\begin{array}{l}\text { TERCEIRA } \\
\text { TURMA }\end{array}$ & NANCY ANDRIGHI & REsp 1741681 / RJ & $26 / 10 / 2018$ \\
\hline $\begin{array}{l}\text { QUARTA } \\
\text { TURMA }\end{array}$ & RAUL ARAÚJO & $\begin{array}{c}\text { AgInt no AREsp } 1311104 \\
\text { / MS }\end{array}$ & $23 / 11 / 2018$ \\
\hline
\end{tabular}


ANEXO B - OUTRAS DECISÕES FAVORÁVEIS À INTERPRETAÇÃO DO PEDIDO

\begin{tabular}{|c|c|c|c|}
\hline $\begin{array}{l}\text { ÓRGÃO } \\
\text { JULGADOR }\end{array}$ & MINISTRO(A) & PROCESSO & PUBLICAÇÃO \\
\hline $\begin{array}{l}\text { PRIMEIRA } \\
\text { TURMA }\end{array}$ & MILTON LUIZ PEREIRA & REsp 40229 / SP & $23 / 05 / 1994$ \\
\hline $\begin{array}{l}\text { SEGUNDA } \\
\text { TURMA }\end{array}$ & ARI PARGENDLER & REsp 68668 / SP & 04/03/1996 \\
\hline $\begin{array}{l}\text { QUARTA } \\
\text { TURMA }\end{array}$ & BARROS MONTEIRO & REsp 39498 / MS & $11 / 11 / 1996$ \\
\hline $\begin{array}{l}\text { SEGUNDA } \\
\text { TURMA }\end{array}$ & $\begin{array}{l}\text { ANTÔNIO DE PÁDUA } \\
\text { RIBEIRO }\end{array}$ & REsp 88642 / DF & $17 / 03 / 1997$ \\
\hline $\begin{array}{l}\text { QUINTA } \\
\text { TURMA }\end{array}$ & EDSON VIDIGAL & EDcl no REsp 61340 / SP & 03/08/1998 \\
\hline SEXTA TURMA & FERNANDO GONÇALVES & REsp 177972 / SP & 28/09/1998 \\
\hline $\begin{array}{l}\text { TERCEIRA } \\
\text { TURMA }\end{array}$ & ARI PARGENDLER & REsp 188622 / BA & $26 / 06 / 2000$ \\
\hline $\begin{array}{l}\text { PRIMEIRA } \\
\text { TURMA } \\
\end{array}$ & $\begin{array}{l}\text { HUMBERTO GOMES DE } \\
\text { BARROS } \\
\end{array}$ & REsp 253344 / RJ & $05 / 06 / 2000$ \\
\hline SEXTA TURMA & FERNANDO GONÇALVES & REsp 406460 / SP & $01 / 07 / 2002$ \\
\hline $\begin{array}{l}\text { PRIMEIRA } \\
\text { TURMA }\end{array}$ & LUIZ FUX & REsp 434283 / RS & $05 / 05 / 2003$ \\
\hline $\begin{array}{l}\text { PRIMEIRA } \\
\text { TURMA }\end{array}$ & LUIZ FUX & REsp 625329 / RJ & $23 / 08 / 2004$ \\
\hline $\begin{array}{l}\text { TERCEIRA } \\
\text { TURMA }\end{array}$ & NANCY ANDRIGHI & REsp 590385 / RS & $05 / 09 / 2005$ \\
\hline $\begin{array}{l}\text { PRIMEIRA } \\
\text { TURMA } \\
\end{array}$ & LUIZ FUX & REsp 612123 / SP & $29 / 08 / 2005$ \\
\hline $\begin{array}{l}\text { QUINTA } \\
\text { TURMA }\end{array}$ & ARNALDO ESTEVES LIMA & REsp 636438 / RS & $05 / 12 / 2005$ \\
\hline $\begin{array}{l}\text { TERCEIRA } \\
\text { TURMA }\end{array}$ & $\begin{array}{c}\text { HUMBERTO GOMES DE } \\
\text { BARROS } \\
\end{array}$ & REsp 234396 / BA & $14 / 11 / 2005$ \\
\hline $\begin{array}{l}\text { QUINTA } \\
\text { TURMA }\end{array}$ & LAURITA VAZ & RMS $11222 /$ MG & $06 / 02 / 2006$ \\
\hline $\begin{array}{l}\text { SEGUNDA } \\
\text { TURMA }\end{array}$ & ELIANA CALMON & REsp 705620 / MG & $09 / 05 / 2006$ \\
\hline $\begin{array}{l}\text { TERCEIRA } \\
\text { TURMA }\end{array}$ & CASTRO FILHO & REsp 515692 / PR & $19 / 06 / 2006$ \\
\hline $\begin{array}{l}\text { QUARTA } \\
\text { TURMA }\end{array}$ & ALDIR PASSARINHO JUNIOR & REsp 241005 / SP & $26 / 06 / 2006$ \\
\hline $\begin{array}{l}\text { PRIMEIRA } \\
\text { TURMA }\end{array}$ & LUIZ FUX & REsp 814076 / RJ & $01 / 08 / 2006$ \\
\hline $\begin{array}{l}\text { QUINTA } \\
\text { TURMA }\end{array}$ & ARNALDO ESTEVES LIMA & REsp 541553 / MG & $11 / 12 / 2006$ \\
\hline $\begin{array}{l}\text { QUARTA } \\
\text { TURMA }\end{array}$ & ALDIR PASSARINHO JUNIOR & REsp 779805 / DF & $12 / 02 / 2007$ \\
\hline $\begin{array}{l}\text { PRIMEIRA } \\
\text { TURMA } \\
\end{array}$ & DENISE ARRUDA & REsp 644995 / SP & $31 / 05 / 2007$ \\
\hline $\begin{array}{l}\text { QUINTA } \\
\text { TURMA }\end{array}$ & ARNALDO ESTEVES LIMA & REsp 884917 / PR & $14 / 05 / 2007$ \\
\hline
\end{tabular}




\begin{tabular}{|c|c|c|c|}
\hline $\begin{array}{c}\text { ÓRGÃO } \\
\text { JULGADOR }\end{array}$ & MINISTRO(A) & PROCESSO & PUBLICAÇÃO \\
\hline $\begin{array}{l}\text { QUARTA } \\
\text { TURMA }\end{array}$ & ALDIR PASSARINHO JUNIOR & $\begin{array}{c}\text { AgRg nos EDcl no Ag } \\
803835 \text { / SC }\end{array}$ & $06 / 08 / 2007$ \\
\hline $\begin{array}{c}\text { TERCEIRA } \\
\text { TURMA }\end{array}$ & ARI PARGENDLER & REsp 931659 / RJ & $18 / 06 / 2007$ \\
\hline $\begin{array}{c}\text { TERCEIRA } \\
\text { TURMA }\end{array}$ & NANCY ANDRIGHI & REsp 866230 / RS & $29 / 06 / 2007$ \\
\hline $\begin{array}{c}\text { SEGUNDA } \\
\text { TURMA }\end{array}$ & JOÃO OTÁVIO DE NORONHA & REsp 488931 / SP & $23 / 11 / 2007$ \\
\hline $\begin{array}{l}\text { TERCEIRA } \\
\text { TURMA }\end{array}$ & $\begin{array}{c}\text { HUMBERTO GOMES DE } \\
\text { BARROS }\end{array}$ & $\begin{array}{c}\text { AgRg nos EDcl no Ag } \\
676841 / \text { PR }\end{array}$ & $26 / 11 / 2007$ \\
\hline $\begin{array}{l}\text { QUINTA } \\
\text { TURMA }\end{array}$ & LAURITA VAZ & REsp 653127 / PR & $03 / 03 / 2008$ \\
\hline $\begin{array}{c}\text { TERCEIRA } \\
\text { TURMA }\end{array}$ & $\begin{array}{c}\text { HUMBERTO GOMES DE } \\
\text { BARROS }\end{array}$ & REsp 904815 / SP & $13 / 05 / 2008$ \\
\hline $\begin{array}{l}\text { PRIMEIRA } \\
\text { TURMA }\end{array}$ & LUIZ FUX & REsp 890183 / SP & $14 / 05 / 2008$ \\
\hline $\begin{array}{l}\text { TERCEIRA } \\
\text { SEÇÃO }\end{array}$ & ARNALDO ESTEVES LIMA & MS 12765 / DF & $04 / 02 / 2009$ \\
\hline $\begin{array}{c}\text { TERCEIRA } \\
\text { TURMA }\end{array}$ & MASSAMI UYEDA & $\begin{array}{c}\text { AgRg no Ag } 1133817 / \\
\text { SP }\end{array}$ & $12 / 06 / 2009$ \\
\hline $\begin{array}{c}\text { SEGUNDA } \\
\text { TURMA }\end{array}$ & HERMAN BENJAMIN & REsp 900380 / RS & 08/09/2009 \\
\hline $\begin{array}{l}\text { PRIMEIRA } \\
\text { SEÇÃO } \\
\end{array}$ & CASTRO MEIRA & AR 3697 / RS & $01 / 02 / 2010$ \\
\hline $\begin{array}{l}\text { SEGUNDA } \\
\text { SEÇÃO }\end{array}$ & SIDNEI BENETI & AgRg na AR 4190 / RJ & $25 / 10 / 2011$ \\
\hline $\begin{array}{c}\text { PRIMEIRA } \\
\text { SEÇÃO }\end{array}$ & LUIZ FUX & Rcl $4421 / D F$ & $15 / 04 / 2011$ \\
\hline $\begin{array}{l}\text { CORTE } \\
\text { ESPECIAL }\end{array}$ & CASTRO MEIRA & $\begin{array}{c}\text { AgRg nos EREsp } 625349 \\
\text { / RJ }\end{array}$ & $01 / 02 / 2012$ \\
\hline $\begin{array}{l}\text { QUARTA } \\
\text { TURMA }\end{array}$ & MARCO BUZZI & $\begin{array}{c}\text { AgRg no AREsp } 175655 / \\
\text { SP }\end{array}$ & $04 / 09 / 2012$ \\
\hline $\begin{array}{l}\text { SEGUNDA } \\
\text { TURMA }\end{array}$ & $\begin{array}{c}\text { MAURO CAMPBELL } \\
\text { MARQUES }\end{array}$ & REsp 1250147 / PR & $08 / 02 / 2013$ \\
\hline $\begin{array}{l}\text { SEGUNDA } \\
\text { TURMA }\end{array}$ & CASTRO MEIRA & $\begin{array}{c}\text { AgRg no REsp } 1322447 \text { / } \\
\text { RJ }\end{array}$ & $25 / 03 / 2013$ \\
\hline $\begin{array}{l}\text { QUARTA } \\
\text { TURMA }\end{array}$ & LUIS FELIPE SALOMÃO & $\begin{array}{c}\text { AgRg no AREsp } 243946 / \\
\text { SC }\end{array}$ & $18 / 04 / 2013$ \\
\hline $\begin{array}{c}\text { TERCEIRA } \\
\text { TURMA }\end{array}$ & $\begin{array}{c}\text { RICARDO VILLAS BÔAS } \\
\text { CUEVA }\end{array}$ & $\begin{array}{c}\text { AgRg no AREsp 65749/ } \\
\text { DF }\end{array}$ & $26 / 06 / 2013$ \\
\hline $\begin{array}{l}\text { TERCEIRA } \\
\text { TURMA }\end{array}$ & SIDNEI BENETI & $\begin{array}{c}\text { AgRg no AREsp } 382483 / \\
\text { TO }\end{array}$ & $09 / 12 / 2013$ \\
\hline $\begin{array}{l}\text { QUARTA } \\
\text { TURMA }\end{array}$ & MARCO BUZZI & $\begin{array}{c}\text { AgRg no REsp } 1102051 / \\
\text { PR }\end{array}$ & $04 / 02 / 2014$ \\
\hline $\begin{array}{c}\text { SEGUNDA } \\
\text { TURMA }\end{array}$ & HUMBERTO MARTINS & \begin{tabular}{|c} 
AgRg no REsp $1426220 /$ \\
RJ
\end{tabular} & $15 / 05 / 2014$ \\
\hline $\begin{array}{l}\text { SEGUNDA } \\
\text { TURMA }\end{array}$ & HERMAN BENJAMIN & $\begin{array}{c}\text { AgRg no AREsp } 478465 \text { / } \\
\text { RS }\end{array}$ & $23 / 05 / 2014$ \\
\hline $\begin{array}{c}\text { SEGUNDA } \\
\text { TURMA }\end{array}$ & HERMAN BENJAMIN & $\begin{array}{c}\text { AgRg no REsp } 1511290 / \\
\text { PE }\end{array}$ & $30 / 06 / 2015$ \\
\hline
\end{tabular}




\begin{tabular}{|c|c|c|c|}
\hline $\begin{array}{l}\text { ORGAOO } \\
\text { JULGADOR }\end{array}$ & MINISTRO(A) & PROCESSO & PUBLICAÇÃO \\
\hline $\begin{array}{l}\text { TERCEIRA } \\
\text { TURMA }\end{array}$ & $\begin{array}{l}\text { RICARDO VILLAS BÔAS } \\
\text { CUEVA }\end{array}$ & $\begin{array}{c}\text { AgRg no AREsp } 188365 \text { / } \\
\text { PE }\end{array}$ & $04 / 08 / 2015$ \\
\hline $\begin{array}{l}\text { SEGUNDA } \\
\text { TURMA }\end{array}$ & HERMAN BENJAMIN & $\begin{array}{c}\text { AgRg no REsp } 1553565 / \\
\text { DF }\end{array}$ & $05 / 02 / 2016$ \\
\hline $\begin{array}{l}\text { SEGUNDA } \\
\text { TURMA }\end{array}$ & HERMAN BENJAMIN & REsp 1568353 / SP & $05 / 02 / 2016$ \\
\hline $\begin{array}{l}\text { TERCEIRA } \\
\text { TURMA }\end{array}$ & JOÃO OTÁVIO DE NORONHA & REsp 1513259 / MS & $22 / 02 / 2016$ \\
\hline $\begin{array}{l}\text { TERCEIRA } \\
\text { TURMA }\end{array}$ & MOURA RIBEIRO & $\begin{array}{c}\text { AgRg no AREsp } 699388 \text { / } \\
\text { SP }\end{array}$ & $01 / 07 / 2016$ \\
\hline $\begin{array}{l}\text { SEGUNDA } \\
\text { TURMA }\end{array}$ & HERMAN BENJAMIN & $\begin{array}{c}\text { AgInt no REsp } 1601655 \text { / } \\
\text { RS }\end{array}$ & $17 / 10 / 2016$ \\
\hline $\begin{array}{l}\text { TERCEIRA } \\
\text { TURMA }\end{array}$ & $\begin{array}{l}\text { RICARDO VILLAS BÔAS } \\
\text { CUEVA }\end{array}$ & $\begin{array}{c}\text { EDcl no REsp } 1606781 / \\
\text { RJ }\end{array}$ & $02 / 02 / 2017$ \\
\hline $\begin{array}{l}\text { TERCEIRA } \\
\text { TURMA }\end{array}$ & NANCY ANDRIGHI & REsp 1342640 / SP & $14 / 02 / 2017$ \\
\hline $\begin{array}{l}\text { TERCEIRA } \\
\text { TURMA } \\
\end{array}$ & MARCO AURÉLIO BELLIZZE & $\begin{array}{c}\text { AgInt no REsp } 1653721 \text { / } \\
\text { RS }\end{array}$ & $02 / 08 / 2017$ \\
\hline $\begin{array}{l}\text { TERCEIRA } \\
\text { TURMA }\end{array}$ & $\begin{array}{l}\text { RICARDO VILLAS BÔAS } \\
\text { CUEVA }\end{array}$ & $\begin{array}{c}\text { AgInt no REsp } 1584566 \text { / } \\
\text { RS }\end{array}$ & $04 / 12 / 2017$ \\
\hline $\begin{array}{l}\text { PRIMEIRA } \\
\text { TURMA }\end{array}$ & GURGEL DE FARIA & REsp $1442440 /$ AC & $15 / 02 / 2018$ \\
\hline $\begin{array}{c}\text { CORTE } \\
\text { ESPECIAL }\end{array}$ & FRANCISCO FALCÃO & $\begin{array}{c}\text { AgInt nos EREsp } \\
1593663 \text { / DF }\end{array}$ & $17 / 04 / 2018$ \\
\hline
\end{tabular}




\section{ANEXO C - DECISÕES FAVORÁVEIS À INTERPRETAÇÃo RESTRITIVA DO PEDIDO}

\begin{tabular}{|c|c|c|c|}
\hline $\begin{array}{l}\text { ÓRGÃO } \\
\text { JULGADOR }\end{array}$ & MINISTRO(A) & PROCESSO & PUBLICAÇÃO \\
\hline $\begin{array}{l}\text { TERCEIRA } \\
\text { TURMA }\end{array}$ & WALDEMAR ZVEITER & REsp 4447 / RS & $17 / 12 / 1990$ \\
\hline $\begin{array}{l}\text { SEGUNDA } \\
\text { TURMA }\end{array}$ & PEÇANHA MARTINS & REsp 18455 / SP & $25 / 10 / 1993$ \\
\hline $\begin{array}{l}\text { PRIMEIRA } \\
\text { TURMA } \\
\end{array}$ & CESAR ASFOR ROCHA & REsp 6716 / MG & $13 / 12 / 1993$ \\
\hline SEXTA TURMA & ADHEMAR MACIEL & REsp 73644 / SP & $11 / 03 / 1996$ \\
\hline $\begin{array}{l}\text { PRIMEIRA } \\
\text { SEÇÃO }\end{array}$ & JOSÉ DELGADO & AgRg no MS 5343 / DF & 06/04/1998 \\
\hline $\begin{array}{l}\text { PRIMEIRA } \\
\text { TURMA }\end{array}$ & JOSÉ DELGADO & REsp 155326/ AL & $06 / 04 / 1998$ \\
\hline $\begin{array}{l}\text { QUARTA } \\
\text { TURMA }\end{array}$ & $\begin{array}{c}\text { SÁLVIO DE FIGUEIREDO } \\
\text { TEIXEIRA }\end{array}$ & REsp 89701 / MG & $22 / 06 / 1998$ \\
\hline $\begin{array}{l}\text { PRIMEIRA } \\
\text { SEÇÃO }\end{array}$ & JOSÉ DELGADO & AgRg no MS 5341 / DF & $17 / 08 / 1998$ \\
\hline $\begin{array}{l}\text { PRIMEIRA } \\
\text { SEÇÃO }\end{array}$ & JOSÉ DELGADO & $\begin{array}{c}\text { EDcl no AgRg no MS } \\
5343 \text { / DF }\end{array}$ & 17/08/1998 \\
\hline $\begin{array}{l}\text { QUARTA } \\
\text { TURMA }\end{array}$ & $\begin{array}{c}\text { SÁLVIO DE FIGUEIREDO } \\
\text { TEIXEIRA }\end{array}$ & REsp 147833 / DF & $21 / 09 / 1998$ \\
\hline $\begin{array}{l}\text { TERCEIRA } \\
\text { TURMA } \\
\end{array}$ & $\begin{array}{l}\text { CARLOS ALBERTO } \\
\text { MENEZES DIREITO }\end{array}$ & REsp 52841 / SP & $08 / 03 / 1999$ \\
\hline $\begin{array}{l}\text { QUARTA } \\
\text { TURMA }\end{array}$ & BARROS MONTEIRO & REsp 59418 / CE & 29/11/1999 \\
\hline $\begin{array}{l}\text { TERCEIRA } \\
\text { TURMA }\end{array}$ & NANCY ANDRIGHI & REsp 301706 / SP & $25 / 06 / 2001$ \\
\hline SEXTA TURMA & FERNANDO GONÇALVES & REsp 285472 / SP & $05 / 11 / 2001$ \\
\hline $\begin{array}{l}\text { TERCEIRA } \\
\text { TURMA }\end{array}$ & CASTRO FILHO & $\begin{array}{c}\mathrm{AgRg} \text { no } \mathrm{AgRg} \text { no } \mathrm{Ag} \\
304720 / \mathrm{SP}\end{array}$ & $03 / 06 / 2002$ \\
\hline $\begin{array}{l}\text { SEGUNDA } \\
\text { TURMA }\end{array}$ & $\begin{array}{l}\text { FRANCISCO PEÇANHA } \\
\text { MARTINS }\end{array}$ & REsp 189274 / SC & $12 / 08 / 2002$ \\
\hline $\begin{array}{l}\text { QUARTA } \\
\text { TURMA }\end{array}$ & BARROS MONTEIRO & AgRg no Ag 303387 / SP & $26 / 08 / 2002$ \\
\hline $\begin{array}{l}\text { QUINTA } \\
\text { TURMA }\end{array}$ & JORGE SCARTEZZINI & REsp 407160 / AM & $11 / 11 / 2002$ \\
\hline $\begin{array}{l}\text { QUARTA } \\
\text { TURMA }\end{array}$ & $\begin{array}{c}\text { SÁLVIO DE FIGUEIREDO } \\
\text { TEIXEIRA }\end{array}$ & REsp 306353 / PR & $07 / 04 / 2003$ \\
\hline $\begin{array}{l}\text { PRIMEIRA } \\
\text { SEÇÃO }\end{array}$ & $\begin{array}{l}\text { HUMBERTO GOMES DE } \\
\text { BARROS }\end{array}$ & MS 8946 / DF & $17 / 11 / 2003$ \\
\hline $\begin{array}{l}\text { QUINTA } \\
\text { TURMA }\end{array}$ & FELIX FISCHER & REsp 549587 / PE & $10 / 05 / 2004$ \\
\hline $\begin{array}{l}\text { QUARTA } \\
\text { TURMA }\end{array}$ & FERNANDO GONÇALVES & REsp 280183 / SP & $23 / 08 / 2004$ \\
\hline $\begin{array}{l}\text { TERCEIRA } \\
\text { TURMA } \\
\end{array}$ & $\begin{array}{c}\text { HUMBERTO GOMES DE } \\
\text { BARROS }\end{array}$ & REsp 246830 / SP & $14 / 03 / 2005$ \\
\hline $\begin{array}{l}\text { PRIMEIRA } \\
\text { TURMA }\end{array}$ & JOSÉ DELGADO & REsp 705631 / MS & $04 / 04 / 2005$ \\
\hline
\end{tabular}




\begin{tabular}{|c|c|c|c|}
\hline $\begin{array}{c}\text { ÓRGÃO } \\
\text { JULGADOR }\end{array}$ & MINISTRO(A) & PROCESSO & PUBLICAÇÃO \\
\hline $\begin{array}{l}\text { TERCEIRA } \\
\text { TURMA }\end{array}$ & $\begin{array}{c}\text { ANTÔNIO DE PÁDUA } \\
\text { RIBEIRO }\end{array}$ & REsp 222644 / RS & $13 / 06 / 2005$ \\
\hline $\begin{array}{l}\text { PRIMEIRA } \\
\text { TURMA }\end{array}$ & DENISE ARRUDA & $\begin{array}{c}\text { EDcl no AgRg no REsp } \\
628558 \text { / MT }\end{array}$ & $15 / 08 / 2005$ \\
\hline $\begin{array}{l}\text { SEGUNDA } \\
\text { TURMA }\end{array}$ & $\begin{array}{c}\text { FRANCISCO PEÇANHA } \\
\text { MARTINS } \\
\end{array}$ & REsp 495178 / CE & 07/04/2006 \\
\hline $\begin{array}{l}\text { TERCEIRA } \\
\text { TURMA }\end{array}$ & NANCY ANDRIGHI & $\begin{array}{c}\text { EDcl no REsp } 698772 \text { / } \\
\text { MG }\end{array}$ & $02 / 10 / 2006$ \\
\hline $\begin{array}{l}\text { QUINTA } \\
\text { TURMA }\end{array}$ & FELIX FISCHER & $\begin{array}{c}\text { EDcl no RMS } 19622 \text { / } \\
\text { MT } \\
\end{array}$ & $30 / 10 / 2006$ \\
\hline $\begin{array}{l}\text { TERCEIRA } \\
\text { TURMA } \\
\end{array}$ & NANCY ANDRIGHI & REsp 686139 / PR & $13 / 11 / 2006$ \\
\hline $\begin{array}{l}\text { SEGUNDA } \\
\text { TURMA }\end{array}$ & ELIANA CALMON & REsp 761894 / PR & $14 / 03 / 2007$ \\
\hline $\begin{array}{l}\text { TERCEIRA } \\
\text { TURMA }\end{array}$ & ARI PARGENDLER & REsp 802927 / PE & $26 / 03 / 2007$ \\
\hline $\begin{array}{l}\text { SEGUNDA } \\
\text { TURMA }\end{array}$ & CASTRO MEIRA & REsp 905719 / RJ & 08/08/2007 \\
\hline $\begin{array}{l}\text { SEGUNDA } \\
\text { TURMA }\end{array}$ & JOÃO OTÁVIO DE NORONHA & REsp 476783 / RJ & $13 / 11 / 2007$ \\
\hline $\begin{array}{l}\text { PRIMEIRA } \\
\text { SEÇÃO }\end{array}$ & DENISE ARRUDA & AR 2677 / PI & $07 / 02 / 2008$ \\
\hline $\begin{array}{l}\text { QUARTA } \\
\text { TURMA } \\
\end{array}$ & FERNANDO GONÇALVES & REsp 824015 / RJ & 05/05/2008 \\
\hline $\begin{array}{l}\text { QUINTA } \\
\text { TURMA }\end{array}$ & ARNALDO ESTEVES LIMA & $\begin{array}{c}\text { AgRg no RMS } 26276 / \\
\text { SP } \\
\end{array}$ & $16 / 02 / 2009$ \\
\hline $\begin{array}{l}\text { TERCEIRA } \\
\text { TURMA }\end{array}$ & $\begin{array}{c}\text { VASCO DELLA GIUSTINA } \\
\text { (DES. CONV. DO TJ/RS) }\end{array}$ & AgRg no Ag 719242 / SP & $25 / 02 / 2010$ \\
\hline $\begin{array}{l}\text { SEGUNDA } \\
\text { TURMA }\end{array}$ & $\begin{array}{c}\text { MAURO CAMPBELL } \\
\text { MARQUES }\end{array}$ & $\begin{array}{c}\text { AgRg no Ag } 1008620 / \\
\text { BA }\end{array}$ & $12 / 04 / 2010$ \\
\hline $\begin{array}{c}\text { TERCEIRA } \\
\text { TURMA } \\
\end{array}$ & NANCY ANDRIGHI & REsp 991872 / MS & $22 / 04 / 2010$ \\
\hline $\begin{array}{c}\text { SEGUNDA } \\
\text { TURMA } \\
\end{array}$ & CASTRO MEIRA & REsp 1093080 / RS & $24 / 06 / 2010$ \\
\hline $\begin{array}{l}\text { PRIMEIRA } \\
\text { TURMA }\end{array}$ & BENEDITO GONÇALVES & REsp $1191346 /$ CE & $15 / 10 / 2010$ \\
\hline SEXTA TURMA & $\begin{array}{c}\text { CELSO LIMONGI (DES. } \\
\text { CONV. DO TJ/SP) }\end{array}$ & $\begin{array}{c}\text { AgRg no REsp } 813783 \text { / } \\
\text { SC }\end{array}$ & $27 / 04 / 2011$ \\
\hline $\begin{array}{l}\text { PRIMEIRA } \\
\text { SEÇÃO }\end{array}$ & HERMAN BENJAMIN & EDcl no MS 16557 / DF & $22 / 05 / 2012$ \\
\hline $\begin{array}{l}\text { QUARTA } \\
\text { TURMA }\end{array}$ & MARIA ISABEL GALLOTTI & $\begin{array}{c}\text { AgRg no AgRg no REsp } \\
805422 \text { / DF }\end{array}$ & $05 / 10 / 2012$ \\
\hline $\begin{array}{l}\text { QUARTA } \\
\text { TURMA }\end{array}$ & $\begin{array}{c}\text { ANTONIO CARLOS } \\
\text { FERREIRA }\end{array}$ & REsp $1052781 /$ PA & $04 / 02 / 2013$ \\
\hline SEXTA TURMA & $\begin{array}{c}\text { ALDERITA RAMOS DE } \\
\text { OLIVEIRA (DES. CONV. DO } \\
\text { TJ/PE) }\end{array}$ & $\begin{array}{c}\text { AgRg no REsp } 668261 / \\
\text { SP }\end{array}$ & $12 / 03 / 2013$ \\
\hline $\begin{array}{l}\text { SEGUNDA } \\
\text { TURMA }\end{array}$ & $\begin{array}{c}\text { MAURO CAMPBELL } \\
\text { MARQUES }\end{array}$ & REsp 1372445 / RS & $25 / 02 / 2014$ \\
\hline $\begin{array}{l}\text { SEGUNDA } \\
\text { TURMA }\end{array}$ & $\begin{array}{c}\text { MAURO CAMPBELL } \\
\text { MARQUES }\end{array}$ & REsp 1446420 / RS & $26 / 05 / 2014$ \\
\hline
\end{tabular}




\begin{tabular}{|c|c|c|c|}
\hline $\begin{array}{l}\text { ÓRGÃO } \\
\text { JULGADOR }\end{array}$ & MINISTRO(A) & PROCESSO & PUBLICAÇÃO \\
\hline $\begin{array}{l}\text { PRIMEIRA } \\
\text { TURMA }\end{array}$ & BENEDITO GONÇALVES & $\begin{array}{c}\text { AgRg no REsp } 1406733 \text { / } \\
\text { RJ }\end{array}$ & 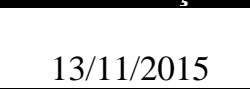 \\
\hline $\begin{array}{l}\text { TERCEIRA } \\
\text { TURMA } \\
\end{array}$ & $\begin{array}{c}\text { RICARDO VILLAS BÔAS } \\
\text { CUEVA }\end{array}$ & $\begin{array}{c}\text { AgRg no AREsp 637839/ } \\
\text { ES }\end{array}$ & $07 / 03 / 2016$ \\
\hline $\begin{array}{l}\text { PRIMEIRA } \\
\text { TURMA }\end{array}$ & $\begin{array}{c}\text { NAPOLEÃO NUNES MAIA } \\
\text { FILHO }\end{array}$ & REsp 929792 / SP & $31 / 03 / 2016$ \\
\hline
\end{tabular}

